Prepared for the

U.S. Nuclear Regulatory Commission under a Related Services Agreement

with the U.S. Department of Energy

Contract DE-AC05-76RL01830

\title{
Assessment of the Mechanical Stress Improvement Process for Mitigating Primary Water Stress Corrosion Cracking in Nickel Alloy Butt Welds in Piping Systems Approved for Leak- Before-Break
}

\author{
EJ Sullivan \\ MT Anderson
}

January 2013 


\title{
DISCLAIMER
}

This report was prepared as an account of work sponsored by an agency of the United States Government. Neither the United States Government nor any agency thereof, nor Battelle Memorial Institute, nor any of their employees, makes any warranty, express or implied, or assumes any legal liability or responsibility for the accuracy, completeness, or usefulness of any information, apparatus, product, or process disclosed, or represents that its use would not infringe privately owned rights. Reference herein to any specific commercial product, process, or service by trade name, trademark, manufacturer, or otherwise does not necessarily constitute or imply its endorsement, recommendation, or favoring by the United States Government or any agency thereof, or Battelle Memorial Institute. The views and opinions of authors expressed herein do not necessarily state or reflect those of the United States Government or any agency thereof.

\author{
PACIFIC NORTHWEST NATIONAL LABORATORY \\ operated by \\ BATTELLE \\ for the \\ UNITED STATES DEPARTMENT OF ENERGY \\ under Contract DE-AC05-76RL01830 \\ Printed in the United States of America
Available to DOE and DOE contractors from the
Office of Scientific and Technical Information,
P.O. Box 62, Oak Ridge, TN 37831-0062;
ph: (865) 576-8401
fax: $(865) \mathbf{5 7 6 - 5 7 2 8}$
email: reports@adonis.osti.gov

\footnotetext{
Available to the public from the National Technical Information Service,

U.S. Department of Commerce, 5285 Port Royal Rd., Springfield, VA 22161

ph: (800) 553-6847

fax: (703) 605-6900

email: orders@ntis.fedworld.gov

online ordering: http://www.ntis.gov/ordering.htm
}

This document was printed on recycled paper.

$(9 / 2003)$ 


\title{
Assessment of the Mechanical Stress Improvement Process for Mitigating Primary Water Stress Corrosion Cracking in Nickel Alloy Butt Welds in Piping Systems Approved for Leak-Before-Break
}

\author{
EJ Sullivan \\ MT Anderson
}

January 2013

Prepared for

U.S. Nuclear Regulatory Commission under a Related Services Agreement with the U.S. Department of Energy Contract DE-AC05-76RL01830

Pacific Northwest National Laboratory

Richland, Washington 99352 



\section{Executive Summary}

In recent years, operating experience has shown that Alloy 82/182/600 materials used in reactor coolant system (RCS) pressure boundaries of pressurized water reactors (PWRs) are susceptible to primary water stress corrosion cracking (PWSCC). Cracking can initiate at the inside surface of these materials, in part, because of tensile residual stresses introduced by welding. These materials are present in piping systems that were approved by the U.S. Nuclear Regulatory Commission (NRC) for leakbefore-break (LBB) before PWSCC was found in RCS dissimilar metal butt welds. The identification of PWSCC led to concerns regarding the potential effect of this degradation on existing LBB analyses.

In response to these concerns, the NRC Office of Nuclear Regulatory Research initiated a program entitled, "PWSCC in Leak-Before-Break Systems," and a follow-on program entitled, "Degradation in Extremely Low Probability of Rupture (xLPR) Systems." Under these programs, Pacific Northwest National Laboratory (PNNL) is assessing the various strategies being used by industry to manage potential or existing PWSCC in susceptible welds in piping systems approved for LBB.

The commercial nuclear power industry has implemented strategies to manage potential or existing PWSCC at Alloy 82/182 dissimilar metal welds (DMW) in PWRs. One general strategy consists of management by a combination of mitigation plus inspection, where several mitigation techniques have been used by industry. The other general strategy is to manage potential PWSCC by inspection alone.

At the request of the NRC, the American Society of Mechanical Engineers (ASME) took actions to develop improvements to the existing Code requirements to address the potential for PWSCC in Class 1 PWR piping butt welds fabricated with Alloy 82/182 weld materials. The ASME developed Code Case N-770, "Alternative Examination Requirements and Acceptance Standards for Class 1 PWR Piping and Vessel Nozzle Butt Welds Fabricated with UNS N06082 or UNS W86182 Weld Filler Material With or Without Application of Listed Mitigation Activities, Section XI, Division 1." It was realized that the Code Case needed to be revised to address specific examinations such as welds with a design life of less than 10 years and post-weld preservice surface examinations. In general, the revised Code Case (N-770-1) has requirements for inspection of unmitigated as well as mitigated Alloy 82/182 RCS butt welds. As such, specific inspection requirements for welds mitigated by the Mechanical Stress Improvement Process (MSIP $\left.{ }^{(}\right){ }^{(a)}$ the subject of this technical letter report (TLR), are contained in the Code Case. The NRC incorporated ASME Code Case N-770-1 by reference into §50.55a (76 FR 36232, p. 36278) in June 2011.

This TLR provides an assessment of MSIP as a mitigation strategy and includes an assessment of the MSIP-related inspection requirements of Code Case N-770-1, as conditioned in $\S 50.55 \mathrm{a}$.

Depending upon the weld geometry, fabrication practices, and the presence of a nearby safe end-topipe weld, Alloy 82/182 piping butt welds may have tensile residual axial and hoop stresses within a zone near the inside surface of the weld. This tensile zone contributes to the susceptibility of Alloy 82/182 to PWSCC. MSIP converts tensile residual stresses along the inside surface of piping in the weld to a zone of compressive residual stresses or substantially reduced tensile residual stresses.

(a) MSIP is a registered trademark of NuVision Engineering, Pittsburgh, Pennsylvania. 
In performing this assessment, PNNL considered operating experience with MSIP and a number of factors that affect the ability of MSIP to perform effectively. Weld residual stress (WRS) and crack growth analyses were evaluated. The reliability of pre- and post-MSIP nondestructive examination (NDE) to detect and characterize PWSCC was evaluated. The requirements of ASME Code Case $\mathrm{N}-770-1$, as conditioned in $\S 50.55 \mathrm{a}(\mathrm{g})(6)(\mathrm{ii})(\mathrm{F})$, were assessed with respect to relying on MSIP as a strategy to manage potential and existing PWSCC. Finally, considering all these factors, an evaluation was performed of the effectiveness of MSIP as a mitigation technique capable of precluding PWSCC from being a potential source of pipe rupture in LBB piping systems.

The results of the WRS analyses showed that MSIP is effective in producing compressive values of axial and circumferential weld residual stresses in the inner region of welds, thereby minimizing the likelihood of initiation of PWSCC in Alloy 82/182 DMWs. However, from the crack growth analyses, in the event that MSIP is applied to a weld with a deep flaw (e.g., $>50 \%$ through wall), it was found the flaw stress intensity would be made much worse by MSIP and the flaw could grow through-wall in a short time period under these loadings. Based on guidance in NUREG-0313, Technical Report on Material Selection and Processing Guidelines for BWR Coolant Pressure Boundary Piping, the MSIP process should only be applied to locations that can be inspected and that are shown to have circumferential cracks where the lengths add to no longer than $10 \%$ of the circumference, and the maximum through-wall depth of any crack does not exceed $30 \%$ of the piping wall thickness. It is shown in the report that Code-allowable flaw sizes under design basis seismic loading in some cases are small. Therefore, our overall conclusion from this assessment is that MSIP is an effective mitigation method against PWSCC, provided that any cracks in the mitigated weld are small.

The reliability of pre-MSIP NDE is of interest because, as noted above, MSIP may be ineffective if applied to welds with deep cracks. Also, the reliability of post-MSIP NDE is important for determining whether any pre-existing flaws are propagating. NDE can be affected by a number of factors, such as geometry or access limitations and the presence of coarse-grained materials such as cast austenitic stainless steel (CASS) adjacent to the weld mitigated. In the case of these adjacent coarse-grained materials, studies have shown that, although ASME performance demonstration requirements for inspecting CASS piping welds have yet to be developed, low-frequency phased-array techniques are capable of detecting and adequately characterizing flaws.

The ability to reliably detect and characterize PWSCC can be distinctly and significantly improved by performing ultrasonic testing (UT) modeling analyses when designing inspection parameters, using encoded techniques that have been qualified by performance demonstration, and employing analysts experienced in distinguishing service-induced flaw signals from other UT signals that may be present. An assessment of ASME Code Case N-770-1 requirements, with NRC conditions that are applicable to MSIP, was performed. Overall, it was concluded that these requirements are comprehensive and will provide an appropriate defense-in-depth function for monitoring the condition of MSIP welds. 
Using the criteria in ASME Code Case N-770-1, Appendix I, to evaluate the effectiveness of MSIP as a mitigation technique, it is concluded that MSIP provides effective mitigation against the initiation of PWSCC and against the growth of existing PWSCC. To satisfy these criteria, the NDE used has to be effective and reliable and any flaws in welds to which MSIP is applied have to be small. Under these conditions, it is concluded that MSIP addresses the qualitative screening criteria in Standard Review Plan (SRP) 3.6.3, Leak Before Break. Per the staff guidance in Regulatory Issue Summary 2010-07, Regulatory Requirements for Application of Weld Overlays and Other Mitigation Techniques in Piping Systems Approved for Leak-Before-Break, dated June 8, 2010, installation of MSIP would not invalidate the SRP 3.6.3 LBB flaw tolerance analyses. On this basis, MSIP would be expected to satisfy the SRP 3.6.3 leak-before-break criteria and preclude PWSCC from being a potential source of pipe rupture. 



\section{Acknowledgments}

The authors would like to acknowledge PNNL staff members Susan Crawford, Tony Cinson, and Tracy Moran; and Jeff Devers and Todd Blechinger from LMT, for their contributions to the NDE workshop held in May 2012. The authors would like to acknowledge the contributions made by Manu Badlani of NuVision Engineering related to applying MSIP to mockup specimens. The authors would also like to thank Ms. Kay Hass for assistance in preparing this manuscript. 



\section{Acronyms and Abbreviations}

\begin{tabular}{|c|c|}
\hline AFEA & advanced finite element analyses \\
\hline ANL & Argonne National Laboratory \\
\hline ASME & American Society of Mechanical Engineers \\
\hline $\mathrm{B} \& \mathrm{~W}$ & Babcock \& Wilcox \\
\hline $\mathrm{BCL}$ & Battelle Columbus Laboratory \\
\hline BWR & boiling water reactor \\
\hline BWRVIP & Boiling Water Reactors Vessels and Internals Project \\
\hline CASS & cast austenitic stainless steel \\
\hline $\mathrm{CE}$ & Combustion Engineering \\
\hline CFR & Code of Federal Regulations \\
\hline CRV & Code-required volume \\
\hline DHD/iDHD & deep hole drilling/incremental deep hole drilling \\
\hline DMW & dissimilar metal weld \\
\hline EDM & electro-discharge machining \\
\hline ET & eddy current testing \\
\hline EPRI & Electric Power Research Institute \\
\hline FEA & finite element analysis \\
\hline GDC & General Design Criterion \\
\hline HAZ & heat-affected zone \\
\hline HIP & hot isostatic pressed \\
\hline ID & inner diameter \\
\hline IGSCC & intergranular stress corrosion cracking \\
\hline IHD & incremental hole drilling \\
\hline INPP & Ignalina Nuclear Power Plant \\
\hline ISI & inservice inspection \\
\hline $\mathrm{K}$ & stress intensity factor \\
\hline LBB & leak-before-break \\
\hline MRP & Materials Reliability Program \\
\hline MSIP & mechanical stress improvement process \\
\hline NDE & nondestructive examination \\
\hline NEI & Nuclear Energy Institute \\
\hline NRC & U.S. Nuclear Regulatory Commission \\
\hline NRR & Office of Nuclear Reactor Regulation \\
\hline OD & outside diameter \\
\hline $\mathrm{OE}$ & operating experience \\
\hline OWOL & optimized weld overlay \\
\hline
\end{tabular}




$\begin{array}{ll}\text { PA } & \text { phased array } \\ \text { PAUT } & \text { phased-array ultrasonic testing } \\ \text { PDI } & \text { Performance Demonstration Initiative } \\ \text { PNNL } & \text { Pacific Northwest National Laboratory } \\ \text { PVP } & \text { Pressure Vessel and Piping (conference) } \\ \text { PWR } & \text { pressurized water reactor } \\ \text { PWSCC } & \text { primary water stress corrosion cracking } \\ \text { PZR } & \text { pressurizer } \\ \text { RCP } & \text { reactor coolant pump } \\ \text { RCS } & \text { reactor coolant system } \\ \text { RES } & \text { Office of Nuclear Regulatory Research } \\ \text { RIL } & \text { Research Information Letter } \\ \text { RIS } & \text { Regulatory Issue Summary } \\ \text { RMSE } & \text { root-mean-square errors } \\ \text { RPV } & \text { reactor pressure vessel } \\ \text { SCC } & \text { stress corrosion cracking } \\ \text { SNR } & \text { signal-to-noise ratio } \\ \text { SRP } & \text { Standard Review Plan } \\ \text { SS } & \text { stainless steel } \\ \text { SSE } & \text { safe-shutdown earthquake } \\ \text { TFC } & \text { thermal fatigue crack } \\ \text { TLR } & \text { technical letter report } \\ \text { TRL } & \text { transmit-receive longitudinal } \\ \text { TRS } & \text { transmit-receive dual shear-wave } \\ \text { UT } & \text { ultrasonic testing } \\ \text { WRS } & \text { weld residual stresses } \\ \text { xLPR } & \text { extremely low probability of rupture } \\ \text { XRD } & \text { X-ray diffraction } \\ & \end{array}$




\section{Contents}



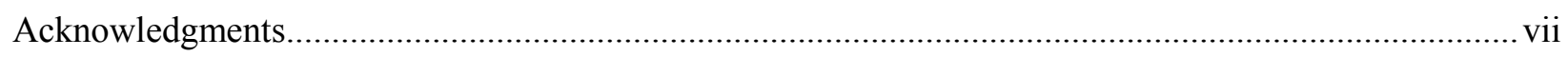

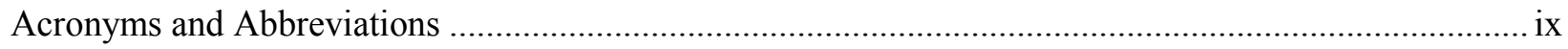

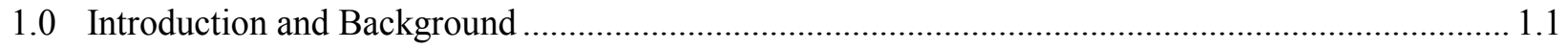

2.0 Assessment of Weld Residual Stress and Crack Growth Analyses ............................................. 2.1

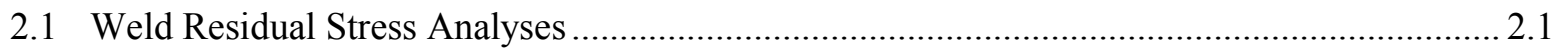

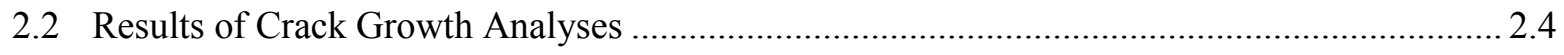

2.3 Crack Extension Under Design Basis Loading ................................................................. 2.6

2.4 Welding Residual Stress Finite Element Analysis Validation Studies ................................. 2.7

2.5 Weld Residual Stress and Crack Growth Conclusions.......................................................... 2.10

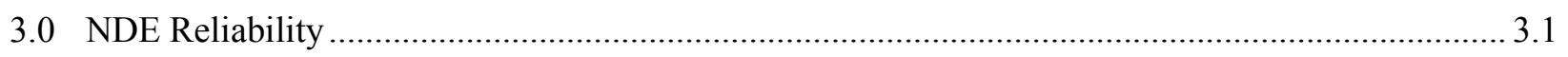

3.1 Assessment of Pre-MSIP UT Examination Results ............................................................. 3.1

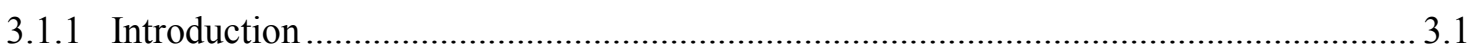

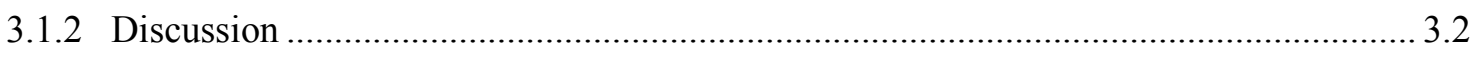

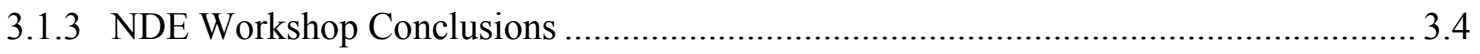

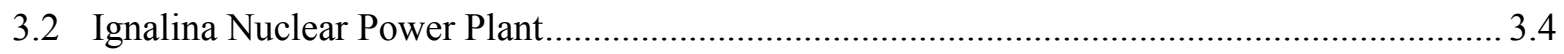

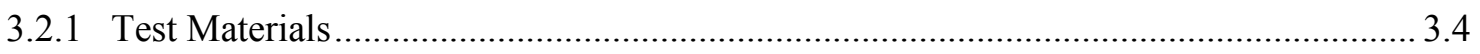

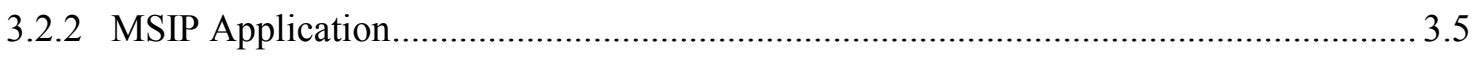

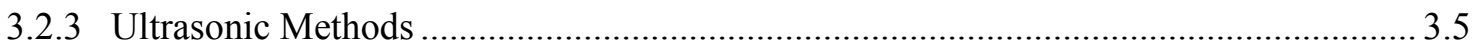

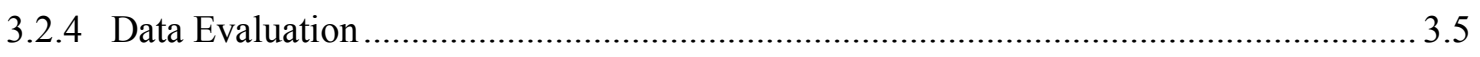

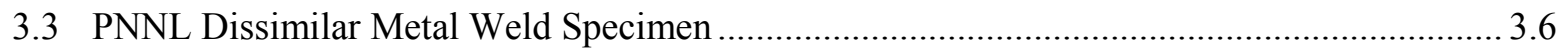

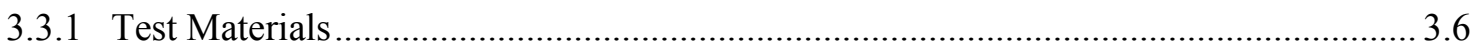



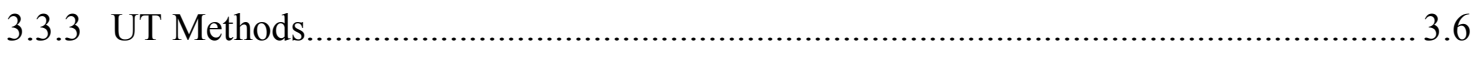

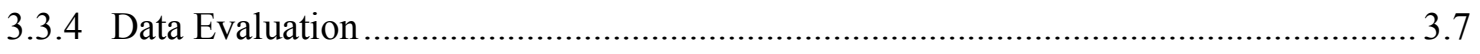

3.4 Comparison of Ignalina and PNNL 9C003 Specimen Data .............................................. 3.7



3.6 NDE Reliability Conclusions ........................................................................................ 3.10

4.0 Assessment of ASME Code Case N-770-1 Requirements ........................................................ 4.1

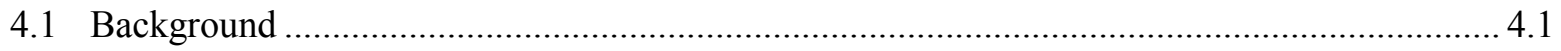

4.2 Overview of Code Case N-770-1 ................................................................................. 4.2

5.0 Evaluation of the Effectiveness of MSIP as a Mitigation Technique............................................ 5.1

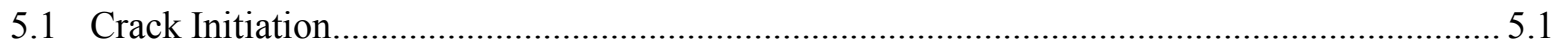



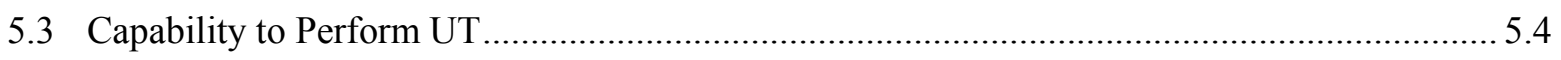

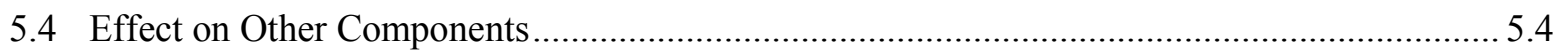




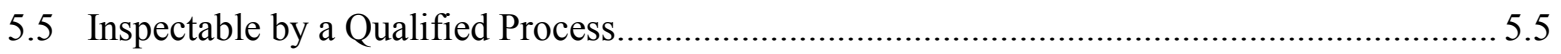

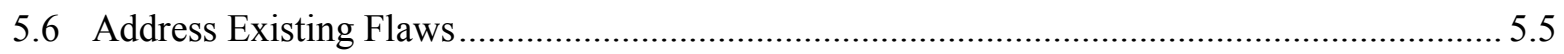

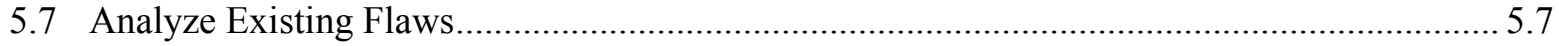

5.8 Conclusions for MSIP as a Mitigation Technique …........................................................ 5.7

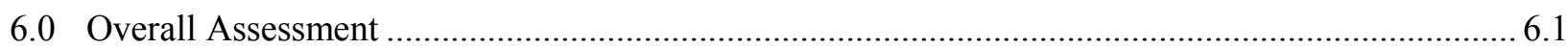



Appendix A - Background on Leak-Before-Break Per the Requirements of 10 CFR 50, Appendix A, General Design Criterion-4................................................................ A.1

Appendix B - Assessment of ASME Code Case N-770-1 as Implemented in 10 CFR



Appendix C - Dissimilar Metal Weld Inspection Limitations of a Typical Westinghouse Plant...........C.1

Appendix D - Dissimilar Metal Weld Inspection Limitations of a Typical Combustion

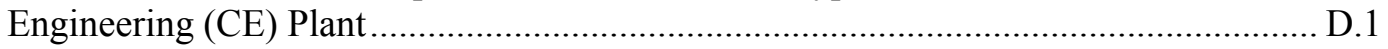




\section{Figures}

$2.1 \quad$ Axial Stress Before Stainless Steel Weld............................................................................ 2.8



\section{Tables}

2.1 NRC/EPRI Weld Residual Stress Validation Studies

3.1 RCS Alloy 82/182 Butt Weld Code Required Volume Coverage Obtained for a Typical Westinghouse Plant.

3.2 RCS Alloy 82/182 Butt Weld Code Required Volume Coverage Obtained for a Typical Combustion Engineering Plant 



\subsection{Introduction and Background}

The U.S. Nuclear Regulatory Commission (NRC) started approving leak-before-break (LBB) analyses in 1984 by granting exemptions from General Design Criterion (GDC)-4, Environmental and Dynamics Effects Design Bases, in Title 10 of the Code of Federal Regulations (CFR), 10 CFR Part 50, Appendix A, "General Design Criteria for Nuclear Power Plants." In 1987, GDC-4 was revised to allow "dynamic effects associated with postulated pipe ruptures to be excluded from the design basis when analyses reviewed and approved by the Commission demonstrate that the probability of fluid system piping rupture is extremely low" (i.e., less than $10^{-6} /$ reactor year). The statement of considerations for the proposed revision to GDC-4 indicated that the LBB approach should not be considered applicable to fluid system piping that operating experience $(\mathrm{OE})$ has shown is particularly susceptible to failure from the effects of corrosion. Draft Standard Review Plan (SRP) 3.6.3, Leak-Before-Break Evaluation Procedures, states "evaluations must demonstrate that these [degradation] mechanisms are not potential sources of pipe rupture" (NRC 1987b). In practice, review criteria were implemented by excluding systems with potential corrosion degradation mechanisms. Satisfying draft SRP review criteria was considered a demonstration that the probability of fluid system piping rupture is extremely low. Appendix A to this report contains background on leak-before-break per the requirements of GDC- 4 .

In recent years, OE has shown that Alloy 82/182/600 materials used in reactor coolant system (RCS) pressure boundaries of pressurized water reactors (PWRs) are susceptible to primary water stress corrosion cracking (PWSCC). Cracking can initiate at the inside surface of these materials, in part, because of tensile residual stresses introduced by welding. These materials are present in piping systems that were approved by the NRC for LBB before PWSCC was found in RCS dissimilar metal butt welds. The identification of PWSCC in recent fleet operating experience led to concerns regarding the potential effect of this degradation on existing LBB analyses.

To begin to address this issue, the Office of Nuclear Reactor Regulation (NRR) issued NRR-2005011, "User Need Request on Primary Water Stress Corrosion Cracking in Leak-Before-Break Systems." NRR requested that the Office of Nuclear Regulatory Research (RES) develop a technical basis to support NRC's establishment of a regulatory policy concerning LBB systems that are subject to conditions that may cause PWSCC. The research results would also be used to recommend licensing criteria and longterm inspection guidance for maintaining safety margin against pipe ruptures that the staff assumed when it approved LBB analyses.

In response to this request, RES initiated a program entitled, "PWSCC in Leak-Before-Break Systems," and a follow-on program entitled, "Degradation in Extremely Low Probability of Rupture (xLPR) Systems." The commercial nuclear power industry had begun to implement strategies to manage potential or existing PWSCC at Alloy 82/182 dissimilar metal welds (DMWs) in PWRs. RES directed Pacific Northwest National Laboratory (PNNL) to assess, under these programs, the various strategies being used by industry to manage potential or existing PWSCC in susceptible welds in piping systems approved for LBB.

One general industry strategy consists of management by a combination of mitigation plus inspection, where three or four mitigation techniques, including the Mechanical Stress Improvement Process (MSIP), have been used. The other general strategy is to manage potential PWSCC by inspection alone.

Materials Reliability Program (MRP)-139, "Primary System Piping Butt Weld Inspection and Evaluation 
Guideline" (EPRI 2005b), provided industry guidance for the volumetric and visual inspections of unmitigated and mitigated butt welds in PWR primary systems (EPRI 2005b, 2008). The MRP-139 inspections augmented examinations of PWSCC-susceptible locations already required by Section XI of the American Society of Mechanical Engineers (ASME) Boiler and Pressure Vessel Code. Section XI is incorporated into the NRC regulations in Title 10, Section 50.55a, Codes and Standards, of the Code of Federal Regulations (10 CFR 50.55a).

In December 2005, the NRC sent a letter to ASME (Dyer 2005) requesting that the Section XI standards body take actions necessary to develop improvements to the existing Code requirements to address the potential for PWSCC in Class 1 PWR piping butt welds fabricated with Alloy 82/182 weld materials. ASME approved the development of an ASME Code Case on appropriate inspection requirements to address PWSCC in Class 1 butt welds containing Alloy 82/182. This Case was later numbered Code Case N-770 (ASME 2009b). Code Case N-770 was revised in 2009 to address NRC concerns and Code Case N-770-1 was issued later that year (ASME 2009a). The NRC incorporated ASME Code Case N-770-1 by reference into 10 CFR 50.55a (76 FR 36232) in June 2011. Code Case N-770-1 contains requirements for inspection of unmitigated as well as mitigated Alloy 82/182 RCS butt welds. Code Case N-770-1 contains specific inspection requirements for welds mitigated by MSIP. This report includes an assessment of the MSIP-related inspection requirements of Code Case N-770-1, as conditioned in 10 CFR 50.55a.

Decisions to mitigate welds against PWSCC have been driven by several factors. Because the majority of PWR butt weld mitigations implemented to date have been pressurizer (PZR) welds, and because those welds have the highest operating temperature and tend to be partially un-inspectable due to tapers, contours, and materials issues, weld overlays have been applied extensively. Weld overlays create a new surface from which to inspect and result in a new examination volume that can, typically, be fully inspected. Mitigation by the MSIP was generally not a viable option for these welds. Because of their design geometries, the required pre-MSIP examinations could not be performed, although MSIP was used to mitigate the PZR surge-nozzle welds at Calvert Cliffs 1 and 2, and at Palisades (EPRI 2006). The recent favorable examination results of baseline examinations for primary system hot-leg and cold-leg temperature weld locations have decreased the urgency to mitigate these welds in the short term.

MSIP was first used in 1986. The NRC Office of Nuclear Regulatory Research issued Research Information Letter (RIL) Number 149, "Evaluation of the Mechanical Stress Improvement Process," on February 12, 1987 (NRC 1987a). RIL No. 149 was based on a review by Argonne National Laboratory (ANL) of information on MSIP submitted to the NRC by O'Donnell \& Associates, Inc. and Westinghouse Electric Corporation, the developers of the process. Also, ANL performed analysis and tests to determine the residual stress state changes using two MSIP-treated, large-diameter pipe sections supplied by Vermont Yankee. The RIL states that, "Based on the results of our research work and the data and analyses provided by O'Donnell \& Associates, MSIP is judged to be an effective means of improving the residual stress state of piping system weldments.... It is as effective for large diameter piping as small diameter piping."

MSIP was approved by the NRC for boiling water reactor (BWR) applications in 1988 with the issuance of NRC Generic Letter 88-01 (NRC 1988) and the guidelines contained in NUREG-0313, Revision 2 (Hazelton and Koo 1988). 
The current holders on the patent for MSIP, NuVision Engineering, have indicated that MSIP has over 25 years of successful operating experience in the United States with more than 1000 welds treated (NuVision 2011).

The RCS branch line Alloy 82/182 nozzle welds that are approximately the size of surge-nozzle welds (about $32.4 \mathrm{~cm}$ [12.75 in.] in diameter) are the smallest diameter Alloy 82/182 piping welds in LBB systems (Cofie 2008). Larger diameter Alloy 82/182 welds in LBB systems are in the primary loop of the RCS. Generally, these are the reactor vessel nozzle-to-pipe welds in Westinghouse plants and reactor coolant pump (RCP) nozzle-to-pipe welds in Combustion Engineering and Babcock and Wilcox plants.

MSIP has been implemented on many PWR reactor vessel nozzle DMWs including V.C. Summer, Salem Unit 1, Seabrook, D.C. Cook, Unit 1, and Watts Bar, Unit 2. MSIP was used at these plants to repair the reactor vessel nozzle welds with indications of cracking. Except for Seabrook, MSIP was used to mitigate the other reactor vessel nozzle welds at these plants that did not have indications of cracking (Dodson 2008; Burritt 2009; O'Keefe 2010). The owners for D.C. Cook, Unit 1, implemented MSIP on reactor pressure vessel (RPV) nozzle DMWs. Ultrasonic testing (UT) and eddy current testing (ET) was performed on the RPV hot-leg nozzle DMWs pre-MSIP and on the cold-leg nozzle welds post-MSIP (Cameron 2010). For the hot-leg nozzle DMWs, the licensee performed pre- and post-MSIP Section XI, Appendix VIII, qualified UT examinations, as modified by an NRC-approved ASME Code relief request (Kobetz 2006). For the cold-leg nozzle DMWs, the licensee performed only a post-MSIP Section XI, Appendix VIII, qualified UT, as modified by an NRC-approved ASME Code relief request, and an ET examination from the inside surface of these piping welds. The licensee noted that ASME Code Case $\mathrm{N}-770$ has provisions to accept post-MSIP UT examinations for these particular nozzles, if supplemented by ET.

MSIP has been applied at Watts Bar, Unit 2, to the six PZR nozzles, the four reactor vessel hot-leg nozzles, and the four reactor vessel cold-leg nozzles. This plant has not started up as it is currently undergoing licensing review (Watts Bar Unit 2, Final Safety Evaluation Report, Section 5.5.3.3.1). MSIP has also been applied to a number of welds in systems that are not approved for LBB. This technique is expected to play an increasing role in the mitigation of Alloy 82/182 welds. WestDyne, Westinghouse's inspection vendor, has indicated that the owners of Byron and Braidwood would be applying MSIP to reactor vessel nozzle welds between 2011 and 2013 (WesDyne 2008).

Mitigation provides an alternative to relying on inspection alone as a means to manage potential PWSCC at these locations. MSIP modifies the existing inner-diameter (ID) residual tensile stresses in the weld metal and heat-affected zone (HAZ) of butt welds in piping. A load is applied to the outside surface of the pipe with a large two-piece mechanical clamshell hydraulic clamping device connected by two pairs of tangentially positioned studs. The studs are tightened with hydraulic tensioners. Displacement is controlled to pre-assigned limits by using shims, providing safety from over-straining the pipe. Loading plastically strains the pipe in compression, which creates compressive residual stress around the weld and counterbore region. Stainless steel, "waffled" contact plates are placed between the tool and the pipe outer surface to aid in uniformly distributing the load. Stresses are most compressive near the weld root on the pipe inside surface and increase toward the outside surface (see Figure 2.2 later in this report). Likewise, the inside surface compressive stress near the weld root becomes progressively less at increasing distances away from the weld fusion line (Smith et al. 1987). 
The ASME has elected not to address the mechanical stress improvement process in Section XI requirements for repair and replacement, as MSIP does not involve welding or replacement of components. The holder of the patent for MSIP, NuVision Engineering, has indicated that the design process for MSIP follows the steps contained in ASME Code Case N-770-1, Appendix I, Performance Criteria and Measurement or Quantification Criteria for Mitigation by Stress Improvement. At a high level, this appendix requires that weld residual stress (WRS) calculations be performed to bench-mark the "squeezing" process. The calculations take into account the length of the tooling and the location to place the tooling. There is some flexibility in the length and location of the tooling and this flexibility is needed to accommodate limited access and other geometric constraints that may be present. The applied radial load permanently reduces the outside diameter (OD) and, to a lesser extent, the ID in the region where the radial load is applied. A typical change in OD caused by MSIP is $1 \%$ of the as-built size, although the vendor may apply somewhat more or less than $1 \%$ to achieve the desired change in residual stresses in the pipe weld. This "squeeze" creates a beneficial compressive stress on the ID of the welded region of interest (Sullivan and Anderson 2011). Candidate welds have to be reviewed during the design process to ensure that the weld can be inspected before and after MSIP by a qualified process. With one exception discussed later in this report, a pre-MSIP UT inspection is required to be performed. Any flaws that are detected during the pre-MSIP UT have to be addressed as part of the mitigation using the rules of Section XI, IWB-3600, Analytical Evaluation of Planar Flaws. Westinghouse Electric Co. works with NuVision Engineering to implement MSIP. Westinghouse indicates that MSIP is only being applied to locations that have circumferential cracks where the lengths add to no longer than $10 \%$ of the circumference, and the maximum through-wall depth of any crack does not exceed $30 \%$ of the piping wall thickness (Hazelton and Koo 1988). This follows the guidelines on application of MSIP that are provided in NUREG-0313, Rev. 2 (Hazelton and Koo 1988). MSIP causes a slight elongation of the region of the pipe being compressed. This elongation has to be analyzed to ensure that it does not adversely affect the piping system or cause ASME Code-allowable stresses to be exceeded.

MSIP has been reported to stabilize existing cracks, or even close them sufficiently, such that they are no longer detected with ultrasonic nondestructive examination (NDE) techniques (Findlan et al. 2004; Crawford et al. 2011).

During meetings held between NRC and industry on May 25-26, 2010, representatives of the Boiling Water Reactors Vessels and Internals Project (BWRVIP) provided a summary of BWR operating experience in 2007 and 2008 for Category C and D welds containing Alloy 82/182 (Wirtz 2010). It was noted that NUREG-0313, Category $\mathrm{C}$ welds are welds susceptible to intergranular stress corrosion cracking (IGSCC) that were treated by stress improvement after 2 years of operation, and Category D welds are welds susceptible to IGSCC with no stress improvement. Ten cases of these welds were found to have planar flaws distributed among several BWRs. The presentation did not separate the cases by weld category. In 2008, after reviewing these ten cases of welds with planar flaws, the BWRVIP developed an accelerated inspection program for Category $\mathrm{C}$ and D welds containing Alloy 82/182 exposed to BWR environments that had not received an Appendix VIII, Supplement 10 examination.

Outside-diameter surface contours in the weld region appeared to be the primary factor affecting initial detection and sizing inaccuracies. Incomplete probe contact resulted in a loss of signal. As part of the accelerated inspection program, the BWRVIP provided guidelines to the owners on surface conditioning to address these UT coupling issues. 
During the May 25-26, 2010 meetings, the BWRVIP reported that there had been instances where unacceptable planar flaws were identified. Five of the ten BWR Category C and D welds were identified with planar indications that required IWB-3600 evaluations and were subsequently overlaid. Some of the welds were determined to contain fabrication flaws and were found to be acceptable. During a meeting on July 20, 2012 (Wirtz 2012), it was reported that two flawed welds were found by the accelerated inspection program since 2009. It was also reported that four Category $\mathrm{C}$ welds remain to be inspected and these welds are scheduled to be inspected by June 2014. The owners of these BWRs believe that none of these flaws were the result of new or continuing intergranular stress corrosion cracking. However, one has to consider that weld crowns may have had a negative effect on the earlier examination results and the ability to conclude that none of the flaws were the result of new or continuing IGSCC.

Based on the issues described above for weld surface condition and ultrasonic examination considerations, it is difficult to be certain that growth of pre-existing cracks had not occurred. Nevertheless, the authors of this report did not find any instances of leaks having occurred post-MSIP in BWR (or PWR) piping.

This operating experience highlights the importance of removing weld crowns and the benefit of performing high-quality examinations using, for example, Appendix VIII-qualified, encoded phased-array UT techniques, prior and subsequent to the application of MSIP.

In performing this assessment of MSIP, PNNL considered several factors. Operating experience of BWR welds mitigated by MSIP was discussed above. Weld residual stress and crack growth analyses and the reliability of NDE to detect and characterize PWSCC are evaluated (Section 2.0). The reliability of NDE in pre- and post-MSIP examinations is assessed (Section 3.0). The requirements of ASME Code Case N-770-1, as conditioned in 10 CFR $50.55 \mathrm{a}(\mathrm{g})(6)(\mathrm{ii})(\mathrm{F})$, are assessed with respect to relying on MSIP as a strategy to manage potential and existing PWSCC (Section 4.0 and Appendix B). Finally, considering all these factors, an evaluation has been performed of the effectiveness of MSIP as a mitigation technique capable of precluding PWSCC from being a potential source of pipe rupture (Section 5.0). Based on the factors considered during this review, conclusions have been drawn and recommendations have been made for improving the ability of MSIP to perform as intended.

The approach described by this report is deterministic in that it relies on empirical data assessments and engineering judgment to arrive at conclusions. A probabilistic modeling approach to assessing PWSCC management strategies is being undertaken in the joint NRC RES-Electric Power Research Institute (EPRI) XLPR project. 



\subsection{Assessment of Weld Residual Stress and Crack Growth Analyses}

RES initiated a program entitled, "PWSCC in Leak-Before-Break Systems." One of the studies performed under this research program involved the evaluation of the evaluation of MSIP and weld overlays and was conducted by Battelle Columbus Laboratory (BCL) (Fredette and Scott 2009, 2010). An assessment of these BCL reports is contained in PNNL-20580, Technical Letter Report Assessment of Battelle Columbus Reports Evaluating Mechanical Stress Improvement and Weld Overlays as Mitigation Strategies for Primary Water Stress Corrosion Cracking in Pressurized Water Reactors (Sullivan and Anderson 2011).

BCL performed axisymmetric analyses of welds associated with (1) a large-diameter hot-leg/RPV nozzle weld, (2) a medium-diameter PZR surge-nozzle weld, and (3) a small-diameter PZR safety nozzle weld. These three nozzle welds cover the range of welds for which the industry has applied MSIP or would consider applying MSIP. BCL analyses of the hot-leg RPV nozzle weld and the surge-line nozzle weld correspond fairly well to the pipe sizes approved for LBB and that would be considered candidates for applying MSIP (EPRI 2005a). Based on MRP-140, "Leak-Before-Break Evaluation for PWR Alloy 82/182 Welds" (EPRI 2005a), Alloy 82/182 welds are contained in the following piping systems that NRC approved for LBB: main coolant loop (Westinghouse, Combustion Engineering [CE], and Babcock $\&$ Wilcox $[B \& W]$ ), surge line (Westinghouse and $C E)$, core flood piping $(B \& W)$, shutdown cooling (CE), and safety injection (CE). No piping systems smaller than 12-inch nominal pipe diameter, which contain Alloy 82/182, have been qualified for LBB.

Section 2.1 contains a summary of the results of BCL's MSIP weld residual stress analysis (Fredette and Scott 2009). Section 2.2 contains a summary of BCL MSIP crack growth analyses. Section 2.3 contains a summary of crack extension analyses performed by BCL for piping systems under safe shutdown earthquake loading. Section 2.4 contains a summary of some of the results from the weld residual stress validation program conducted jointly by NRC and EPRI. Section 2.5 contains conclusions based on the work described in this section.

\subsection{Weld Residual Stress Analyses}

The methods used by BCL to calculate weld residual stress take into account detailed temperaturedependent material property data for the ferritic, Alloy 82/182/600, and stainless steel (SS) components. The methods use finely meshed models; simulate detailed thermal modeling of the fabrication process using layering of individual weld beads; model all the major steps in weld fabrication such as preheat, weld buildup, root pass grind out and re-weld, in some cases the installation of a heat shield, and, as applicable, the installation of a secondary SS safe-end weld; and use appropriate boundary conditions and accepted constitutive laws and stress intensity formulations. In each case, WRS, before and after MSIP application, were estimated by finite element analysis (FEA) techniques.

For the welds analyzed, BCL calculated both hoop and axial weld residual stresses. For the hot-leg RPV nozzle weld, the pre-MSIP hoop stresses are predominantly tensile through the entire wall thickness. The hoop stress results for the hot-leg RPV case, which were analyzed without the beneficial effect of the secondary SS safe-end weld, indicate that one might expect an axial crack to grow completely through the 
wall thickness. This finding is supported by V.C. Summer experience, although extensive field repairs at the leaking weld were a strong contributor to this cracking (Ray et al. 2003). Applying MSIP in this analysis significantly reduced these hoop stresses for the hot leg by introducing a compressive residual stress field in the hoop direction for the inner $50 \%$ of the wall thickness. Operating temperature and pressure cause the post-MSIP hoop stresses to increase somewhat and the hoop stress at the ID surface is about $70 \mathrm{MPa}(10 \mathrm{ksi})$. The residual hoop stresses at operating pressure and temperature are generally well below $140 \mathrm{MPa}(20 \mathrm{ksi})$ for the inner $50 \%$ of the wall thickness, which should mitigate the possibility of axial through-wall crack growth. For the surge nozzle and the safety nozzle, the post-MSIP hoop stresses at operating pressure and temperature for the inner $50 \%$ of the wall thickness are similar to the hot-leg RPV nozzle except that the hoop stresses at the ID surface are compressive.

There is a similarity in the results of the axial WRS for the geometries considered. High tensile stresses at the inside surface of the weld tend to be somewhat mitigated by the presence of the secondary SS safe-end weld. For example, the surge-nozzle axial stresses at the inside surface after fabricating the Alloy $82 / 182$ nozzle to safe-end DMW weld are in the range of $345 \mathrm{MPa}$ to $380 \mathrm{MPa}$ (50 ksi to $55 \mathrm{ksi}$ ) tensile. Those stresses remain tensile for approximately the inner $50 \%$ of the wall thickness. After fabricating the secondary SS safe-end to pipe weld, the axial stress at the inside surface drops to $207 \mathrm{MPa}$ (30 ksi) compressive and remains compressive for most of the inner $50 \%$ of the wall thickness. Also, the inside surface of the entire safe end is in compression after fabricating the secondary SS weld. MSIP further reduces the surge-nozzle weld axial stresses near the weld centerline from $207 \mathrm{MPa}$ (30 ksi) compressive (post-secondary SS weld) to $345 \mathrm{MPa}$ (50 ksi) compressive. In the buttered region, near the interface of the butter to the A508 nozzle material, the MSIP reduces the inside surface axial stresses from $140 \mathrm{MPa}(20 \mathrm{ksi})$ tension to $70 \mathrm{MPa}(10 \mathrm{ksi})$ compression. After application of operating pressure and temperature, the through-wall axial stresses increase only slightly. For example, at the weld centerline, the axial stress at the ID increases from about $345 \mathrm{MPa}(50 \mathrm{ksi}$ ) to $324 \mathrm{MPa}$ (47 ksi) compression. A similar result is evident for the hot-leg RPV nozzle, except the effect is more pronounced. For the hot leg, the MSIP reduces the inside surface axial stresses from approximately $345 \mathrm{MPa}(50 \mathrm{ksi})$ tension to approximately $207 \mathrm{MPa}$ (30 ksi) compression. After application of operating pressure and temperature, the through-wall axial stresses increase only slightly. The difference between the hot-leg results and the PZR surge-nozzle results is that there is no secondary SS weld for the hot-leg geometry considered in this study. Thus, for the hot-leg geometry considered, the MSIP is even more beneficial to the weld residual stress profile in that there is no prior benefit due to the secondary SS weld.

BCL considered a series of WRS sensitivity analyses. The following effects were considered by these analyses: the effect of modeling different boundary conditions; the effect on WRS of having or not having a nearby secondary SS weld (configuration); and the effects of changes in MSIP clamp location, the level of plastic deformation introduced, and tool size (fabrication). BCL also performed sensitivity studies on 3D versus 2D analyses. The major findings from these sensitivity analyses were as follows.

- Boundary Conditions - Fixed and free displacement boundary conditions at the ends of the modeled section were varied to study the effect of the boundary conditions on the MSIP results. The length of the model was also varied under the boundary conditions studies. These studies showed that the MSIP has a localized effect. Varying the boundary conditions on the section of surge nozzle examined was found to have minimal effect on the MSIP results. 
- Clamp Location and Amount of Squeeze - Sensitivity analyses demonstrated that the process can be applied with some element of imprecision with respect to the positioning of the tool or the amount of squeeze applied. If field conditions are such that the tool cannot be located exactly as planned based on the initial design or the amount of squeeze is slightly less or slightly more than the design specified, the sensitivity analyses indicates that the process is still effective at mitigating the weld residual stresses at the inside surface.

- Effect of Clamp Size/Geometry - When there is a secondary SS weld, the clamping tool bridges the stainless steel weld. A sensitivity study was performed to understand the effect of different tooling configurations that may be needed. The results show that the length of the tool away from the weld to be treated is of little significance. Increased length of the MSIP tool would increase the force required to deform the pipe, but would have little effect on the results. The amount of squeeze and the distance that the edge of the tool is away from the weld to be treated are the variables with the most effect.

- Effect of Second Stainless Steel Weld on the MSIP Results - Sensitivity study results show that the axial stress results after the MSIP has been applied are almost identical for the case with and without the secondary (SS) weld residual stresses.

- Three-Dimensional Analyses - A series of 3D analyses were conducted. The objective of the first series of 3D analyses was to evaluate the uniformity of the MSIP squeeze. Even though there is an element of non-uniformity in the process around the pipe/nozzle geometry and the MSIP is less effective $90^{\circ}$ from the application direction than at a location in line with the squeeze direction $\left(0^{\circ}\right)$, the process is still effective at reducing the weld residual stresses at the inside surface completely around the circumference.

The objective of the second series of 3D analyses was to evaluate the effect of an applied bending moment on the WRSs post-MSIP. The moment axis was oriented to create the greatest tension at the location $90^{\circ}$ from the MSIP tool application direction. While the moment loading added a tensile bending stress $90^{\circ}$ from the tool application direction (i.e., the location where the MSIP is least effective), the stress at the inside surface remained strongly compressive. The analyses also demonstrate that the stresses generated as a result of steady-state bending loads were not large in comparison with WRSs. With the exception of the 3D analyses described above, BCL used 2D axi-symmetrical analyses.

These sensitivity studies assessed factors that might affect the WRS state prior to and after application of MSIP. These studies showed that the analyzed variables in general do not have a significant impact on the effectiveness of MSIP.

The criteria in ASME Code Case N-770-1, Appendix I, "Performance Criteria and Measurement or Quantification Criteria for Mitigation by Stress Improvement," stipulates consideration of a 50\% throughthickness ID weld repair in the qualification of mitigation by stress improvement methods without welding. The reason for consideration of weld repairs in mitigation by stress improvements is that fabrication weld repairs were made in many of the welds presently in service and weld repairs produce ID tensile stresses. Although a 50\% weld thickness ID repair was not modeled in these analyses, several of BCL's analyses represent a similar effect and suggest that MSIP would produce a similar improvement in the inside-surface residual stress state for a weld with a 50\% through-wall repair. 
PNNL constructed a mockup to be used to evaluate pre- and post-MSIP NDE results. The NDE results are discussed in Section 3.3 of this report. This mockup was constructed to represent a PZR surge nozzle-to-safe end weld with an attached section of pipe. BCL was requested to perform a finite element analysis of a PWR PZR surge-nozzle mockup to both predict the weld residual stresses created in its construction and the final stress state after the application of the MSIP (Fredette 2011). Strain gages were applied to the inner diameter of the mockup to record strain changes during the MSIP. These readings from the strain gages were used in an attempt to calculate the final stress state of the mockup.

Conversion of strain-to-stress values in cases in which there has been yielding, or in the cases of welding, with many yielding cycles, is not simple. Strain gages only give results for change in strain from the initial state in which the gages were applied, or "delta" strain. No valid stress results can be drawn without knowing the original stress state of the mockup. To illustrate this point, calculations of stress values were made using three different sets of assumptions. The resulting calculations were compared with post-MSIP stresses predicted using two-dimensional axi-symmetric FEA models.

The presentation of the data in the 2011 report by Fredette shows the difficulty in calculating the final stress state based on strain gage data in a structure that has experienced yielding stress cycles and has built-in residual stresses be they from welding or a yield-inducing process like the MSIP. To perform these calculations, assumptions had to be made regarding the stress state prior to MSIP. Notwithstanding the difficulty in calculating the final stress state, in all cases examined, the strain gage measurements indicate that both the axial and hoop stresses in the area of the Alloy 82/182 weld are made compressive by the MSIP process.

\subsection{Results of Crack Growth Analyses}

One concern with MSIP is the effect it would have on welds with cracks. Regulatory guidance for applying MSIP to BWR piping welds stipulated that the process should only be applied to locations that can be inspected and that are shown to have circumferential cracks where the lengths add to no longer than $10 \%$ of the circumference and the maximum through-wall depth of any crack does not exceed $30 \%$ of the piping wall thickness (Hazelton and Koo 1988). The rate of crack detection by UT increases with crack depth. It is important to understand the crack depths at which MSIP would cause the stress intensity factor to increase, rather than decrease, and, therefore, shorten the life of a weld.

BCL's crack growth analyses included hot-leg nozzle welds, without the secondary SS weld, and surge-nozzle welds, with and without the secondary SS welds. Cracks $75 \%$ of the thickness and $100 \%$ of the circumference were modeled to simulate the situation in which a very large crack went undetected. A full $360^{\circ}$ internal surface crack $75 \%$ of the pipe wall thickness in depth should be detected with performance-demonstrated ultrasonic techniques, although there is a finite possibility that even deep cracks may not all be detected. Circumferential cracks have been found to occur in the Alloy 82/182 weld and at the interface between the butter layer and the A508 nozzle material. Both crack locations were analyzed in the hot-leg and surge-nozzle weld geometries. For convenience, in the BCL MSIP report, the instantaneous crack growth rate was reported in terms of years required to break through the remaining thickness of material, assuming that the crack growth rate remained constant.

The results for the analyses where cracks were introduced were consistent for the geometries studied. In each case, the results demonstrate that MSIP is an effective technique for reducing the inner-wall weld 
residual stresses even in the presence of cracks, provided the cracks are less than approximately $60 \%$ through wall. If a crack greater than approximately $60 \%$ of the wall thickness existed in the weld prior to the application of MSIP, this process actually accelerated crack growth. For the case of these pre-existing cracks greater than $60 \%$ of the wall thickness, MSIP increased the stress intensity factors $(\mathrm{K})$ such that the time required for the crack to grow through the remaining wall thickness is very short (on the order of a few years or less). Assuming that these pre-existing cracks were at the butter/ferritic steel interface, the crack depth was $75 \%$ of the wall thickness, and the crack growth rate remained constant through the remaining wall thickness of the pipe, the time required for the mitigated (post-MSIP) crack to grow through the remaining wall thickness under normal operating pressure and temperature conditions was 1 year for the hot-leg/RPV nozzle and 3 years for the PZR surge-nozzle geometry with the secondary SS weld. Conversely, for the untreated cases (no MSIP applied), the time required to grow these $75 \%$ deep cracks through the remaining wall thickness under normal operating pressure and temperature conditions was indefinite for the hot leg and 34 years for the PZR surge nozzle. For the hot leg, the K value for the untreated $75 \%$ deep crack was zero because of the compressive weld residual stresses, so no crack growth was predicted under normal operating pressure and temperature conditions. Slightly different results were found for postulated cracks at the butter/weld interface.

The BCL MSIP report notes that, with the exception of the experience at Crystal River, Unit 3, in 2008 , no circumferential indications greater than approximately $30 \%$ of the wall thickness have been found in service. The Crystal River indication detected in the "B" hot-leg decay heat nozzle-to-pipe DMW originated from the inner diameter of the weld. A limited circumferential segment of the indication was reported to extend to approximately $65 \%$ through-wall at its deepest point. About $50^{\circ}$ from this segment of indication, another limited-extent circumferential segment was reported that was approximately $50 \%$ through-wall at its deepest point. The balance of the indication was less than $30 \%$ through-wall. No indication of cracking was found in slightly more than half the circumference for this weld. There was no secondary SS weld at Crystal River (PEFI 2008). As a result, the beneficial effect of secondary SS weld on the weld residual stresses was absent. For the BCL surge-nozzle analysis without the secondary SS weld, the tensile stresses in the surge-nozzle weld in the axial direction extended to a depth of approximately $50 \%$ to $60 \%$ of the wall thickness. The service history experience at Crystal River tends to support the results from this surge-nozzle analysis. In the case of the Crystal River decay heat nozzle weld, if MSIP had been applied to this cracked nozzle weld, MSIP may have been detrimental for the portion of the flaw reported to be $65 \%$ through-wall. However, the MSIP would still have introduced compressive residual stresses in the pipe wall containing the shallower portions of the flaw or no flaw, thereby providing a constraining effect on circumferential extension of the deepest portion(s) of the crack. In this case, one could theorize that the crack may have resulted in leakage prior to rupture. The Crystal River experience emphasizes the importance of the requirement for pre-MSIP examination; this requirement is even more critical for weld geometries for which there is no secondary SS safe-end weld (welds without the beneficial effect the secondary SS safe-end weld can have on reducing residual welding stresses). In those cases, the welds may be more likely to be affected by PWSCC and the likelihood of a deep crack existing that may be adversely affected by the MSIP is expected to be higher than the case where there is a secondary SS weld. There is a finite possibility that deep circumferential cracks can be missed in the pre-MSIP examination. The Crystal River experience points out that welds without the beneficial effect of a secondary stainless steel safe end-to-pipe weld may be more likely to be affected by PWSCC than welds with a safe end-to-pipe weld. On that basis, periodically examining welds lacking the beneficial effect of a secondary SS safe end-to-pipe weld by placing them in the $25 \%$ inspection sample for MSIP welds would improve the safety basis for sample selection. It may be 
necessary to perform WRS analyses to verify that the secondary stainless steel weld produces beneficial (compressive) WRSs, because this effect is not always the case.

\subsection{Crack Extension Under Design Basis Loading}

One limiting issue for MSIP is the possibility to miss cracks during pre-MSIP inspections. The BCL MSIP report provided the results of crack growth analyses of pre-existing flaw sizes in welds for which MSIP can be applied and effectively reduce inner-wall weld residual stresses and flaw stress intensity. The report also provides results of crack growth analyses of pre-existing flaw sizes where MSIP would negatively affect the performance of the weld. These analyses were performed for welds under normal operating temperature and pressure. However, PNNL was interested in obtaining results of additional crack growth analyses under design basis loading for the hot-leg and surge-nozzle welds addressed by the BCL MSIP report. From regulatory and xLPR perspectives, it was important to perform allowable flaw size analyses for Service Level D safe-shutdown earthquake (SSE) conditions to understand how the results compare with analyses performed under normal operating pressure and temperature conditions. These analyses were performed by BCL and the results of these analyses are contained in Appendix A to PNNL-20580 (Sullivan and Anderson 2011). The maximum allowable depths of flaws in these welds as a function of circumferential extent under Service Level D SSE loading conditions was determined by both ASME Code analyses and "best-estimate" analyses.

From the analyses in the BCL MSIP report considering normal operating pressure loading and temperature, in the event that a flaw were to grow beyond approximately $60 \%$ through-wall thickness, it was found the flaw would be made much worse by MSIP. In other words, the flaw would grow through the wall in a shorter time period under these loadings. The flaws considered in the Battelle MSIP report were $360^{\circ}$ circumferential flaws. In all of the Code-allowable flaw size analyses contained in Appendix A to PNNL-20580, the Service Level D SSE loadings were limiting for a long flaw. In other words, in all cases analyzed, long circumferential flaws less than $60 \%$ through-wall thickness would fail to satisfy ASME Code-required structural factors on crack stability under Service Level D SSE loadings.

From the results of the Code analyses under Service Level D SSE loadings, it can be seen that the allowable flaw sizes in some cases are small. For example, for the hot-leg nozzle case with high SSE stresses, a flaw $30 \%$ through-wall and approximately $15 \%$ of the circumference is allowed, consistent with the guidance in NUREG-0313 (Hazelton and Koo 1988), but the allowable flaw depth drops to little more than $10 \%$ through-wall at a flaw length of about $50 \%$ of the circumference. For the hot-leg nozzle case with intermediate SSE stresses, a $30 \%$ deep flaw is allowed for flaws up to slightly over $40 \%$ of the circumference, which is larger than the guidance in NUREG-0313, but the allowable flaw depth drops to little more than $25 \%$ for flaws longer than $50 \%$ of the circumference.

From the results of the "best-estimate" analyses, the allowable flaw sizes are relatively large reflecting the inherent margins in the Code analyses.

The results of the analyses in Appendix A to PNNL-20580 provide useful insights regarding the importance of detecting even small flaws by conducting effective and reliable pre-MSIP inspections of welds and the importance of evaluating the effects of all the loads on cracked MSIP welds to be left in service. 


\subsection{Welding Residual Stress Finite Element Analysis Validation Studies}

Improvements in computational efficiency have facilitated advances in WRS predictions, but no universally accepted guidelines for these analyses have been established. Therefore, assumptions and WRS estimation techniques vary from analyst to analyst, causing large variability in the predicted residual stress profiles for a given weld. The NRC staff and its contractors are completing a WRS analysis validation program aimed at both (1) refining computational procedures for residual stress simulations in DMWs and (2) developing and categorizing the uncertainties in the resulting residual stress predictions. This program consists of four phases, with each phase increasing in complexity. Parts of this program are being cooperatively completed with EPRI. These four phases are outlined in Table 2.1.

Table 2.1. NRC/EPRI Weld Residual Stress Validation Studies

\begin{tabular}{|c|c|c|}
\hline Phase/Title & Organization Lead & Description of Work \\
\hline Phase 1: Plates and Cylinders & EPRI & $\begin{array}{l}\text { Validate WRS models with basic } \\
\text { geometries and monitored welding } \\
\text { conditions }\end{array}$ \\
\hline Phase 2: Pressurizer Surge Mockups & $\begin{array}{l}\text { NRC lead with international } \\
\text { round robin }\end{array}$ & $\begin{array}{l}\text { Validate WRS analysis methods } \\
\text { with plant prototypic component } \\
\text { and monitored welding conditions }\end{array}$ \\
\hline $\begin{array}{l}\text { Phase 3: Pressurizer Safety and Relief } \\
\text { Nozzles }\end{array}$ & EPRI & $\begin{array}{l}\text { Validate WRS analysis methods } \\
\text { with small components from } \\
\text { cancelled plant }\end{array}$ \\
\hline $\begin{array}{l}\text { Phase 4: Cold-leg Optimized Weld } \\
\text { Overlay (OWOL) Validation }\end{array}$ & EPRI & $\begin{array}{l}\text { Validate WRS analysis methods } \\
\text { with large component from } \\
\text { cancelled plant }\end{array}$ \\
\hline
\end{tabular}

This section summarizes the results of Phase 2 because it is the most applicable study to LBB piping that might be mitigated by MSIP.

As discussed in a paper on this topic presented at the ASME 2011 Pressure Vessel and Piping (PVP) Conference, the second phase of this program consisted of an analytical international round-robin for validation of predicted WRSs in a prototypical PWR PZR surge-nozzle geometry (Rathbun et al. 2011). The results from the round robin were validated through comparison of predicted residual stress fields with a variety of physical measurements performed on the mockup. The validation was double blind; that is, the finite element analysis and measurement participants were not allowed to compare their results before submission, permitting the NRC staff to develop unbiased measures of uncertainties in WRS predictions. The prototypical surge nozzle was constructed of SA-205 carbon steel. The nozzle was welded to a F316L forged stainless steel safe end with an Alloy 82 weld. The stainless steel pipe was Schedule 160, 14-inch diameter, constructed of TP316 stainless steel. The pipe was welded to the safe end with TP 308 stainless steel. Mockup dimensions, materials, and material properties appropriate to the actual mockup and thermocouple data were provided to the analysts. 
To provide data against which the FEA could be validated, a suite of WRS measurements were made on the round-robin mockup, including incremental hole drilling (IHD) and X-ray diffraction (XRD) for surface measurements, and deep hole drilling/incremental deep hole drilling (DHD/iDHD) (Kingston et al. 2006) for through-thickness measurements. One goal of the round-robin study was to assess the effect of the safe end-to-stainless steel pipe weld on stresses in the main DMW. Hence, the suite of WRS measurements described above was taken before and after completion of the safe end-to-stainless steel weld. Only DHD/iDHD results were presented and discussed in Rathbun's (2011) PVP paper. The XRD and IHD results are to be presented in a future publication. To retain brevity in this report, only two sets of stress comparisons will be shown.

For the axial stresses shown in Figure 2.1, the general trend in the average calculated result is in reasonable agreement with the measured results, although there is a significant difference of up to approximately $200 \mathrm{MPa}(29,000 \mathrm{psi})$ in some portions of the curves. The scatter in the finite element results is large at approximately $\pm 200 \mathrm{MPa}(29,000 \mathrm{psi})$. For the axial stress component after application of the stainless steel safe end-to-pipe weld (Figure 2.2), the curves show a similar trend with the average calculated axial ID stress after application of the stainless steel weld being reduced at the ID by almost $400 \mathrm{MPa}(58,000 \mathrm{psi})$ to near zero. For the hoop stresses (not shown here), the same general comments could be made.

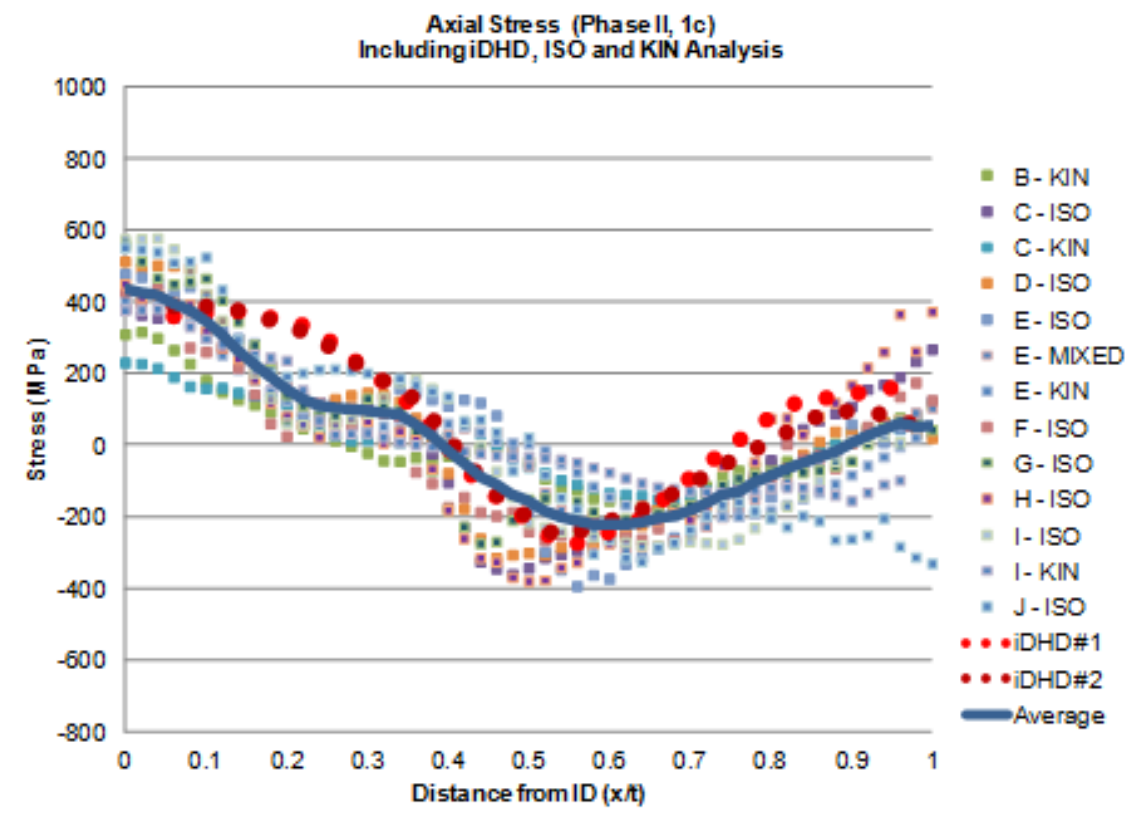

Figure 2.1. Axial Stress Before Stainless Steel Weld. Measured results (DHD/iDHD) are as indicated and the remaining data points are round-robin analyst finite element results. ${ }^{\text {(a) }}$

(a) The axial stress results from Rathbun et al. (2011) were updated and provided in email correspondence from H. Rathbun to E. Sullivan, dated April 9, 2012; Figure 2.1 and Figure 2.2 reflect the updated results. 


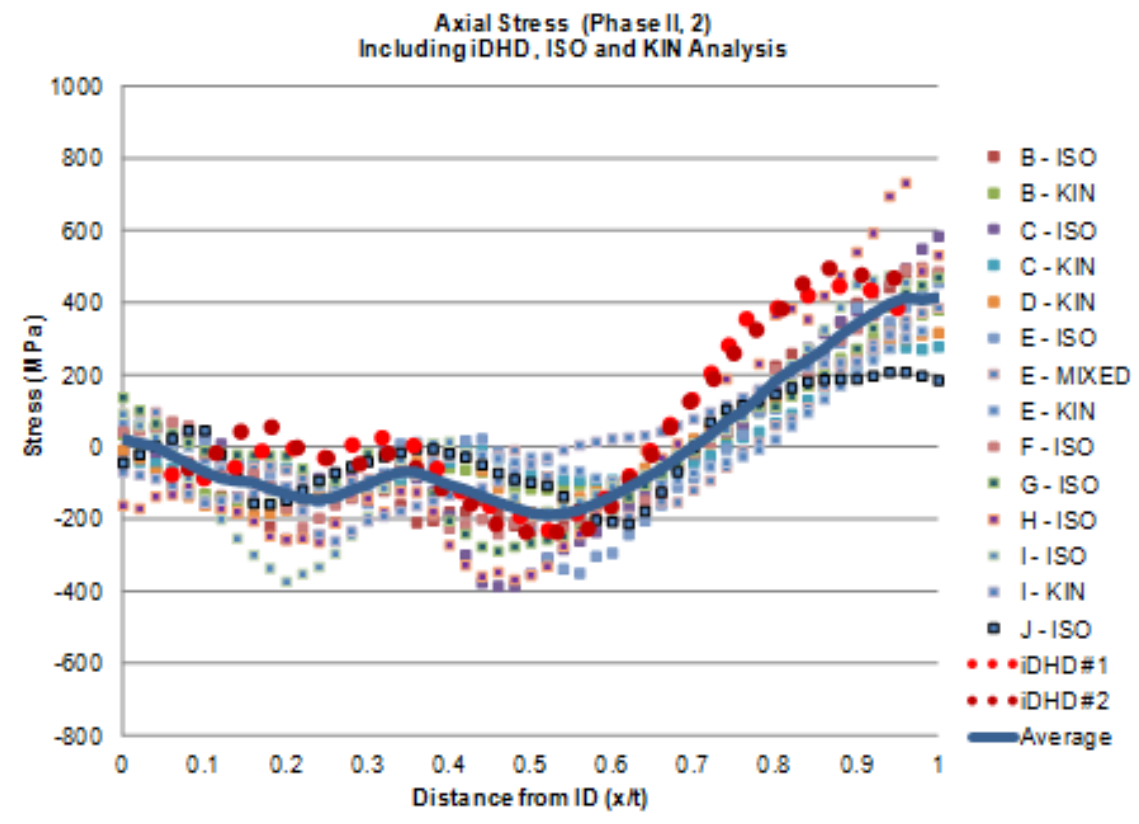

Figure 2.2. Axial Stress After Stainless Steel Weld. Measured results (DHD/iDHD) are as indicated and the remaining data points are round-robin analyst finite element results.

There is a significant amount of scatter in the calculated residual stress profiles; it would be unreasonable to anticipate that a particular analysis result represents a highly accurate representation of a residual stress distribution in an actual component. Although the average measurements and individual FEA results differ in places by significant stress levels, given the overall scatter in the results, to a reasonable approximation, they do occupy the same distribution. Rathbun et al. (2011) discusses factors to which the stress results from the Phase 2 study were sensitive.

Based on the validation studies reported in this section, a large uncertainty is expected in several areas, including:

- actual WRS values,

- the depth of compression induced by MSIP,

- the stress intensity factors for potential pre-existing flaws in MSIP welds, and

- flaw growth predictions.

WRS analyses may better predict changes between pre- and post-MSIP residual stress values than the actual WRSs. Notwithstanding uncertainly in the absolute WRS values, the analyses of Fredette and Scott (2009) and the analysis by Fredette (2011) of pre- and post-MSIP strain measurements indicate the effectiveness of MSIP for significantly reducing the stresses that can lead to the initiation and propagation of PWSCC. Operating experience in BWRs and PWRs also indicates that MSIP is an effective measure for reducing inner-diameter WRS. 


\subsection{Weld Residual Stress and Crack Growth Conclusions}

Based on the discussions in Sections 2.1 through 2.4, it is reasonable to draw the following conclusions.

a. MSIP is an effective method to reduce weld residual tensile stresses at the inside surface and mitigate growth of existing cracks by PWSCC, provided any such existing cracks are small.

b. The behavior of circumferential cracks in DMWs under normal operating loads indicates that the guidelines for maximum allowable cracks in BWR welds mitigated by MSIP that were specified in NUREG-0313 (Hazelton and Koo 1988) remain valid and should also be applied to using MSIP on PWRs. These provisions state that MSIP not be used if the weld to be treated cannot be inspected, or if existing crack indications are greater than $30 \%$ through the pipe wall (or circumferential cracks are longer than $10 \%$ of the circumference). Based on BCL's analyses, if a deep crack existed in the weld prior to the application of MSIP, this process actually accelerated crack growth.

c. Welds without the beneficial effect of a secondary SS safe end-to-pipe weld may be more likely to be affected by PWSCC than welds with a safe end-to-pipe weld. On that basis, periodically examining welds lacking the beneficial effect of a secondary stainless steel safe end-to-pipe weld in the $25 \%$ inspection sample for MSIP welds would improve the safety basis for sample selection. It may be necessary to perform WRS analyses to verify that the secondary SS weld produces beneficial (compressive) WRSs, because this effect is not always the case.

d. Based on sensitivity analyses, the MSIP process does not require a high degree of precision with respect to the positioning of the tool or the amount of squeeze applied.

e. Three-dimensional models of the process show that MSIP is effective around the entire circumference of the treated weld, even if its application does not produce a uniform effect around the entire circumference of the pipe.

f. From the perspective of applying MSIP to welds with flaws, the Code-allowable flaw sizes under Service Level D SSE loading in some cases are small. In all of the Code-allowable flaw size analyses, the Service Level D SSE loadings were limiting for a long flaw. The results of the analyses of Code-allowable flaw sizes under Service Level D SSE provide useful insights regarding the importance of detecting even small flaws by conducting high-quality pre-MSIP inspections of welds and the importance of evaluating the effects of all the loads on cracked MSIP welds to be left in service.

g. Based on the validation studies reported in this section, large uncertainty should be expected in analytical estimates made of stress and flaw growth. WRS analyses may better predict changes between pre- and post-MSIP residual stress values than the actual WRSs. Notwithstanding uncertainly in the absolute WRS values, analyses indicate that MSIP is effective in significantly reducing the residual stresses that can lead to the initiation and propagation of PWSCC. Operating experience in BWRs and PWRs also indicates that MSIP is an effective measure for reducing inner-diameter WRS. 


\subsection{NDE Reliability}

To evaluate the reliability of ultrasonic inspections, PNNL considered flaws evaluated both before and after MSIP application. The data used to make pre- and post-MSIP UT comparisons came from multiple sources: UT data on unmitigated welds presented during a workshop held by PNNL in May 2012, a nuclear power plant in Lithuania, and a specimen built by PNNL. Section 3.1 summarizes the findings of the PNNL UT workshop. Section 3.2 summarizes the results of an investigation based on data acquired from cracked areas in 325-mm (12.8-in.) diameter piping at the Ignalina Nuclear Power Plant (INPP) in Lithuania. Section 3.3 summarizes the results of a follow-on exercise in which PNNL acquired and evaluated UT data from a PNNL DMW specimen containing implanted thermal fatigue cracks. Section 3.4 contains a comparison of the UT data from Ignalina and the PNNL specimen (Crawford et al. 2011). Section 3.5 provides a discussion on potential limitations to conducting pre- and post-MSIP inspections. Section 3.6 provides conclusions regarding the reliability of NDE for MSIP welds.

\subsection{Assessment of Pre-MSIP UT Examination Results}

As noted in Section 1.0 of this report, the MSIP design requires that the subject piping weld be inspected immediately prior to the application of this process, using an inspection technique qualified in accordance with ASME Section XI, Appendix VIII. Any flaws that are detected during the pre-MSIP UT have to be addressed as part of the mitigation using the rules of Section XI, IWB-3600, Analytical Evaluation of Planar Flaws.

This section provides a discussion and conclusions on NDE reliability issues related to detection and characterization of stress corrosion cracking (SCC) in unmitigated welds. These NDE reliability issues are also relevant to the reliability of pre-MSIP inspections.

\subsubsection{Introduction}

On May 8 and 9, 2012, PNNL held a workshop in Richland, Washington, with LMT, Inc., an NDE vendor for the commercial nuclear power industry. LMT uses UT examination methods qualified under ASME Code, Section XI, Appendix VIII. Both phased-array (PA) and conventional UT techniques in encoded and non-encoded delivery modes are employed, as specified by the utility. LMT performs examinations of piping welds from the piping OD and has been involved with the inspection of a number of welds in PWRs and BWRs in which indications were attributed to SCC.

The topics that follow were discussed during this workshop.

- Characterization of flaws attributed to SCC,

- Encoded versus non-encoded examinations,

- Characterization of embedded flaws in field welds, and

- Comparison of serviced-induced cracks with flaws in performance demonstration mockups. 


\subsubsection{Discussion}

Encoded phased-array UT techniques were used to detect and characterize SCC found in a BWR control rod drive (N9) nozzle DMW during a spring 2008 refueling outage and in a PWR PZR surge-line DMW during a spring 2007 refueling outage. In both cases, the stress corrosion cracking was subsequently mitigated with NRC-approved full structural weld overlays. Additionally, encoded phased array UT examinations were performed in 2008 on safety and relief nozzle welds on a PZR removed from St. Lucie, Unit 1, to assess results obtained previously from manual non-encoded PA examinations.

In the case of the BWR N9 weld, the full ASME Code-required inspection volume was not achieved with encoded phased-array ultrasonic testing (PAUT) techniques because of an interfering weld crown, geometry limitations from the nozzle contour, and the presence of an end cap. Only axial scanning for circumferentially oriented flaws was conducted using PA, as the component was being prepared for a full structural weld overlay procedure and full ASME Code UT volume coverage was not required.

With minor geometric reflections in this weld, a circumferential flaw was readily detected and was localized at the weld-to-butter interface, determined to be ID-connected, and was attributed to intergranular stress corrosion crack. The overall thickness of the weld was approximately $19 \mathrm{~mm}$ (0.75 in.) and the crack was depth sized at approximately $60 \%$ through-wall. A general observation made by LMT analysts during the workshop was that this circumferential flaw was relatively easy to detect and characterize on this somewhat thin-walled component. They noted that inspection of heavier-walled components can present additional challenges.

Regarding the surge-line flaw, full volumetric inspection of the flawed region was precluded by the specimen's taper and the presence of lugs near the nozzle weld. During the initial conventional manual (non-encoded) examination, an axial flaw was detected. A decision was made to remove the lugs and use encoded PAUT to fully characterize the axial flaw as well as to conduct a more complete inspection of the Code-required inspection volume. Using encoded PAUT, an ID-connected circumferential flaw was observed that was not initially detected by the manual conventional UT examination. The weld thickness is approximately $38 \mathrm{~mm}$ (1.50 in.) at the flaw location, and the flaw was depth-sized at 34\% through-wall. It is unclear whether interference by the lugs prevented detection of the circumferential flaw during the initial manual examination. However, general observations made by the LMT analysts were that use of the encoded PAUT technique facilitated detection and characterization of this flaw, which would not have been straightforward in this weld using manual non-encoded techniques, even with the lugs removed. This observation is based on the presence of spurious reflections caused by a short safe-end, numerous geometrical reflections, and various mode-conversion signals. The use of encoded techniques enabled the spurious reflections to be reviewed sufficiently to distinguish the circumferential flaw from the other reflections and characterize it properly.

In the case of the St. Lucie, Unit 1, PZR safety and relief nozzle welds, the conclusions of the initial manual (non-encoded) PA examinations were that the safety and relief nozzle welds contained deep non-uniform $360^{\circ}$ ID-connected circumferential flaws indicative of SCC. This result raised questions about the applicability of the advanced finite element analyses (AFEA) safety assessment performed after deep circumferential flaws were detected in 2006 in Wolf Creek PZR nozzles (EPRI 2007). The Wolf Creek flaws were attributed to PWSCC. A number of operating PWRs had delayed the PZR nozzle weld inspections to their next refueling outage based on the AFEA assessment. Because of the significance of the initial St. Lucie, Unit 1, inspection result to these operating PWR plants, the initial examinations were 
reevaluated and the welds were reexamined shortly thereafter with encoded techniques. A PNNL UT expert participated in the reexamination activity. Further scanning and data analysis indicated that the welds were not cracked, but rather contained embedded fabrication flaws, attributed to slag, porosity, and/or lack of fusion. The $360^{\circ}$ indications at the ID were weld root signals. Despite the abundance of fabrication flaws, a reevaluation of these flaws in accordance with ASME Code Section III criteria confirmed that the welds were acceptable. During the reevaluation, numerous problems were found with the initial examinations. These problems included use of probes that were inappropriately focused for the welds being examined, improper execution of Performance Demonstration Initiative (PDI)-qualified procedures, and the inability of the examiners to distinguish the signals from the weld root and embedded flaws from ID-connected flaws with the manual techniques. The workshop participants noted the disadvantage of using manual PA techniques in this situation because of the inability to review the UT data and carefully determine the origin of the signals present. It was also noted that opportunities in the PDI qualification process for candidates to be required to interpret reflections from false-call signals such as those weld roots, counterbores, and welding fabrication flaws, may not be sufficiently realistic. Thus, examiners may pass the PDI qualification process with manual (both conventional and PA) non-encoded techniques without sufficiently demonstrating the ability to distinguish ID-connected flaws from other signals that may be expected to be present in a weld inspection volume, especially in DMWs.

Workshop participants indicated that there are numerous factors that affect the reliability of NDE to detect and characterize flaws. These factors include the ability of the techniques used to obtain full ASME Code-required coverage of the inspection volume, the presence of interfering signals from geometric or metallurgical reflectors, the use of manual versus encoded techniques, the reflectivity of the flaw, the impedance of the materials being examined, the signal attenuation and dispersion through those materials, and the experience and skill of the examiner. Other related factors may include the use of proper modeling methods to design the examination and the representativeness of the mockups used for performance demonstration. The St. Lucie, Unit 1, experience and the recent North Anna, Unit 1, experience in 2012 (discussed in Anderson et al. 2012), reinforce the importance of carefully considering these factors before conducting an examination. It was suggested that additional observations on NDE reliability could possibly be drawn if more encoded data on service-induced SCC were available for review.

A portion of the workshop was devoted to discussing preliminary results of a program at PNNL on comparing UT data from service-induced cracks with implanted flaws being used for demonstration testing. PAUT data was acquired on several specimens that contained a variety of different flaw or simulated flaw types. Data were presented to compare the responses observed from each flaw type. The flaw types consisted of hot isostatic pressed (HIP) notches produced by electro-discharge machining (EDM) and implanted thermal fatigue cracks (TFCs) in wrought SS, implanted TFCs in cast austenitic stainless steel (CASS), IGSCC in Hatch and Nine Mile Point in specimens owned by EPRI, as well as TFCs implanted in CASS piping material. A primary goal of this work is to identify quantifiable variables that affect flaw responses, analyze the variables, and use this information to compare flaw types. It is of particular interest to identify the degree to which implanted flaws, such as those currently used by industry, are representative of service-induced flaws and, therefore, provide sufficiently challenging targets for performance demonstration.

In selectively comparing the implanted TFCs and the HIP EDM notches, a general observance was that less overall gain was needed to produce similar responses for the HIP EDM notches. Overall, it was concluded that additional work on signal analysis will be needed to complete the program goals. 


\subsubsection{NDE Workshop Conclusions}

The conclusions of the workshop were the following.

1. The reliability of NDE to detect and accurately characterize service-induced SCC flaws is dependent upon a number of factors, including:

- the ability of the applied NDE to obtain full coverage of the required inspection volume,

- the presence of interfering signals such as from geometric or metallurgical reflectors,

- the use of non-encoded or PA versus encoded techniques,

- general reflectivity of the service-induced flaw,

- acoustic impedance of the materials being examined and the signal attenuation and dispersion through those materials,

- the experience and skill of the examiner,

- the use of proper modeling methods to design examinations, and

- the representativeness of the mockups used for performance demonstration to qualify UT examiners.

2. Given these factors and the constraints of field conditions involving UT inspection of RCS DMWs, the use of encoded UT techniques offers a distinct and significant advantage over non-encoded techniques in detection and characterization of flaws, because of the ability to review the UT data offline and carefully determine the origin of the signals present in the images produced.

3. Current mockups and protocols used by industry during the PDI qualification process may not provide sufficient opportunities such that candidates may demonstrate adequate skills for interpreting realistic false-call signals from non-crack reflection sources that may be encountered in the field; for example, fabrication flaws, weld root response variations, or other geometrical/metallurgical responses. Thus, examiners may pass the PDI qualification process without sufficiently demonstrating the ability to distinguish ID-connected flaws from other signals that may be expected to be present in a weld inspection volume, especially in DMWs.

4. Additional work will be needed to determine the degree to which artificial implanted flaws are representative of service-induced flaws.

\subsection{Ignalina Nuclear Power Plant}

\subsubsection{Test Materials}

Data was acquired from piping in the INPP (Crawford et al. 2011). The piping base material is 08X18H10T, $18 \% \mathrm{Cr}, 10 \% \mathrm{Ni}, \mathrm{C}$ wrought stainless steel with a nominal outside diameter of $325 \mathrm{~mm}$ (12.8 in.) and a wall thickness of approximately $16 \mathrm{~mm}(0.63 \mathrm{in}$.$) . Two field welds and five shop-$ fabricated welds were included in this study.

Service-induced IGSCC was present in the HAZ of many of the INPP piping welds because of high residual stresses imparted by autogenous root-welding procedures and the welds having been exposed to 
an oxygen-rich water chemistry. Eight circumferentially oriented flaws from the Ignalina plant were included in this study.

\subsubsection{MSIP Application}

During the MSIP process, plastic deformation of the pipe wall adjacent to the weld (under the mechanical clamp) results in contouring of the inner and outer surfaces of the weld. These surface conditions can potentially misalign subsequent ultrasonic transducer placement causing examination volumes to be limited except at extremely high insonification angles, and may produce flaw reflections to be redirected at a higher angle than would occur on a flat surface. This surface condition introduces a gap between transducers and the OD surface of the pipe, which decreases ultrasonic coupling, and causes lack of sufficient sound penetration and/or irrelevant signals in the data. Because the effects of possible ultrasonic beam redirection and loss of coupling in the ultrasonic data from the MSIP-applied side is a concern, only UT data from the non-MSIP side of the INPP welds is discussed.

\subsubsection{Ultrasonic Methods}

The pipes at INPP were scanned using a PA transmit-receive dual shear-wave (TRS) probe, which allowed examiners to scan the piping welds with good coverage in a short amount of time. A ZETEC Z-Scan phased-array system with a 32/128PR channel configuration was used to record rectified A-scan data in line scans. The shear-wave phased-array probe had $2 \times 32$ elements and was designed to operate at $4.0 \mathrm{MHz}$ with refracted angles from $50^{\circ}$ to $80^{\circ}$.

A 4.0-MHz shear-wave probe would likely be ineffective for penetrating austenitic welds in commercial U.S. reactors, as the dendritic grain structure of the weld metal absorbs and redirects sound beams, especially in this frequency regime. For this reason, most through-weld applications in austenitic piping at U.S. plants use refracted longitudinal waves in the 1.0- to 2.25-MHz frequency range. However, the titanium-stabilized SS used for INPP piping and welds produced a fine, equiaxed and randomly oriented grain structure only slightly coarser than would be found in carbon steel. This grain structure allows higher frequency shear waves to penetrate the welds much more effectively, thus facilitating ultrasonic examination and producing higher-resolution images.

Line scans adjacent to the welds were acquired with a calibrated probe orientated perpendicular to the weld for detection of circumferential flaws; that is, flaws parallel to the weld. Data was acquired at 1-mm (0.04-in.) increments circumferentially while the sound beam was swept from $50^{\circ}$ to $80^{\circ}$ through the weld in $1^{\circ}$ increments. The resolution of the mechanical scanning movement along the weld was $1.0 \mathrm{~mm}$ (0.04 in.).

\subsubsection{Data Evaluation}

Staff from INPP identified areas of the subject welds containing IGSCC during previous in-service inspections (ISIs). Phased-array data were collected from the cracked pipe welds and on the crack-free pipe weld, typically for $360^{\circ}$ around the pipe. Each of the areas containing indications was analyzed to determine the signal-to-noise ratio (SNR) and the depth and length of the indication. The SNR was calculated from the peak flaw response and the average noise level in a flawless zone at the same part 
path or depth. Flaw depth was estimated using tip-diffracted signals where present, and flaw length was measured to the loss-of-signal level.

One IGSCC indication in weld P27z1 was detected prior to MSIP but not during the post-MSIP inspection. The amplitude response for all but one of the indications decreased after MSIP, with the one indication exhibiting a very small increase in amplitude response. The measured length of all the indications decreased after MSIP.

\subsection{PNNL Dissimilar Metal Weld Specimen}

\subsubsection{Test Materials}

Data were acquired from a DMW specimen, 9C003, fabricated by PNNL to simulate a PZR surge nozzle (Crawford et al. 2011). The weld of interest is an A106B/A105 carbon steel nozzle welded to a 316 stainless steel safe end. The safe end is welded to a 316 stainless steel pipe, and a large carbon steel flange was added to the nozzle to provide rigidity during the MSIP. The nozzle butter and nozzle-to-safe end weld material are $\mathrm{NiCrFe} 3$ (Alloy 82/182) with the safe end-to-pipe weld material being 308 stainless steel. The nozzle-to-safe end and safe end-to-pipe weld crowns were ground smooth and flush with the OD surface.

Six circumferential and one axial thermal fatigue cracks were implanted in the butter-to-weld region nearer the carbon steel nozzle side. The circumferential cracks were tilted between $8^{\circ}$ and $15^{\circ}$ and varied in depth from $16 \%$ to $90 \%$ through-wall. Flaws were implanted within the butter material to minimize the potential for disturbing the parent material, thus avoiding the introduction of implantation anomalies that could result in the reflection of coherent sound energy.

\subsubsection{MSIP Application}

MSIP on the 9C003 specimen was applied over the safe end-to-pipe weld adjacent to the targeted nozzle DMW containing the implanted flaws. A $0.94 \%$ reduction was achieved on the specimen as measured by NuVision during the MSIP application. Circumferential change measurements were taken at an axial mark on the safe end before and after MSIP. Surface profile measurements were also taken at PNNL in the weld region to estimate the amount of reduction caused by the MSIP. These measurements gave a deformation of $0.78 \%$ and $0.55 \%$ at the $0^{\circ}$ and $90^{\circ}$ positions. The OD-based values are lower than the NuVision-measured circumferential deformation of $0.94 \%$ and should be considered as estimates because they are point measurements.

\subsubsection{UT Methods}

The PNNL 9C003 specimen was examined with two phased-array probes with designed center frequencies of 1.5 and $2.0 \mathrm{MHz}$. Both probes were operated in a transmit-receive longitudinal (TRL) mode.

Phased-array data was acquired with a ZETEC DYNARAY system in conjunction with a manualencoded scanner mounted directly on the specimen. Two encoders provided positional information in the circumferential direction for line scans and in both circumferential and axial directions for raster scans. 
The probes were water-coupled and data were acquired over inspection angles of $30^{\circ}$ to $70^{\circ}$ in $1^{\circ}$ increments. Line scan and raster scan data were acquired from both sides of the weld with the $1.5-\mathrm{MHz}$ probe for the six circumferential flaws and the axial flaw. Line and raster data were also acquired from both sides of the axial flaw at $1.5 \mathrm{MHz}$. At $2.0 \mathrm{MHz}$, line scan data were acquired from both sides of the weld on the six circumferential flaws. Raster data was limited to three of the circumferential flaws from both sides of the weld and no data were acquired on the axial flaw.

\subsubsection{Data Evaluation}

All six of the implanted TFCs were detected with both probes both before and after the MSIP application. Because the true dimensions of the implanted flaws are known, the error in measurements could be determined. The measurement error data show that the pre- and post-MSIP values overlap and do not indicate a reduction in flaw length after MSIP application. The smaller flaws are over length-sized in both the pre- and post-MSIP data. Root-mean-square errors (RMSEs) were within the ASME guidelines of $19.05 \mathrm{~mm}(0.75 \mathrm{in}$.) for acceptable length sizing.

The pre- and post-MSIP flaw depth values overlap, showing little difference between the two sets of measurements. The depth sizing was very good for all but the two deepest flaws. Neither PA probe focused well at the higher angles needed for detection of deep flaw tips. RMSEs were within the ASME guidelines of $3.18 \mathrm{~mm}(0.125 \mathrm{in}$.) in depth sizing for only half of the scans.

\subsection{Comparison of Ignalina and PNNL 9C003 Specimen Data}

A comparison of the changes in flaw characteristics between pre- and post-MSIP data for both types of flaws was made. One of the eight INPP flaws was no longer detected after MSIP; however, all six of the implanted flaws in the 9C003 specimen remained detectable after MSIP. On average, the Ignalina data show a length change of $-18.4 \mathrm{~mm}(-0.72 \mathrm{in}$.) if all flaws are included. The change in length for the implanted flaws in the PNNL specimen does not show a negative or a positive trend. An increase in flaw length is unreasonable; therefore, any such observation of small growth is attributed to measurement error rather than an actual growth in the flaw length. This lack of a noticeable decrease in flaw length with the MSIP application in the PNNL specimen was not expected.

The Ignalina data show a loss in flaw response as measured by SNR at $-6.4 \mathrm{~dB}$ if all eight flaws are included. The implanted flaw data on 9C003 for both probes, and line and raster images, trend toward a reduction in amplitude, but on average a small change of only $-1.9 \mathrm{~dB}$ is observed.

On average, the six implanted flaws in the 9C003 specimen showed minimal change, if any, after MSIP. Because the flaw implantation process may have introduced a slight misalignment of the two crack faces on each flaw, it is hypothesized that during MSIP, this misalignment would have prevented the crack from closing, leading to similar ultrasonic responses for the pre- and post-MSIP data.

\subsection{Inspection Limitations}

Condition $\S 50.55 \mathrm{a}(\mathrm{g})(6)(\mathrm{ii})(\mathrm{F})(2)$ that imposes Code Case N-770-1 allows welds mitigated by mechanical stress improvement to be categorized as Inspection Items D or E, as appropriate, provided the criteria of Appendix I of the Code Case have been met. Code Case N-770-1, Appendix I, Criterion 5, 
requires that, "the mitigated weld shall be inspectable by a qualified process." Criterion 5 further requires that, "An evaluation shall be performed to confirm that the required examination volume of the mitigated configuration is within the scope of an Appendix VIII supplement or supplements and that the examination procedures to be used have been qualified in accordance with Appendix VIII. The evaluation shall confirm that the geometric limitations (e.g., weld crown, nozzle contour) of an Appendix VIII qualification are not exceeded for the mitigated weld." If examination of the required examination volume cannot be satisfied, a licensee would be expected to obtain NRC approval of an alternative examination prior to performing the mitigation.

Information on limitations to performing inspections of typical Westinghouse and CE plant RCS Alloy 82/182 welds was obtained from LMT, Inc., an NDE vendor for the commercial nuclear power industry, during a workshop PNNL held in May 2012. Appendices C and D contain weld coverage assessment diagrams for these plants that show the probe angles used and percent coverage obtained with Section XI, Appendix VIII, qualified techniques. These appendices also indicate the materials of construction for the welds depicted. As noted above, qualified UT examinations are required prior to applying MSIP.

For the plant-specific designs used to prepare Appendices C and D, Tables 3.1 and 3.2 provide the Code-required volume coverage achievable for Alloy 82/182 RCS butt welds in the typical Westinghouse and Combustion Engineering plants used for this assessment. These tables indicate the welds for which Code-required inspection coverage would not be achieved based on the plant-specific designs used in the assessment. It should also be noted that the Westinghouse RPV nozzle welds in this study were examined from the OD, although the RPV nozzle welds in many Westinghouse plants are examined from the inside surface, where the inspection limitations differ and the Code-required volume (CRV) coverage obtained is generally understood to be higher.

In CE plants, the safe ends of medium- and large-bore piping are typically made of cast stainless steel. The CRV coverage presented in Table 3.2 takes credit for the scan coverage in the CASS safe ends using the Supplement 10 techniques used for the carbon steel and Alloy 82/182 volumes. This approach for reporting CRV coverage was used because Code Case N-770-1 requires the examination volume to be examined by Appendix VIII procedures to the maximum extent practical, including $100 \%$ of the susceptible material volume.

Table 3.1. RCS Alloy 82/182 Butt Weld Code Required Volume Coverage Obtained for a Typical Westinghouse Plant

\begin{tabular}{lcc}
\hline \multicolumn{1}{c}{ Description } & Axial Scan, \% & Circumferential Scan, \% \\
\hline PZR Surge Nozzle & 80 & 100 \\
PZR Spray Nozzle & 40 & 34 \\
PZR Safety and Relief Nozzle & 0 & 0 \\
RPV Hot Leg Nozzle & 28.8 & 100 \\
SG Hot Leg Nozzle & 95.4 & 100 \\
SG Cold Leg Nozzle & 95.4 & 100 \\
RPV Cold Leg Nozzle & 100 & 100 \\
\hline PZR - pressurizer; RPV - reactor pressure vessel; SG - steam generator \\
\hline
\end{tabular}


Table 3.2. RCS Alloy 82/182 Butt Weld Code Required Volume Coverage Obtained for a Typical Combustion Engineering Plant

\begin{tabular}{lcc}
\hline \multicolumn{1}{c}{ Description } & Axial Scan, \% & Circumferential Scan, \% \\
\hline RCP Suction to RC Pipe & 100 & 44.3 \\
RCP Discharge to RC Pipe & 77 & 34 \\
RC Loop Surge Nozzle & 82.4 & 31.3 \\
Letdown and Drain Nozzle & 100 & 100 \\
Hot Leg Drain Nozzle & 100 & 100 \\
Charging Inlet Nozzle & 100 & 100 \\
Safety Injection Nozzle & 94.3 & 26.6 \\
Shutdown Cooling Nozzle & 98 & 100 \\
Spray Nozzle & 100 & 100 \\
PZR Surge Nozzle & 100 & 100 \\
PZR Spray Nozzle & 100 & 68.9 \\
PZR Safety Nozzle & 100 & 100 \\
\hline RCP - reactor coolant pump; RC - reactor coolant; PZR - pressurizer \\
\hline
\end{tabular}

Inspection limitations exist for welds adjacent to cast stainless steel products. Since Appendix VIII, Supplement 9 for examination of CASS piping welds has yet to be developed, there are no performance demonstration qualification requirements for inspection of cast materials. Some NRC guidance on performing examinations of welds adjacent to CASS products is contained in the summary of the July 12 , 2011, public meeting (Collins 2011) in the response to Question 31. The public meeting was held by the NRC to discuss implementation of Code Case N-770-1. Additional guidance may be found in the summary of the NRC public meeting with the PWROG on January 10, 2012. This meeting was held to discuss an industry template for a generic relief request from the requirements of Code Case N-770-1, as conditioned by the NRC (Rowley 2012). Consistent with the requirements of -2500(b) of the Code Case, this NRC guidance stipulates that $100 \%$ of the susceptible material volume (non-stainless steel volume) is to be examined with a qualified Appendix VIII procedure and the cast stainless steel portion of the required examination volume is to be examined to the maximum extent practical using an Appendix VIII procedure. Licensees are expected to obtain NRC authorization to apply MSIP on welds that contain inspection limitation.

ASME Section XI prepared Code Case N-824, entitled, "Alternate Requirements for Ultrasonic Examination of Cast Austenitic Piping Welds from the Outer Diameter Surface." The requirements in this Code Case are deterministic rather than performance-based. However, this Code Case is considered to be a first step in the development of Supplement 9. NDE reliability would be expected to be improved by applying this Code Case in situations where $100 \%$ of the susceptible material cannot be examined from the ferritic side of the weld.

Research conducted by the NRC Office of Nuclear Regulatory Research on inspection of cast stainless steel demonstrated that the Appendix III UT techniques are inadequate when applied to cast materials. However, some of the techniques used during Appendix VIII qualifications may perform well on cast stainless steels, especially for thinner-walled cast stainless steel. NRC research has shown that, for piping less than approximately 4 to $5.1 \mathrm{~cm}$ (1.6 to $2.0 \mathrm{in}$.) in thickness, refracted longitudinal waves (transmit-receive L-waves) operating at frequencies between 0.8 and $2.0 \mathrm{MHz}$, work fairly well. Much lower frequency ranges, on the order of 0.4 to $1.0 \mathrm{MHz}$, are needed for primary system cast stainless steel 
piping (greater than $5.1 \mathrm{~cm}$ [2.0 in.] in thickness). To date using these frequencies, inspections can reliably detect flaws in the $25 \%-30 \%$ through-wall range. Additional information is contained in NUREG/CR-6933, Assessment of Crack Detection in Heavy-Walled Cast Stainless Steel Piping Welds Using Low-Frequency Ultrasonic Methods (Anderson et al. 2007). NUREG/CR-7122, An Evaluation of Ultrasonic Phased Array Testing for Cast Austenitic Stainless Steel Pressurizer Surge Line Piping Welds. (Diaz et al. 2011) provides information on crack detection with UT in thinner-walled cast stainless steel. The information in these NUREGs should be helpful to industry in improving the reliability of inspections and to NRR in evaluating relief requests and inspection-related issues involving cast stainless steel.

Another examination limitation that should be noted in the context of MSIP involves Westinghouse reactor vessel nozzle welds that are inspected from the nozzle ID surface. These weld configurations would not satisfy the requirements of Appendix I, Criterion 5, since the ID examination procedures for these welds are not qualified for depth sizing. The lack of a qualified procedure for these nozzles precludes application of MSIP without prior NRC approval of alternative examination techniques. With respect to cold-leg reactor vessel nozzle welds that may not have to be inspected prior to mitigation, MSIP may cause crack faces to close or partially close and change the UT response of the flaws. This phenomenon may increase the difficulty of qualifying procedures for detection as well as depth sizing. This topic is discussed in more detail in Section 4.2 and Appendix B, B.1 of this report.

\subsection{NDE Reliability Conclusions}

The reliability of NDE is of interest to welds mitigated by MSIP for several reasons. As discussed in Section 2.2, the guidelines in NUREG-0313 indicate that the MSIP process should only be applied to locations that can be inspected and that are shown to have circumferential cracks where the lengths add to no longer than $10 \%$ of the circumference and the maximum through-wall depth of any crack does not exceed $30 \%$ of the piping wall thickness. From the perspective of applying MSIP to welds with flaws, Section 2.4 shows that the Code-allowable flaw sizes under design basis seismic loading in some cases are small. Based on BCL's analyses, if a deep crack existed in the weld prior to the application of MSIP, this process actually accelerated crack growth. Therefore, effective and reliable NDE has to be used to detect and characterize flaws, especially prior to the application of MSIP, in order for MSIP to perform as intended.

PNNL held a workshop in May 2012 with LMT, Inc., a commercial nuclear NDE vendor, to review UT data from service-induced flaws and to discuss factors that affect the reliability of various NDE techniques qualified in accordance with Section XI. This workshop, which related to inspection of premitigated piping welds, identified the following issues.

In assessing the overall reliability of the subject examinations to detect and accurately characterize service-induced SCC, there are a number of factors that must be considered. These include:

- ability of the applied NDE to obtain full coverage of the required inspection volume,

- presence of interfering signals such as from geometric reflectors,

- the use of non-encoded versus encoded techniques,

- general reflectivity of the service-induced flaw, 
- acoustic impedance of the materials being examined and the signal attenuation and dispersion through those materials,

- relative experience and skill of the examiner (and/or data analyst),

- use of modeling to design examination parameters, and

- representativeness of mockups used for performance demonstration qualifications.

Given these factors and the constraints of field conditions involving UT inspection of RCS DMWs, the use of encoded UT techniques offers a distinct and significant advantage over non-encoded techniques in detection and characterization of flaws, because of the ability to review the UT data off-line and carefully determine the origin of the signals present in the images produced.

Current mockups and protocols used by industry during the PDI qualification process may not provide sufficient opportunities such that candidates may demonstrate adequate skills for interpreting realistic false-call signals from non-crack reflection sources that may be encountered in the field; for example, fabrication flaws, weld root response variations, or other geometrical/metallurgical responses. Thus, examiners may pass the PDI qualification process without sufficiently demonstrating the ability to distinguish ID-connected flaws from other signals that may be expected to be present in a weld inspection volume, especially in DMWs.

A comparison of the changes in flaw characteristics between pre- and post-MSIP data for both SCC and implanted thermal fatigue flaws was made. One of the eight INPP flaws was no longer detected after MSIP. On average, after MSIP the Ignalina data show a decrease in length and a loss in flaw response as measured by SNR. All six of the implanted flaws in the MSIP mockup specimen remained detectable after MSIP. The implanted flaw data trend toward a reduction in amplitude, but on average only a small change was seen. On average, the six implanted flaws in the mockup specimen showed minimal change in SNR, if any, after MSIP. The contrast between the INPP data and the data from 9C003 was not expected. Because the flaw implantation process may have introduced a slight misalignment of the two crack faces on each flaw, it is hypothesized that during MSIP, this misalignment would have prevented the crack from closing, leading to similar ultrasonic responses for the pre- and post-MSIP data.

Inspection limitations can affect the effectiveness of NDE requirements. The following issues were identified based on an assessment of MSIP inspection limitations.

- The criteria of Code Case N-770-1, Appendix I, Paragraph 5 require that a qualified pre-mitigation examination be performed before the application of an MSIP. Departure from the requirements of Code Case N-770-1, and applicable conditions imposed by the NRC, because of pre- or post-MSIP inspection limitations have to be evaluated and an alternative examination authorized by the NRC staff.

- Geometry or access may limit performing a complete pre-MSIP weld examination. Information on limitations to performing inspections of typical Westinghouse and CE plant RCS Alloy 82/182 welds was obtained from an inspection vendor for the commercial nuclear power industry. Appendices $\mathrm{C}$ and $\mathrm{D}$ to this report contain weld coverage assessment diagrams that show the probe angles used and percent coverage obtained with Section XI, Appendix VIII, qualified techniques. ASME Coderequired volumetric coverage appears achievable for many, although not all, Westinghouse and CE Alloy $82 / 182$ butt welds. 
- Inspection limitations exist for welds adjacent to CASS products and qualification requirements do not yet exist in Appendix VIII for inspection of cast piping welds. Code Case N-770-1 requires the examination volume to be examined by Appendix VIII procedures to the maximum extent practical including $100 \%$ of the susceptible material volume. ASME Section XI prepared Code Case N-824, entitled, "Alternate Requirements for Ultrasonic Examination of Cast Austenitic Piping Welds from the Outer Diameter Surface." NDE reliability would be expected to be improved by applying this Code Case in situations where $100 \%$ of the susceptible material cannot be examined from the ferritic side of the weld.

- During the MSIP process, plastic deformation of the pipe wall adjacent to the weld (under the mechanical clamp) results in contouring of the inner and outer surfaces of the weld. These surface conditions can potentially misalign subsequent ultrasonic transducer placement causing examination volumes to be limited. 


\subsection{Assessment of ASME Code Case N-770-1 Requirements}

\subsection{Background}

LBB evaluations and approvals did not depend directly upon the ongoing ISI program, because the qualitative screening evaluation of SRP 3.6.3 relied upon the results of past ISI and other monitoring programs to exclude welds from LBB consideration that were known to be susceptible to corrosion. The quantitative fracture mechanics analysis of SRP 3.6.3 did not depend upon ISI and no additional ISIrelated requirements or conditions were placed upon the LBB approvals. Furthermore, not all welds in piping systems approved for LBB were fully inspectable in accordance with ASME Code requirements.

NDE of welds has been relied upon for defense-in-depth except in cases where welds are known to be susceptible to degradation. When a degradation mechanism, such as PWSCC, is determined to be active, the role of NDE has to be shifted from defense-in-depth to being relied upon to help maintain the design bases.

After the events at V.C. Summer and Ringhals in 2000, the NRC began to evaluate the adequacy of the inspection requirements for Alloy 82/182 butt welds in the ASME Code, Section XI. Also, the NRC started considering the potential impact of these events on LBB.

The U.S. nuclear industry undertook certain activities to address PWSCC in Alloy 82/182 butt welds. Those activities included performing growth rate studies and undertaking an initiative known as Nuclear Energy Institute (NEI) 03-08, "Guideline for the Management of Materials Issues" (NEI 2003). This initiative established policy, direction, oversight, and support for industry programs involving the management of materials issues. The initiative committed each nuclear utility to adopt the responsibilities and processes described in NEI 03-08.

In September 2005, the industry issued MRP-139, "Materials Reliability Program: Primary System Piping Butt Weld Inspection and Evaluation Guideline" (EPRI 2005b). In accordance with NEI 03-08, all PWR plants agreed to implement these guidelines. MRP-139 provided industry guidance for the volumetric and visual inspections of Alloy 82/182 butt welds in PWR primary systems. The MRP-139 inspections augmented inspections of these locations already required by Section XI of the ASME Code.

The industry actions to develop and implement the MRP-139 inspections allowed the NRC staff to pursue a process to codify new requirements. The ASME Code requirements for inspection of Alloy 82/182 butt welds were not considered frequent enough to ensure that ASME Code-allowable limits would continue to be met in the event that PWSCC initiates. The NRC staff concluded that the approach of working with ASME to revise inspection requirements and subsequently revise 10 CFR 50.55a was both necessary and in the best interest of protecting public health and safety. ASME Code inspection requirements, incorporated by reference in 10 CFR $50.55 \mathrm{a}$, provide a regulatory foundation for ensuring the integrity of pressure-retaining components.

In 2006, ASME approved the development of an ASME Code Case (Code Case N-770) on appropriate inspection requirements to address PWSCC in Class 1 butt welds containing Alloy 82/182. ASME Code Case N-770 was approved by ASME on January 30, 2009, and was published in Supplement 8 of the 2007 Edition of the ASME Boiler and Pressure Vessel Code Nuclear Code Cases 
book. The title of ASME Code Case N-770 is "Alternative Examination Requirements and Acceptance Standards for Class 1 PWR Piping and Vessel Nozzle Butt Welds Fabricated with UNS N06082 or UNS W86182 Weld Filler Material With or Without the Application of Listed Mitigation Activities, Section XI, Division 1" (ASME 2009b).

Code Case N-770 was revised in response to a number of issues raised by the NRC. Code Case N-770-1 (ASME 2009a) was approved by the ASME in December 2009. On June 21, 2011, the NRC issued a final rule (76 FR 36232, p. 36278) incorporating ASME Code Case N-770-1 into the regulations by reference. The new rule is contained in 10 CFR $50.55 \mathrm{a}(\mathrm{g})(6)(\mathrm{ii})(\mathrm{F})$ and imposes Code Case N-770-1 with ten conditions the NRC concluded were necessary to ensure that the condition of these welds are appropriately monitored and assessed over their design life.

Code Case N-770-1 requires the performance of UT qualified in accordance with Section XI, Appendix VIII, coupled with certain visual and surface examinations, to be performed at specified intervals. By imposing Code Case N-770-1, with conditions, the NRC concluded that the revised rule would ensure that potential PWSCC would be detected before pressure boundary integrity could be seriously challenged. At this time, the NRC has not issued any separate or supplemental requirements for Alloy 82/182 butt welds in piping systems approved for LBB. Based on NRC's safety basis for incorporating Code Case N-770-1 by reference into the regulations, adoption of these inspection requirements, in conjunction with NRC approval of weld mitigation techniques, where applicable, is necessary to ensure that ASME Code-allowable limits will not be exceeded and PWSCC will not lead to leaks or ruptures of piping welds.

Section 4.2 contains an overview of the Code Case N-770-1 requirements. A detailed assessment of these requirements, as imposed by the NRC, is provided in Appendix B. Appendix B.1 contains an assessment of the MSIP-related requirements of Code Case N-770-1 and Appendix B.2 contains an assessment of the NRC implementing requirements; that is, the conditions imposed by $10 \mathrm{CFR}$ $50.55 \mathrm{a}(\mathrm{g})(6)(\mathrm{ii})(\mathrm{F})$. Appendix B contains a discussion of recommendations for changes to the MSIPrelated requirements of Code Case N-770-1. These recommendations are also summarized in Section 4.2.

\subsection{Overview of Code Case N-770-1}

ASME Code Case N-770-1 provides examination methods, volumes or areas, and frequencies for Alloy 82/182 butt welds that are unmitigated as well as for Alloy 82/182 butt welds that have been mitigated against PWSCC by one of several specified mitigation methods. The requirements of this Code Case pertain to inspections for potential PWSCC. The ASME Code, Section XI, requirements continue to apply to Alloy 82/182 welds to monitor for other degradation mechanisms, such as fatigue. Code Case N-770-1 contains baseline and ISI requirements for unmitigated Alloy 82/182 butt welds and preservice and ISI requirements for mitigated Alloy $82 / 182$ butt welds. The structure of Code Case N-770-1 is patterned after the requirements of Section XI, Subsection IWB. The Code Case has requirements in Sections $-1000,-2000$, and -3000 that parallel the requirements in Subsection IWB-1000, -2000, and -3000 . Pressure test requirements are unaffected by the Code Case so there are no -5000 requirements in the Code Case. The examination requirements are contained in Table 1 of the Code Case in the -2000 section. Inspection Items in Table 1 are assigned for each "type and condition" of component. Inspection Items in the Code Case are similar to Examination Categories and Item Numbers used in the Section XI, Table IWB-2500-1. The "type and condition" of component refers to: 
(1) unmitigated welds at three different service temperatures addressed by Inspection Item A-1, A-2, and B; and (2) cracked and uncracked welds, mitigated by one of several specified methods addressed by Inspection Items $\mathrm{C}$ through $\mathrm{K}$. The Code Case includes various figures needed to implement the examination requirements.

Table 1 contains the examination requirements and includes the parts examined, the examination volumes and surfaces shown in figures, examination methods, references to acceptance standards, extent and frequency of examination, and rules regarding deferral of the examination to the end of the interval. In Code Case N-770-1, Table 1 includes 18 explanatory notes that contain additional requirements. These notes are necessary because of the range of weld types and conditions covered by the case.

As discussed in Appendix B.1, the examination requirements of Table 1 and the notes to Table 1 provide a set of comprehensive inspection requirements that parallel existing Section IWB Class 1 requirements. The Code Class 1 butt weld examination requirements of Section XI were based on a defense-in-depth philosophy for monitoring welds to ensure that the welds were not experiencing an active degradation mechanism.

Code Case N-770-1 reflects the full range of ASME Code requirements that apply to other ASME Code Class 1 components. They deal with scope, baseline examination, preservice examination, inservice examination schedules, successive and additional examinations, examination requirements, and acceptance standards for the various types of examinations and resulting conditions that might arise. ASME adopted an MSIP inspection frequency requirement of once per interval. The Code Case permits both uncracked and cracked MSIP welds to be placed into 25\% inspection samples. The once-perinterval inspection frequency reflects an implicit conclusion by the ASME and, in imposing the Code Case, by the NRC that the MSIP technique results in effective mitigation and that inspection of MSIP welds serves a defense-in-depth monitoring function rather than a degradation management function.

The MSIP-related conditions in the rule that imposed Code Case N-770-1 are discussed in detail in Appendix B.2. These conditions, which are over and above the Code Case requirements, were imposed by the NRC to ensure that the level of quality and safety provided by the requirements for MSIP welds is consistent with that provided by existing ASME and NRC requirements for butt welds in Code Class 1 systems that do not need to be addressed by Code Case N-770-1. The effectiveness of MSIP is discussed in Section 5.0.

A discussion of recommendations identified in the assessment in Appendix B of ASME Code Case N-770-1, as implemented, follows.

Note (12)(c) permits repaired welds to be placed in Inspection Item D with no further consideration of the effect that weld repairs may have on life of the repaired weld. Because repairs can have a large effect on flaw initiation and growth, periodically examining welds with known repairs by placing them in the Inspection Item D, 25\% inspection sample would improve the safety basis for sample selection.

Note (12)(e) permits cold-leg RPV nozzles mitigated by MSIP to forego a pre-MSIP examination provided that a post-MSIP preservice UT and surface examination is performed. The surface examination shall be performed on the butt weld inside surface, extent E-F of Fig. 1, and shall consist of an eddy current examination in accordance with IWA-2223. IWA-2223 requires that eddy current examination (ET) be conducted in accordance with Appendix IV. Appendix IV contains demonstration requirements 
only and allows the demonstrations to be performed on notches. Because the MSIP may decrease or eliminate the UT response of cracks, the ability of the surface examination to detect cracks takes on greater significance. Qualification of ET procedures and personnel by performance demonstration would increase the reliability of ET examination. Code Case N-773 contains ET performance demonstration requirements that may be used in lieu of Appendix IV, Supplement 2 when ET is used to complement UT performed on the inside surfaces of austenitic, DMW, and clad piping welds. The ASME Code, Section XI, is working on an action to incorporate the requirements of Code Case N-773 in Appendix IV.

Code Case N-770-1 specifies that if no cracks are found during the post-MSIP preservice examinations of cold-leg RPV nozzle welds, the welds will be considered uncracked and subject to the examination requirements of Inspection Item D. However, these provisions do not explicitly say what the user is required to do if during the surface examination the weld is determined to be cracked. There are currently no Appendix VIII, Supplement 10, procedures to examine welds from the ID surface that are qualified for depth-sizing flaws in unmitigated welds. The compressive stresses in the mitigated weld may cause crack faces to close or partially close and change the UT response of the flaws. This phenomenon may increase the difficulty of qualifying procedures for detection as well as depth sizing. PNNL recommends that the Code Case be revised to address this issue. If a weld were determined by the surface examination to be cracked, the issue may have to be resolved outside of the rules of the Code Case, prior to restart, and involve the NRC staff review of a relief request.

Finally, PNNL recommends that operating experience and the tools developed under the xLPR, Version 2.0 project be used to reevaluate the sample examination provision of the Inspection Item D and E requirements and the adequacy of MSIP for satisfying the requirements of GDC -4 . 


\subsection{Evaluation of the Effectiveness of MSIP as a Mitigation Technique}

Code Case N-770-1 requires that the criteria of Code Case N-770-1, Appendix I, be satisfied and documented prior to being able to take credit for the reduced examination requirements for stress improved welds in Inspection Items $\mathrm{D}$ and $\mathrm{E}$, as compared to the requirements for unmitigated welds in Inspection Items A-1, A-2, or B. These performance criteria were developed for Code Case N-770-1 by ASME Section XI. They provide rules for the implementation of MSIP, since the rules of IWA-4000, Repair/Replacement Activities, do not apply to MSIP. These criteria have been approved by ASME and adopted by the NRC as the set of factors needed to ensure effective mitigation by stress improvement. Therefore, they were used by the authors of this report to assess the effectiveness of MSIP. These criteria are paraphrased as follows.

- The mitigation technique has to minimize the likelihood of crack initiation.

- The effect on the susceptible weld material produced by the mitigation process has to be permanent.

- The capability to perform UT of the required inspection volume of the component cannot be adversely affected by the mitigation.

- The mitigation process cannot have degraded the component or adversely affected other components in the system.

- The mitigated weld has to be inspectable by a qualified process.

- Existing flaws, if any, have to be addressed as part of the mitigation.

- The effect of the mitigation on any existing flaws has to be analyzed.

\subsection{Crack Initiation}

This criterion states that to minimize the likelihood of crack initiation, the process shall have resulted in a compressive stress in the susceptible material along the entire wetted surface under steady-state operation. As discussed in Sections 2.1 and 2.2, BCL showed from various analyses they conducted that application of MSIP led to significant reductions in axial and hoop residual stresses. BCL analyzed a hotleg RPV nozzle weld, a PZR surge-nozzle weld, and a PZR safety-nozzle weld. For the welds analyzed, BCL calculated both hoop and axial weld residual stresses. The hot-leg RPV nozzle weld was analyzed without the beneficial effect of the secondary SS safe-end weld, similar to the geometry at V.C. Summer. The PZR nozzles included safe end-to-pipe welds. MSIP significantly reduced these hoop stresses for the hot-leg RPV nozzle weld by introducing a compressive residual stress field in the hoop direction for approximately the inner $50 \%$ of the wall thickness. Operating temperature and pressure cause the postMSIP hoop stresses to increase somewhat and the hoop stress at the ID surface was calculated to be about $70 \mathrm{MPa}(10 \mathrm{ksi})$. For the surge nozzle and the safety nozzle, the post-MSIP through-wall hoop stresses at operating pressure and temperature for the inner $50 \%$ of the wall thickness are similar to the hot-leg RPV nozzle, except that the hoop stresses at the ID surface are compressive.

There is a similarity in the results of the axial WRS for the geometries considered. The surge-nozzle axial stresses at the inside surface after fabricating the Alloy 82/182 nozzle-to-safe end DMW weld were calculated to be in the range of $345 \mathrm{MPa}$ to $380 \mathrm{MPa}(50 \mathrm{ksi}$ to $55 \mathrm{ksi}$ ) tensile. After making the safe 
end-to-pipe weld, MSIP reduced the calculated surge-nozzle weld inside surface axial stresses near the weld centerline from $207 \mathrm{MPa}$ (30 ksi) compressive to $345 \mathrm{MPa}$ (50 ksi) compressive. In the buttered region, near the interface of the butter to the A508 nozzle material, the MSIP reduced the calculated inside surface axial stresses from $140 \mathrm{MPa}(20 \mathrm{ksi})$ tension to $70 \mathrm{MPa}(10 \mathrm{ksi})$ compression. After application of operating pressure and temperature, the through-wall axial stresses increased slightly. A similar result was obtained for the hot-leg RPV nozzle, except the compressive effect was more pronounced. For the hot leg, the MSIP reduced the calculated inside surface axial stresses from approximately $345 \mathrm{MPa}$ (50 ksi) tension to approximately $207 \mathrm{MPa}(30 \mathrm{ksi})$ compression. After application of operating pressure and temperature, the through-wall axial stresses increased slightly.

Code Case N-770-1, Appendix I, Performance Criterion 1 requires that a properly bench-marked analysis or demonstration test be performed to confirm the post-mitigation stress state. The demonstration of a compressive stress state has to be made for a weld with a $50 \%$ deep, $360^{\circ}$ repair. The analyses performed by BCL did not include a 50\% deep, $360^{\circ}$ repair. The intent of including a $50 \%$ through-thickness inner-diameter weld repair is that weld repairs cause inner-surface tensile stresses. Although a 50\% weld-thickness inner-diameter repair was not modeled in the BCL analyses, several analyses show that a similar effect was considered and showed that MSIP improved the inside-surface residual stress state for those cases as well.

BCL performed sensitivity studies on the amount of "squeeze" or plastic deformation applied by MSIP. The studies analyzed the surge-nozzle weld axial stresses for $0.5 \%$ through $3 \%$ permanent compressive deformation. The analyses showed that the axial stresses on the inner surface did not change with the amount of plastic strain; however, the stresses in the inner region of the pipe weld became increasingly compressive with increased MSIP compression. The results for hoop stress were not provided for this sensitivity study. Therefore, it is not possible to draw conclusions from the analyses regarding whether MSIP will create compression on the entire wetted surface of susceptible materials under steady-state operations. However, it is clear from the analyses BCL performed that MSIP produces highly compressive stresses in the inner region of a pipe weld. Under MSIP, it is unlikely that cracks would initiate and continue to grow, even if the inner-surface stresses are not compressive.

Nevertheless, any welds being considered for MSIP must first be analyzed and, before MSIP can be applied, a documented evaluation must demonstrate that all the criteria of Appendix I must be met, including Criterion 1 on compressive stresses in the weld ID under steady-state operation. Satisfying Code Case N-770-1, Appendix I, Performance Criterion 1 will preclude the initiation of PWSCC because cracks cannot initiate in a compressive stress field.

\subsection{Permanent Mitigation}

This criterion states that the effect produced by the mitigation process shall be permanent. Code Case $\mathrm{N}-770-1$ requires that an analysis or demonstration test be performed to confirm that the process is permanent.

Appendix I, Criterion 1-2.1, provides the following "Measurement or Qualification Criteria" relative to permanence of the mitigation process. 
"An analysis or demonstration test shall be performed to confirm that the mitigation process is permanent. The analysis and demonstration test plan shall include startup and shutdown stresses, normal operating pressure stress, thermal cyclic stresses, transient stresses, and residual stresses. The analysis or demonstration test shall account for (a) load combinations that could relieve stress due to shakedown and (b) any material properties related to stress relaxation over time."

The analysis of Criterion 1-2.1 is required, includes a comprehensive set of loads and load combinations, and ensures that the residual stresses not relieve due to shakedown.

To address the second part of this criterion, accounting for stress relaxation due to material properties, PNNL relied upon the following evaluation by Fredette and Scott (2009).

"The MSIP effect relies on the yielding of the pipe material to leave a $1 \%$ permanent radial deformation in the pipe under the tool application site. The analyses that were performed in this report included operating pressures, temperatures, and moment loading and showed that none of these loads are great enough to re-yield the material in a way that would negate the beneficial effects of the MSIP. The pipe material yielded by the MSIP in all of the cases studied was stainless steel. Long duration creep data for typical stainless steels is not available for temperatures below $538 \mathrm{C}(1,000 \mathrm{~F})$ which is well above the upper limit of the typical operating temperature for the PZR nozzles, i.e., $343 \mathrm{C}(650 \mathrm{~F})$.

"Furthermore, Paragraph NB-1120 (Temperature Limits) of Section III of the ASME Code states:

'The rules of Subsection NB shall not be used for items which are to be subjected to metal temperatures that exceed the temperature limit in the applicability column shown in Section II, Part D, Subpart 1, Tables 2A, 2B, and 4 for design stress intensity values. Above these temperatures, the creep and stress rupture characteristics of materials permitted to be used become significant factors which are not presently covered by the rules of this Subsection.'

"The temperature limits specified in Section II are typically $371 \mathrm{C}$ (700 F) for ferritic and low alloy steels and $427 \mathrm{C}(800 \mathrm{~F})$ for austenitic and nickel based alloys, which again are above the upper limit on the operating temperature for the pressurizer nozzle dissimilar metal welds. As such, creep effects on the MSIP deformation are expected to be small. However, assuming that they were not, the only consequential effect would be that the beneficial residual compressive stresses would fade to zero over time. Since the MSIP causes a bending stress in the treated weld area, it will cause compressive stresses on the inner diameter and tension stresses on the outer diameter of equivalent magnitudes. Long term creep effects would tend to neutralize these residual stresses and should not make them worse."

Accordingly, it is reasonable to conclude that creep will not lead to a change in weld residual stress values. 
Therefore, because the possibility of relaxation of residual stresses by either shakedown or creep is precluded by the requirements of Code Case N-770-1, it is reasonable to conclude that the effect on the susceptible weld material produced by MSIP is permanent.

\subsection{Capability to Perform UT}

This criterion states that the capability to perform UT of the required inspection volume of the component cannot be adversely affected by the mitigation.

During MSIP, plastic deformation of the pipe wall adjacent to the weld results in contours on the inner and outer surfaces of the weld. This was shown in PNNL-17367 (Anderson et al. 2008) for an MSIP weld at the Ignalina nuclear plant in Lithuania. The plastic deformation from MSIP imparts the targeted compressive strain, and thus compressive stress, on the inner region of the susceptible weld. However, the surface curvatures can potentially misalign subsequent ultrasonic transducer placement when acquiring data and may cause the expected examination volume to be limited except at extremely high insonification angle. The plastic deformation can produce reflections from a flaw to be projected at a higher angle than would occur on a flat surface. This surface condition may also introduce a gap between the transducer and the OD surface of the pipe, which would subsequently decrease ultrasonic coupling, causing lack of sufficient sound penetration and irrelevant signals in the data.

Code Case N-770-1 requires that mockup testing and NDE qualified to Appendix VIII performance demonstration requirements be performed to demonstrate that a qualified examination of the relevant volume of the mitigated component can be accomplished subsequent to the mitigation by MSIP, including changes in component geometry or other factors. Mockup testing and qualified NDE would be expected to determine whether the examinations are capable of examining the relevant volume subsequent to MSIP.

MSIP has been used extensively in BWR stainless steel piping systems. The inspections performed under the industry BWRVIP-75 program determined that flaws could be detected in BWR welds mitigated by MSIP, except in some cases where weld crowns had not been removed (Wirtz 2010).

Procedures qualified under Section XI, Appendix VIII, requirements generally meet provisions of Section XI, Non-Mandatory Appendix D, which stipulate that any gap between the examination surface and the UT probe not exceed 1/32 inch. Satisfying this criterion was found to produce acceptable examination results by PNNL (Greenwood 1998). Based on the requirement to demonstrate on a mockup that a qualified examination of the relevant volume of the mitigated component can be accomplished using Appendix VIII-qualified UT, it is reasonable to conclude that the MSIP will not adversely affect or prevent the capability to perform UT of the required inspection volume of welds mitigated by MSIP.

\subsection{Effect on Other Components}

This criterion states that the mitigation process shall not have degraded the component or adversely affected other components in the system. Code Case N-770-1 requires that an analysis be performed to verify that the MSIP does not result in changes to the piping system geometry that exceed Section III or original Construction Code design criteria. 
The effects of any geometric changes induced by MSIP on other items in the piping system (e.g., support loads, support clearances, and nozzle loads) have to be evaluated to ensure that ASME requirements continue to be satisfied. Likewise, existing flaws previously accepted by analytical evaluation shall be evaluated in accordance with Section XI, IWB-3640.

Because Code Case N-770-1 contains requirements and acceptance criteria to address the effect of MSIP on other system components, it is reasonable to conclude that the designs for mitigation by MSIP will satisfactorily address the effects of the mitigation on other components in the system.

\subsection{Inspectable by a Qualified Process}

This criterion states that the mitigated weld shall be inspectable by a qualified process. ASME Code Case N-770-1 requires that an evaluation be performed to confirm that the required examination volume of the mitigated configuration is within the scope of an Appendix VIII supplement or supplements and that the examination procedures to be used have been qualified in accordance with Appendix VIII. For example, the evaluation has to confirm that the geometric limitations (e.g., weld crown, nozzle contour) of an Appendix VIII qualification are not exceeded for the mitigated weld.

If examination of essentially $100 \%$ of the required examination volume cannot be satisfied, a licensee would be expected to obtain NRC approval of an alternative examination prior to performing the mitigation. Other examples in which the configurations to be mitigated are not within the scope of an Appendix VIII supplement are cases where the welds are adjacent to a cast stainless steel component. Appendix VIII, Supplement 9, Qualification Requirements for Cast Austenitic Piping Welds, is in the course of preparation. Code Case N-770-1 in Section -2500(b) states that, "For cast stainless steel items for which no supplement is available in Appendix VIII, the required examination volume shall be examined by Appendix VIII procedures to the maximum extent practical including $100 \%$ of the susceptible material volume (non-stainless steel) volume." Based on NRC staff review of cases where this requirement of -2500 (b) cannot be satisfied, it is reasonable to conclude that the requirements of Code Case N-770-1 will ensure that MSIP welds are inspectable by a qualified process or by an acceptable alternative.

\subsection{Address Existing Flaws}

This criterion requires that an examination qualified to Section XI, Appendix VIII, performance demonstration requirements shall have been performed prior to the application of the MSIP to identify and size any existing flaws. Existing flaws, if any, have to be addressed as part of the mitigation. Any flaws identified shall be specifically analyzed, per performance criterion 7 discussed below, to ensure that any cracks found are not and will not become unacceptable. 
PNNL has two concerns with the ability of the MSIP mitigation to satisfy this criterion. Code Case N-770-1 permits owners to mitigate reactor vessel cold-leg nozzle welds prior to performing a UT examination when core barrel removal is required to perform the examination; in other words, when the UT has to be performed from the ID surface. PNNL's concerns with this provision of the Code Case are discussed in Section 4.2 and Appendix B.1 of this technical letter report (TLR).

A second concern with MSIP in relation to this criterion is the possibility that a flaw is missed during the pre-mitigation inspection. If a flaw were missed during the pre-MSIP examination, the pre-service examination presents a second opportunity to detect the flaw. Table 1 of Code Case N-770-1 requires that Inspection Item D welds, uncracked welds mitigated with stress improvement, be inspected once within 10 years following stress improvement. This inspection may be performed any time during this interval, including during the next refueling outage after applying MSIP. If the flaw is missed again, the weld may not be included in the $25 \%$ inspection sample for Inspection Item D welds and not be inspected again. If the undetected flaw is shallow, the flaw would likely be arrested and may be acceptable under SSE conditions (see the discussion on Service Level D conditions in Section 2.3). If the undetected flaw is deep, the analyses performed by BCL showed that MSIP causes the crack stress intensity to increase, which increases the rate of crack growth and decreases the weld's resistance to high loading such as SSE loads. Because the probability of detection is less than unity, it is likely that a small percentage of potential cracks will not be detected during pre-MSIP examinations. For example, axial flaws in a North Anna, Unit 1, hot-leg steam generator nozzle were missed during manual pre-weld overlay inspection performed in March 2012. Leaks through two flaws were found when the nozzle weld OD region was machined in preparation to install weld overlays (Anderson et al. 2012).

At this time, it is not possible to reliably estimate the likelihood of such an occurrence because the likelihood of crack detection is not well understood for the various weld configurations that may be mitigated by MSIP. It is clear that for welds with deep undetected flaws, MSIP has been analytically demonstrated to make the situation worse than if MSIP had not been applied. The negative effect of undetected flaws highlights the importance of performing effective and reliable NDE as discussed in Section 3.1 of this report, prior to and subsequent to application of MSIP.

Despite the concerns discussed above, the experience with MSIP in BWRs has been favorable. For example, a large number of BWR welds in the United States have been mitigated by MSIP and no leaks have been found. Some welds were found to be cracked subsequent to application of MSIP using improved examination techniques or improved surface conditioning. In these cases, where deep cracks were found, weld overlays were subsequently applied to the welds (see the discussion in Section 1.0 of this TLR). In preparing Code Case N-770-1, the ASME Code placed a high degree of reliance on the favorable BWR experience in accepting the $25 \%$ sample inspection requirements for welds mitigated by MSIP.

Based on the preceding, it would be reasonable to conclude that the requirements of mitigation by MSIP and inspection per Code Case N-770-1 appropriately address the possibility of pre-existing flaws, provided effective and reliable NDE is used. 


\subsection{Analyze Existing Flaws}

This criterion states that the effect of the mitigation on any existing flaws has to be analyzed. Code Case N-770-1 requires that the stress intensity factor at the depth of the flaw shall be determined using combined residual and steady-state operating stresses, and shall not be greater than zero. Code Case N-770-1 requires that an analysis be performed using IWB-3600 evaluation methods and acceptance criteria to verify that the mitigation process will not result in any existing flaws to become unacceptable over the life of the weld or before the next scheduled examination.

These requirements combined with the requirements of the preceding criterion ensure that the effect of the mitigation on any existing flaws is analyzed and appropriate criteria be satisfied.

\subsection{Conclusions for MSIP as a Mitigation Technique}

As noted above, to provide effective mitigation against PWSCC, the mitigation technique should be able to satisfy the seven factors or criteria contained in Appendix I to ASME Code Case N-770-1. The preceding discussion of these seven factors or criteria provides an evaluation of the effectiveness of MSIP to mitigate the effects of PWSCC.

It is clear that MSIP is effective in producing compressive values of WRS in the inner region of welds, thereby minimizing the likelihood of initiation and growth of PWSCC in Alloy 82/182 DMWs. Based on creep properties of the materials involved, the operating temperature of MSIP welds, and analyses to show that residual stresses do not relieve during subsequent loading cycles, the MSIP mitigation method is expected to be permanent. Analyses are required to be performed on the effect of MSIPs on other components in the system and ASME Code criteria are required to be satisfied, which makes it reasonable to conclude that the designs for mitigation by MSIP will satisfactorily address this potential effect.

Mockup testing and NDE qualified to Section XI, Appendix VIII, performance demonstration requirements would be expected to show that the capability to perform UT of the weld has not been adversely affected by the mitigation, including possible geometric changes that may result from MSIP. Welds mitigated by MSIP are required to be inspectable by a qualified process. An evaluation has to be performed to confirm whether the weld to be mitigated is within the scope of an Appendix VIII supplement and that the procedures to be used have been qualified. For these examinations to perform as intended, the NDE used has to be effective and reliable. Limitations involving incomplete coverage have to be reviewed by the NRC to ensure that alternative inspections satisfy regulatory criteria; for example, to ensure that an adequate level of quality and safety is provided.

Existing flaws must be shown using IWB-3600 to not become unacceptable over the life of the weld or before the next scheduled examination.

Assuming that these criteria are satisfied as discussed above, it is reasonable to conclude that MSIP provides effective mitigation against the initiation of PWSCC and against the growth of any existing PWSCC that has been detected and allowed to remain in service. 
Regarding the effectiveness of MSIP for LBB welds, it is clear that MSIP provides an effective means for preventing the initiation of new cracks. To address uncertainties regarding pre-existing flaws that may be present, examination requirements for monitoring the condition of MSIP welds throughout their service life are contained in Code Case N-770-1. In general, welds would be expected to be inspected prior to installation, during the pre-service examination, and at least one additional inspection prior to placing welds in a sampling inspection program of inspections once per interval. These inspection requirements parallel existing Section IWB, Class 1, requirements. For this monitoring to perform as intended, effective and reliable NDE has to be used. Any flaws detected must be evaluated per the ASME Code criteria to ensure that flaws do not become unacceptable over the life of the weld, or before the next scheduled examination. This layered approach is expected to address the qualitative screening criteria in SRP 3.6.3 regarding corrosion. Although not specifically discussed in any further detail in this report, licensees' original LBB flaw tolerance analyses for welds mitigated by MSIP are not required to be revised. This point is discussed in RIS 2010-07 (NRC 2010). On the basis of this evaluation, it is reasonable to conclude that mitigation by MSIP addresses the qualitative and quantitative criteria in SRP 3.6.3 and would be expected to preclude PWSCC from being a potential source of pipe rupture. 


\subsection{Overall Assessment}

This report provides an assessment of the effectiveness of MSIP for mitigation of PWSCC in LBB systems. The authors focused on four key areas related to welds mitigated by MSIP; namely, (1) weld residual stress and crack growth analyses performed during the design phase; (2) the reliability of pre- and post-MSIP NDE; (3) ASME Code Case N-770-1 examination requirements, with conditions, as imposed by NRC; and (4) the overall effectiveness of MSIP as a mitigation technique.

The results of the WRS analyses showed that the MSIP is effective in producing compressive values of axial and circumferential WRSs in the inner region of welds, thereby minimizing the likelihood of initiation of PWSCC in Alloy 82/182 DMWs. However, from the crack growth analyses, in the event that MSIP is applied to a weld with a deep flaw (e.g., $>50 \%$ through-wall), it was found the flaw stress intensity would be made much worse by MSIP and the flaw would grow through-wall in a short time period under these loadings. From the results of the Code analyses under design basis seismic loadings, it was shown that the allowable flaw sizes in some cases are small. Therefore, our overall conclusion from this assessment is that MSIP is an effective mitigation method against PWSCC, provided that any cracks in the mitigated weld are small.

The reliability of pre-MSIP NDE is of interest because, as noted above, MSIP is ineffective if applied to welds with deep cracks. Also, the reliability of post-MSIP NDE is important for determining whether any pre-existing flaws are propagating.

NDE effectiveness and reliability can be affected by a number of factors. For example, geometry or access may limit performing a complete pre-MSIP weld examination. Information on limitations to performing inspections of typical Westinghouse and CE plant RCS Alloy 82/182 welds was obtained from an NDE vendor for the commercial nuclear power industry. ASME Code-required volumetric coverage appears achievable for many, although not all, Westinghouse and CE Alloy 82/182 butt welds.

The ability to reliably detect and characterize PWSCC can be distinctly and significantly improved by performing UT modeling analyses when designing the inspection, using encoded techniques qualified by performance demonstration, and having analysts experienced in distinguishing service-induced flaw signals from other UT signals that may be present. In the case of CASS materials adjacent to the weld mitigated, studies with surge-piping weld mockups have demonstrated that, although ASME-qualified procedures for inspecting CASS piping welds have not yet been developed, low-frequency techniques discussed in the report are capable of detecting and characterizing flaws to within ASME sizing tolerances.

An assessment of the ASME Code Case N-770-1 requirements, with NRC conditions that are applicable to MSIP, was performed. Overall, it is concluded that these requirements are comprehensive and will provide an appropriate defense-in-depth function for monitoring the condition of MSIP welds. Three recommendations were developed as part of this assessment.

- It is recommended that in those cases where ET is required to complement UT, the performance demonstration requirements of Code Case N-773 be used in lieu of the currently specified requirements. 
- Because repairs can have a large effect on flaw initiation and growth, it is recommended that the safety basis for MSIP sample selection would be improved by including welds with known repairs in the $25 \%$ inspection sample. Welds without the beneficial effect of a secondary safe end-to-pipe weld are also important candidates for the $25 \%$ inspection sample. These welds may be more likely to be cracked than welds attached to safe ends.

- Code Case N-770-1 permits cold-leg reactor vessel nozzle welds, which have to be inspected from the ID surface when the core barrel is removed, to be mitigated by MSIP prior to a weld examination. However, the Code Case does not explicitly say what the user is required to do if during the surface examination the weld is determined to be cracked. PNNL recommends that the Code Case or $10 \mathrm{CFR}$ $50.55 \mathrm{a}(\mathrm{g})(6)(\mathrm{ii})(\mathrm{F})$ be revised to address this issue.

Using the criteria in ASME Code Case N-770-1, Appendix I, to evaluate the effectiveness of MSIP as a mitigation technique, it is concluded that MSIP provides effective mitigation against the initiation of PWSCC and against the growth of existing PWSCC. To satisfy these criteria, the NDE used has to be effective and reliable and any flaws in welds to which MSIP is applied have to be small. Under these conditions, it is concluded that MSIP addresses the qualitative screening criteria in SRP 3.6.3, Leak Before Break. Per the staff guidance in RIS 2010-07, installation of MSIP would not invalidate the SRP 3.6.3 LBB flaw tolerance analyses. This point is discussed in RIS 2010-07. On this basis, MSIP would be expected to satisfy the SRP 3.6.3 leak-before-break criteria and preclude PWSCC from being a potential source of pipe rupture.

Finally, PNNL recommends that operating experience and the tools developed under the xLPR, Version 2.0 project be used to reevaluate the sample examination provision of the Inspection Items D and E requirements and the adequacy of MSIP for satisfying the requirements of GDC -4 . 


\subsection{References}

76 FR 36232. June 21, 2011. "American Society of Mechanical Engineers (ASME) Codes and New and Revised ASME Code Cases." Federal Register 76(119):36232-36279. Nuclear Regulatory Commission, Washington, D.C.

Anderson MT, SL Crawford, SE Cumblidge, KM Denslow, AA Diaz and SR Doctor. 2007. Assessment of Crack Detection in Heavy-Walled Cast Stainless Steel Piping Welds Using Advanced Low-Frequency Ultrasonic Methods. NUREG/CR-6933, PNNL-16292, U.S. Nuclear Regulatory Commission, Washington, D.C.

Anderson MT, SE Cumblidge and SL Crawford. 2008. Technical Letter Report - Analysis of Ultrasonic Data on Piping Cracks at Ignalina Nuclear Power Plant Before and After Applying a Mechanical Stress Improvement Process, JCN-N6319, Task 2. PNNL-17367, Pacific Northwest National Laboratory, Richland, Washington.

Anderson MT, AA Diaz and SR Doctor. 2012. Evaluation of Manual Ultrasonic Examinations Applied to Detect Flaws in Primary System Dissimilar Metal Welds at North Anna Power Station. PNNL-21546, Pacific Northwest National Laboratory, Richland, Washington. ADAMS Accession No. ML12200A216.

ASME. 2009a. Code Case N-770-1, Alternative Examination Requirements and Acceptance Standards for Class 1 PWR [pressurized water reactor] Piping and Vessel Nozzle Butt Welds Fabricated with UNS N06082 or UNS W86182 Weld Filler Material With or Without the Application of Listed Mitigation Activities, Section XI, Division 1. American Society of Mechanical Engineers, New York. Approved December 25, 2009.

ASME. 2009b. Code Case N-770, Alternative Examination Requirements and Acceptance Standards for Class 1 PWR [pressurized water reactor] Piping and Vessel Nozzle Butt Welds Fabricated with UNS N06082 or UNS W86182 Weld Filler Material With or Without the Application of Listed Mitigation Activities, Section XI, Division 1. American Society of Mechanical Engineers, New York. Approved January 26, 2009.

Bateman WH. 2002. Letter to Mr. Carl Terry. "Final Safety Evaluation of the 'BWRVIP Vessel and Internals Project, BWR Vessel and Internals Project, Technical Basis for Revisions to Generic Letter 8801 Inspection Schedules (BWRVIP-75), EPRI Report TR-113932, October 1999." May 14, 2002, U.S. Nuclear Regulatory Commission, Washington, D.C. ADAMS Accession No. ML021350645.

Burritt AL. 2009. Letter to Mr. Thomas Joyce. "Salem Nuclear Generating Station, Unit Nos. 1 and 2 NRC Integrated Inspection Report 05000272/2008005 and 05000311/2008005." February 9, 2009, Region I, U.S. Nuclear Regulatory Commission, King of Prussia, Pennsylvania. ADAMS Accession No. ML090400796.

BWRVIP-75NP. 1999. BWR Vessel and Internals Project, Technical Basis for Revisions to Generic Letter 88-01 Inspection Schedules. TR-113932NP, Electric Power Research Institute, Boiling Water Reactor Owners Group's Vessel and Internals Project, Palo Alto, California. ADAMS Accession No. ML003688842.

Cameron JL. 2010. Letter to Mr. Joe Jensen. "D. C. Cook Nuclear Power Plant, Units 1 and 2 Integrated Inspection report; 05000315/2010002; 05000316/2010002." May 5, 2010, Region III, U.S. Nuclear Regulatory Commission, Lisle, Illinois. ADAMS Accession No. ML101250243. 
Cofie N. 2008. "An Industry-Developed Technical Basis for Demonstrating Leak Before Break in Susceptible Piping Materials." Electric Power Research Institute, Palo Alto, California. Presented at International Leak-Before-Break Workshop in PWSCC Systems, Rockville, Maryland, January 9, 2008. ADAMS Accession No. ML080250141.

Collins JW. 2011. Memorandum to TR Lupold. "Summary of Public Meeting Between the Nuclear Regulatory Commission Staff and Industry Representatives on Implementation of ASME Code Case N770-1." August 12, 2011, U.S. Nuclear Regulatory Commission, Washington, D.C. ADAMS Accession No. ML112240818.

Crawford SL, AD Cinson, TL Moran and MT Anderson. 2011. Ultrasonic Data Comparison of Flaw Responses Before and After Mechanical Stress Improvement Process Application. PNNL-20853, Pacific Northwest National Laboratory, Richland, Washington. ADAMS Accession No. ML113010152.

Diaz AA, AD Cinson, SL Crawford, R Mathews, TL Moran, MS Prowant and MT Anderson. 2011. An Evaluation of Ultrasonic Phased Array Testing for Cast Austenitic Stainless Steel Pressurizer Surge Line Piping Welds. NUREG/CR-7122, PNNL-19497, U.S. Nuclear Regulatory Commission, Washington, D.C.

Dodson JS. 2008. Letter to MJB Archie. "Virgil C. Summer Nuclear Station - NRC Integrated Inspection Report 05000395/2008004." October 30, 2008, Region II, U.S. Nuclear Regulatory Commission, Atlanta, Georgia. ADAMS Accession No. ML083050135.

Dyer JE. 2005. Letter to GC Park. "Primary Water Stress Corrosion Cracking in Reactor Coolant System Nickel-Based Alloy Butt Welds." December 20, 2005, U.S. Nuclear Regulatory Commission, Washington, D.C. ADAMS Accession No. ML053480359.

EPRI. 2005a. Materials Reliability Program: Leak-Before-Break Evaluation for PWR Alloy 82/182 Welds (MRP-140). EPRI Report 1011808, Electric Power Research Institute, Palo Alto, California.

EPRI. 2005b. Materials Reliability Program: Primary System Piping Butt Weld Inspection and Evaluation Guidelines (MRP-139). EPRI Report 1010087, Electric Power Research Institute, Palo Alto, California.

EPRI. 2006. Letter to T Mensah. "MRP 2006-050, PWR Fleet Survey - MRP-139 Implementation Plans for Pressurizers - Revision 1." December 18, 2006, U.S. Nuclear Regulatory Commission, Washington, D.C. ADAMS Accession No. ML063560374.

EPRI. 2007. Materials Reliability Program: Advanced FEA Evaluation of Growth of Postulated Circumferential PWSCC Flaws in Pressurizer Nozzle Dissimilar Metal Welds: Evaluations Specific to Nine Subject Plants. MRP-216, Rev. 1, EPRI Report No. 1015499, Electric Power Research Institute, Palo Alto, California. ADAMS Accession Nos. ML072410240 and ML072410241.

EPRI. 2008. Materials Reliability Program: Primary System Piping Butt Weld Inspection and Evaluation Guideline (MRP-139, Revision 1). EPRI Report 1015009, Electric Power Research Institute, Palo Alto, California.

Findlan SJ, RE Smith, ML Badlani and T Damico. 2004. Electric Power Research Institute Materials Reliability Program: Mechanical Stress Improvement Process (MSIP) Implementation and Performance Experience for PWR Applications (MRP-121). Report 1009503, Final Report, Electric Power Research Institute, Palo Alto, California. 
Fredette L and PM Scott. 2009. Evaluation of the Mechanical Stress Improvement Process (MSIP) as a Mitigation Strategy for Primary Water Stress Corrosion Cracking in Pressurized Water Reactors. Battelle Columbus, Columbus, Ohio. ADAMS Accession No. ML092990646.

Fredette L and PM Scott. 2010. Evaluation of Full Structural and Optimized Weld Overlays as Mitigation Strategies for Primary Water Stress Corrosion Cracking in Pressurized Water Reactors. Battelle Columbus, Columbus, Ohio. ADAMS Accession No. ML101260540.

Fredette LF. 2011. Technical Letter Report: Surge Nozzle NDE Specimen Mechanical Stress Improvement Analysis, NRC JCN N6319. PNNL-20549, Pacific Northwest National Laboratory, Richland, Washington. ADAMS Accession No. ML111960318.

Greenwood MS. 1998. The Effects of Surface Condition on an Ultrasonic Inspection: Engineering Studies Using Validated Computer Model. NUREG/CR-6589, PNNL-11751, U.S. Nuclear Regulatory Commission, Washington, D.C.

Hazelton W and WH Koo. 1988. Technical Report on Material Selection and Processing Guidelines for BWR Coolant Pressure Boundary Piping. NUREG-0313, Rev. 2, U.S. Nuclear Regulatory Commission, Washington, D.C.

Kingston EJ, D Stefanescu, AH Mahmoudi, CE Truman and DJ Smith. 2006. "Novel Applications of the Deep-Hole Drilling Technique for Measuring Through-Thickness Residual Stress Distributions." Journal of ASTM International 3(4). Paper ID JAI2568.

Klecker RW, SH Bush, SH Hou, J Strosnider and KR Wichman. 1984. Report of the U.S. Nuclear Regulatory Commission Piping Review Committee - Evaluation of Potential for Pipe Breaks. NUREG1061, Vol. 3, U.S. Nuclear Regulatory Commission, Washington, D.C. ADAMS Accession No. ML093170485.

Kobetz TJ. 2006. Letter to Mr. Mano K. Nazar. "Donald C. Cook Nuclear Plant, Units 1 and 2 (DCCNP-1 and -2) - Alternatives Regarding Requirements for Examination of Dissimilar Metal Piping Welds." February 16, 2006, U.S. Nuclear Regulatory Commission, Washington, D.C. ADAMS Accession No. ML060320691.

NEI. 2003. Guideline for the Management of Materials Issues. NEI 03-08, Nuclear Energy Institute (NEI), Washington, D.C. ADAMS Accession No. ML032190048.

NRC. 1987a. "Evaluation of the Mechanical Stress Improvement Process." U.S. Nuclear Regulatory Commission, Office of Nuclear Regulatory Research, Washington, D.C. Research Information Letter No. 149, February 12, 1987.

NRC. 1987b. Standard Review Plan for the Review of Safety Analysis Reports for Nuclear Power Plants: LWR Edition, Section 3.6.3, Leak-Before-Break Evaluation Procedures. NUREG-0800, U.S. Nuclear Regulatory Commission, Washington, D.C. Formerly issued as NUREG-75/087.

NRC. 1988. NRC Position on IGSCC in BWR Austenitic Stainless Steel Piping. Generic Letter 88-01, U.S. Nuclear Regulatory Commission, Washington, D.C. ADAMS Accession No. MLML031130463.

NRC. 2007. Standard Review Plan for the Review of Safety Analysis Reports for Nuclear Power Plants: LWR Edition, Section 3.6.3, Leak-Before-Break Evaluation Procedures, Revision 1. NUREG-0800, Rev. 1, U.S. Nuclear Regulatory Commission, Washington, D.C. 
NRC. 2010. Regulatory Requirements for Application of Weld Overlays and Other Mitigation Techniques in Piping Systems Approved for Leak-Before-Break. RIS 2010-07, U.S. Nuclear Regulatory Commission, Washington, D.C. ADAMS Accession No. ML101380231.

NuVision. 2011. NuVision Engineering Commercial Nuclear \& Power Plant Services. NuVision Engineering, Inc. Pittsburgh, Pennsylvania. Accessed May 5, 2012. Available at http://nuvisioneng.com/CommercialServices/MSIP/BWRApplications.aspx.

O'Keefe M. 2010. Letter to NRC Document Control Desk. "Seabrook Station, Inservice Inspection Examination Report." February 9, 2010, NextEra Energy Seabrook, LLC, Seabrook, New Hampshire. U.S. Nuclear Regulatory Commission, ADAMS Accession No. ML100490381.

PEFI. 2008. Crystal River Unit 3 - Relief Request \#08-001-RR, Revision 1, 60-Day Response - Summary of Analysis Calculations. Progress Energy Florida, Inc. (PEFI), Crystal River, Florida. ADAMS Accession No. ML081410058.

Rathbun HJ, LF Fredette, PM Scott, AA Csontos and DL Rudland. 2011. "NRC Welding Residual Stress Validation Program International Round Robin Program and Findings." In Proceedings of the ASME Pressure Vessels and Piping Conference, 2011 (PVP2011). July 17-21, 2011, Baltimore, Maryland. American Society of Mechanical Engineers, New York. Paper PVP2011-57642. U.S. Nuclear Regulatory Commission, ADAMS Accession No. ML111680405.

Ray EA, K Weir, C Rice and T Damico. 2003. "Mechanical Stress Improvement Process (MSIP) Used to Prevent and Mitigate Primary Water Stress Corrosion Cracking (PWSCC) in Reactor Vessel Piping at V.C. Summer." In ASME 2003 Pressure Vessels and Piping Conference (PVP2003): Aging Management and Component Analysis, pp. 113-121. July 20-24, 2003, Cleveland, Ohio. American Society of Mechanical Engineers, New York. Paper PVP2003-2160.

Rowley JG. 2012. Memorandum to JR Jolicoeur. "Summary of January 10, 2012, Meeting with the Pressurized Water Reactor Owners Group Regarding Relief Request from the Requirements of Code Case N-770-1." March 5, 2012, U.S. Nuclear Regulatory Commission, Washington, D.C. ADAMS Accession No. ML120460312 (package ML12047A099).

Smith RE, KE Perry and WH Wolf. 1987. An Application of the Mechanical Stress Improvement Process to Large-Bore Piping. EPRI Report Number T305-1, Electric Power Research Institute, Palo Alto, California.

Sullivan EJ and MT Anderson. 2011. Technical Letter Report Assessment of Battelle Columbus Reports Evaluating Mechanical Stress Improvement and Weld Overlays as Mitigation Strategies for Primary Water Stress Corrosion Cracking in Pressurized Water Reactors. PNNL-20580, Pacific Northwest National Laboratory, Richland, Washington.

WesDyne. 2008. Westinghouse Teams with NuVision Engineering; Successfully Applies MSIP ${ }^{\circledR}$ Mitigation to Reactor Vessel Nozzles at Salem Unit 1. Available at https://www.wesdyne.com/Public/documents/SalemMSIP.pdf.

Wirtz C. 2010. "Status of BWR Dissimilar Metal Welds Category C and D." Presented at EPRI-NRC Technical Exchange Meeting, May 25-26, 2010, Rockville, Maryland. U.S. Nuclear Regulatory Commission, ADAMS Accession No. ML101590642. 
Wirtz C. 2012. "Dissimilar Metal Weld Update for BWRs." Presented at EPRI-NRC Technical Information Exchange Meeting, July 20, 2012, Rockville, Maryland. U.S. Nuclear Regulatory Commission, ADAMS Accession No. ML12202B121. 



\section{Appendix A}

\section{Background on Leak-Before-Break Per the Requirements of}

10 CFR 50, Appendix A, General Design Criterion-4 



\section{Appendix A}

\section{Background on Leak-Before-Break Per the Requirements of 10 CFR 50, Appendix A, General Design Criterion-4}

The governing requirement for leak-before-break (LBB) is General Design Criterion (GDC)-4. GDC-4, "Environmental and Dynamic Effects Design Bases," in Appendix A, "General Design Criteria for Nuclear Power Plants," to 10 CFR Part 50 requires, in part, that nuclear power facilities be protected against the effects of postulated pipe ruptures. GDC-4 states that "dynamic effects associated with postulated pipe ruptures in nuclear power units may be excluded from the design basis when analyses reviewed and approved by the Commission demonstrate that the probability of fluid system piping rupture is extremely low under conditions consistent with the design basis for the piping."

Technical procedures and criteria for using LBB analysis are provided in NUREG-1061, Report of the U.S. Nuclear Regulatory Commission Piping Review Committee, Volume 3, "Evaluation of Potential for Pipe Breaks," issued in November 1984 (Klecker et al. 1984). The NRC subsequently incorporated the procedures and criteria of NUREG-1061, Volume 3, into Section 3.6.3, "Leak-Before-Break Evaluation Procedures," of NUREG-0800, Standard Review Plan (SRP) for the Review of Safety Analysis Reports for Nuclear Power Plants: LWR [light-water reactor] Edition, issued March 1987 (NRC 1987b). Section 3.6.3 of NUREG-0800, Revision 1, was issued in March 2007 (NRC 2007). It provides review procedures and acceptance criteria for the NRC staff to evaluate licensees' LBB submittals and determine whether they satisfy the requirements of GDC-4 for eliminating the dynamic effects of postulated pipe rupture.

The first part of the SRP Section 3.6.3 is a qualitative screening evaluation. SRP Section 3.6.3 specifies that the NRC reviewer should evaluate the material susceptibility to corrosion, the potential for high residual stresses, and potential for high loading such as water hammer and environmental conditions that could lead to degradation by stress corrosion cracking. This SRP further specifies that the NRC reviewer's evaluation should demonstrate that stress corrosion cracking is not a potential source of pipe rupture.

The second part of the SRP Section 3.6.3 review is set of a quantitative LBB analyses to support an LBB application. LBB analyses consist of a leakage rate calculation and a fracture mechanics calculation. The leakage calculation determines the size (arc length) of a postulated, idealized throughwall crack that would leak at a specified flow rate based on the capability of the applicable leakage detection systems multiplied by a margin of 10 . This is called the leakage size crack. The fracture mechanics calculation ensures that the largest crack (i.e., critical crack) that satisfies the fracture mechanics acceptance criteria in SRP Section 3.6.3 is at least two times larger than the leakage size crack. LBB analysis applies only to an entire piping system or a portion thereof that can be analyzed. Portions of the piping system that can be analyzed are typically segments located between anchor points. When LBB technology is applied, all potential pipe rupture locations are examined. An LBB analysis examines or calculates the leakage and fracture mechanics margins at critical locations in the analyzed segment, and the analysis summary typically includes the margins for the location(s) with the lowest margins in each piping system. Critical locations would generally include the locations that have the least favorable 
combination of stress and material properties for base metal, weldments, nozzles, and safe ends relative to the leakage and fracture mechanics margins.

The quantitative analysis described above is essentially a flaw tolerance evaluation. The Commission reviewed and approved the various plant-specific evaluations before it authorized the removal of the dynamic effects of postulated high-energy pipe ruptures from the design bases. Licensee applications for approval of LBB analyses have been made through the license amendment process.

GDC-4 is stated in terms of probability. When the LBB review criteria were adopted, the NRC staff concluded that a reliable approach for demonstrating compliance with GDC-4 was satisfaction of the SRP Section 3.6.3 deterministic criteria; that is, through a comprehensive screening evaluation and a fracture mechanics analysis demonstrating high margins against rupture. 
Appendix B

Assessment of ASME Code Case N-770-1 as Implemented in 10 CFR 50.55a(g)(6)(ii)(F) 



\section{Appendix B}

\section{Assessment of ASME Code Case N-770-1 as Implemented in 10 CFR 50.55a(g)(6)(ii)(F)}

\section{B.1 Assessment of ASME Code Case N-770-1 Requirements for Butt Welds Mitigated by MSIP}

\section{B.1.1 Table 1}

There are two Inspection Items in Code Case N-770-1 pertaining to butt welds mitigated by MSIP. Inspection Item $\mathrm{D}$ applies to uncracked butt welds mitigated with stress improvement and Inspection Item $\mathrm{E}$ applies to cracked butt welds mitigated with stress improvement. Welds with these Inspection Items are required to be volumetrically examined as discussed below. There are surface examination requirements that apply in a case discussed relative to Table 1 , Note 12 . There are no visual inspection requirements for stress-improved welds.

Inspection Item $\mathrm{D}$ welds are required to be examined within 10 years following stress improvement. If the examination volumes of the welds show no indication of cracking, the welds shall be placed into a population to be examined on a sample basis. Twenty-five percent of this population shall be examined once each interval. The examination requirements for Inspection Item E welds only differ from the requirements for Inspection Item D welds in that Inspection Item E welds are required to be examined once during the first or second refueling outage following stress improvement, rather than within 10 years following stress improvement. If the examination volumes show no indication of crack growth or new cracking, the welds shall be placed into a population to be examined once each interval. The examination volume for welds mitigated by MSIP is shown in Figure 1 of the Code Case. The examination volume shown in Figure 1 applies to welds in NPS 2 (DN 50) or larger and is the same volume as shown in Fig. IWB-2500-8(c), "Similar and Dissimilar Metal Welds in Components, Nozzles, and Piping."

The Code Case provides requirements to examine a 25\% sample once per interval for Inspection Item D welds, uncracked welds mitigated by MSIP, which is similar to the Section XI requirements for B-J welds and the provisions of BWRVIP-75 (1999) for Category C, non-resistant materials stress improved after 2 years operation and with no evidence of cracking from ISI. These provisions of BWRVIP-75 were discussed and found acceptable by the NRC in its safety evaluation issued in 2002 (Bateman 2002).

However, the examination frequency requirements of Code Case N-770-1 for Inspection Item E welds (cracked stress improved welds) are significantly different from those approved by the NRC staff for BWRVIP-75, Category E (cracked stress improved) welds. BWRVIP-75 Category E welds without improvements in water chemistry are all required to be inspected once every 6 years. With hydrogen or 
noble metal water chemistry improvements, BWRVIP-75 welds are all required to be inspected once every 10 years, with at least $50 \%$ completed within the first 6 years. ${ }^{(a)}$

In the interval between when the BWRVIP-75 inspection frequencies were proposed to the NRC staff and Code Case N-770-1 was developed, the NRC staff required that UT inspection of the welds addressed by BWRVIP-75 be qualified in accordance with the performance demonstration requirements of Section XI, Appendix VIII. In addition, there was almost a decade of generally favorable experience with the inspections performed on cracked MSIP welds. In allowing a 25\% per interval sampling inspection frequency for cracked MSIP welds in Code Case N-770-1, the NRC and ASME Code gave significant weight to the favorable operating experience with cracked MSIP welds in BWRs.

Adopting MSIP inspection frequency requirements of once per interval, with or without sampling, reflects an implicit conclusion by the ASME and the NRC that MSIP results in effective mitigation and that the inspection serves a defense-in-depth function rather than a degradation management function.

The effectiveness of MSIP as a mitigation technique is discussed in detail in Section 5.0 of this report.

\section{B.1.2 Notes}

The notes to Table 1, which are applicable to MSIP welds in Inspection Items D and E, are notes (4), (10), (11), (12), and (13).

Note (4) states, "Ultrasonic volumetric examination shall be used and shall meet the applicable requirements of Appendix VIII." This note requires UT examinations to be qualified in accordance with requirements that the NRC previously has found to be acceptable.

Note (10) requires that the " $25 \%$ sample consist of the same welds in the same sequence during successive intervals to the extent practical provided the $25 \%$ sample contains the welds that experience the highest operating temperature in the Inspection Item. If hot-leg and cold-leg welds are included in the same Inspection Item, the initial 25\% sample does not need to include the cold-leg welds. Those welds not included in the $25 \%$ sample shall be examined prior to the end of the mitigation evaluation period if the plant is to be operated beyond that time." These requirements bias the $25 \%$ sample in the conservative direction and ensure that all welds are examined before reaching the end of life. The Code Case requirements would be improved by requiring that repaired welds be included in the $25 \%$ inspection sample, because repairs can have a large effect on flaw initiation and growth. See a similar comment under the discussion of Note (12)(c) below.

Note (11) pertains to deferral of examinations, and in this context, relates to Inspection Items D and E. Note (11)(a) provides that examination of welds originally classified Table IWB 2500-1, Category B-J welds (piping welds) prior to the mitigation are not permitted to be deferred to the end of the interval. The reason for Note (11)(a) is that examination of these welds does not need to be performed in conjunction with the RPV examinations, so this note prohibits deferral.

(a) The examination frequencies for Category $\mathrm{C}$ and $\mathrm{E}$ welds are not provided in BWRVIP-75NP, but EPRI agreed that the NRC staff could provide them in the NRC safety evaluation (Bateman 2002). 
For welds originally classified Table IWB 2500-1, Category B-F welds (nozzle welds) prior to the mitigation, Note (11)(b) in conjunction with the NRC condition 10 CFR 50.55a(g)(6)(ii)(F)(9) requires that the first examination of MSIP welds in Inspection Items D (uncracked MSIP) be performed no sooner than the third refueling outage and no later than 10 years after the MSIP was applied, thereby prohibiting deferral of the initial examination. This condition was provided to resolve an inconsistency between the Code Case N-770-1, Table 1 and Note (11)(b), initial examination requirements of Inspection Item D welds. Note (11)(b) in conjunction with NRC condition 10 CFR 50.55a(g)(6)(ii)(F)(9) requires that the first examination of welds with MSIP in Inspection Item E (cracked MSIP) be performed during the first or second refueling outage after the MSIP was applied. Although a crack in a weld mitigated by an MSIP is addressed in the design, Inspection Item $\mathrm{E}$ welds are required by the Code Case to have an initial examination soon after installation, possibly as a check on uncertainties with the pre-MSIP examination and other aspects of the design. Subsequent examinations of Inspection Item D and E welds may be performed coincident with the vessel nozzle examinations required by Category B-D. For successive inspection intervals following MSIP, examinations may be deferred to the end of the interval, provided no additional repair/replacement activities have been performed on the examination item, and no flaws or relevant conditions requiring successive examinations are contained in the mitigated weld.

Note (12) contains additional requirements related to examinations, acceptance standards, and evaluations and has five parts.

(1) Note (12)(a) requires that, except for reactor vessel nozzle welds at cold-leg temperatures requiring the core internals to be removed to perform the examination, "volumetric exams shall be performed ... before the stress improvement (MSIP) techniques are applied. The pre-stress improvement (MSIP) exam shall be conducted in the same outage as the application of stress improvement (MSIP) or, for non-cracked welds, no more than one cycle previous to the application of stress improvement (MSIP). The examination volume Fig. 1 (of the Code Case, i.e., for unmitigated welds) applies." Performing an examination on a weld prior to application of an MSIP would yield more reliable detection than performing the examination on the mitigated weld, because MSIP generates compressive residual stresses that may close cracks and decrease the UT flaw response. Moreover, no UT procedures have been qualified for detection or depth sizing in accordance with Appendix VIII, Supplement 10, with specimens to which MSIP was applied. Allowing one cycle of operation between the pre-MSIP examination and application of the MSIP is based on the engineering judgment that it is unlikely that PWSCC would initiate and grow during the cycle prior to MSIP to the extent that it could adversely affect weld integrity.

(2) Note (12)(b) states that, "Post-stress improvement examinations are required and shall be considered the preservice baseline examination." Notes 12(b)(1)-(3) provide the acceptance standards to evaluate new flaws or changes in the size of previously detected flaws. These acceptance standards are consistent with ASME Code, Section XI, standards and with the philosophy that no new planar surface-connected flaws should originate or existing flaws grow as a result of applying stress improvement to welds.

(3) Note (12)(c) states that, "If the crack is completely removed by repair/replacement activity in accordance with IWA-4000 and the stress improvement (MSIP) is then applied, the weld will be restored to Item number D." This note should say "Inspection Item D" rather than "Item number D." Inspection Item D is uncracked butt welds mitigated with stress improvement (OWOL). (This note was not corrected in Code Case N-770-2.) This note clarifies that if a crack in a butt weld is completely removed and repaired in accordance with Code requirements, it may 
be treated as an uncracked weld. Analyses performed by BCL have shown that a weld repair affects the post-MSIP residual stress state. Even though weld repairs have to be assumed in the MSIP design per Appendix I, Performance Criterion I, including welds with known repairs in the $25 \%$ inspection sample would improve the safety basis for sample selection, because repairs can have a large effect on flaw initiation and growth

(4) Note (12)(d) states that, "A documented evaluation demonstrating that the stress improvement technique meets the performance criteria in Appendix I shall be completed. This note requires a documented evaluation to demonstrate that each MSIP satisfies the performance criteria of Appendix I. The requirements of Code Case N-770-1, Appendix I are discussed below.

(5) Note (12)(e) states that, "For reactor vessel nozzle welds at cold-leg temperatures requiring the core internals to be removed to perform the examination, the volumetric examinations are not required prior to application of the stress improvement technique. If the pre-stress improvement volumetric examination is not performed, a post stress improvement preservice surface examination and volumetric examination shall be performed after removal of the core internals. If these examinations do not detect cracks, the weld will be considered uncracked and be subject to the examination requirements of Inspection Item D. This post stress improvement preservice volumetric examination must include the examination volume shown in Fig. 1. ... The post stress improved preservice surface examination shall be performed on the butt weld inside surface, extent E-F of Fig. 1, and shall consist of an eddy current examination in accordance with IWA-2223." IWA-2223 requires that eddy current examination (ET) be conducted in accordance with Appendix IV. Appendix IV contains demonstration requirements only and allows the demonstrations to be performed on notches. Because the MSIP decreases or eliminates the UT response of cracks, the ability of the surface examination to detect cracks takes on greater significance. Code Case N-773 contains ET performance demonstration requirements that may be used in lieu of Appendix IV, Supplement 2 when ET is used to complement UT performed on the inside surfaces of austenitic, DMW, and clad piping welds. Qualification of ET procedures and personnel by performance demonstration would increase the reliability of ET examination. The ASME Code, Section XI, is working on an action to incorporate the requirements of Code Case N-773 in Appendix IV.

However, these provisions do not explicitly say what the user is required to do if during the surface examination the weld is determined to be cracked. There are currently no Appendix VIII, Supplement 10 procedures to examine welds from the ID that are qualified for depth sizing flaws in unmitigated welds. The compressive stresses in the mitigated weld may cause crack faces to close or partially close and change the UT response of the flaws. This phenomenon may increase the difficulty of qualifying procedures for detection as well as depth sizing. PNNL recommends that the Code Case or $10 \mathrm{CFR}$ $50.55 \mathrm{a}(\mathrm{g})(6)(\mathrm{ii})(\mathrm{F})$ be revised to address this issue. If this issue were to arise, it may have to be resolved outside of the rules of the Code Case and involve the NRC staff through a relief request.

Note (13) pertains to inservice inspection (ISI) for stress improvement and states that, “... the required examination volume in Fig. 1 shall be ultrasonically examined to determine the acceptability of the mitigated weld. If inservice examinations ... reveal crack growth, or new cracking, meeting the acceptance standards, the weld examination volume ... shall be reexamined during the first refueling outage following discovery to the crack growth or new cracking. The examination volume of Figure $1 \ldots$ shall be subsequently examined during each of the next two refueling outages. If the examinations ... 
reveal that the flaws remain essentially unchanged for three successive examinations, the weld examination schedule may revert to the sample and schedule of examinations identified in Table 1. This weld shall be included in the $25 \%$ sample." The requirements of Note (13) are consistent with ASME Code, Section XI, requirements for successive examinations.

\section{B.1.3 Appendix I to Code Case N-770-1}

Appendix I to the Code Case contains seven performance criteria that have to be met by welds mitigated by MSIP. Each of the seven performance criteria is followed by a measurement or quantification criterion. A brief discussion of these criteria follows.

- To minimize the likelihood of crack initiation, Criterion 1 stipulates that MSIP shall have resulted in a compressive state in the susceptible material along the entire wetted surface under steady-state operation.

- Criterion 2 stipulates that the mitigation process shall be permanent.

- Criterion 3 stipulates that the capability to perform ultrasonic examinations of the relevant volume shall not have been adversely affected by the MSIP.

- Criterion 4 states that the mitigation process shall not have degraded the component or adversely affected other components in the system.

- Criterion 5 stipulates that the mitigated weld shall be inspectable by a qualified process.

- Criterion 6 stipulates that existing flaws, if any, shall be addressed as part of the mitigation.

- Criterion 7 states that the effect of mitigation on the presence of existing flaws shall be analyzed.

These criteria were developed to provide requirements to ensure that MSIP is an effective mitigation technique for preventing the initiation of PWSCC or the growth of existing PWSCC. They were developed because MSIP does not involve welding and other Code requirements such as contained in IWA-4000, Repair/Replacement Activities do not apply. MSIP has traditionally been performed outside of Code requirements; that is, Code requirements are considered not to apply.

The requirements of Appendix I constitute a performance-based approach for ensuring that the basic objectives of Section XI for maintaining structural integrity are met. They were developed by a task group under the Section XI Subgroup on Flaw Evaluation. They address the intent of accomplishing effective mitigation to inhibit crack initiation, prevent undesirable effects of mitigation on other components, ensure that examinations qualified in accordance with Section XI requirements are performed, and require that flaws are evaluated in accordance with Section XI rules. While broad, these performance criteria appear to be comprehensive. An assessment of each performance criterion is contained in Section 5.0 of Fredette and Scott (2009). This assessment of the Appendix I performance criteria supports the appropriateness of each criterion and does not suggest the need for supplementary criteria.

The examination requirements of Table 1, the notes to Table 1, and Appendix I provide a set of comprehensive inspection requirements that parallel existing Section IWB Class 1 requirements and are similar to or more conservative than the requirements in the ASME Code for Class 1 butt welds in systems that do not need to be addressed by Code Case N-770-1. The Code Class 1 butt weld 
examination requirements of Section XI were based on a defense-in-depth philosophy for monitoring welds to ensure that the welds were not experiencing an active degradation mechanism. For consistency with this approach, the NRC imposed a number of additional conditions to appropriately design and apply MSIP and to monitor and assess these welds over their design life. These conditions are discussed below.

\section{B.2 NRC Implementing Requirements}

This section discusses the conditions in the rule imposing Code Case N-770-1 (76 FR 36232) that pertain to welds mitigated by mechanical stress improvement, that is, conditions $(\mathrm{F})(1),(2),(4),(6)$, and (9).

Condition $\$ 50.55 \mathrm{a}(\mathrm{g})(6)(\mathrm{ii})(\mathrm{F})(\mathrm{l})$ of the rule requires licensees of existing operating PWRs as of July 21, 2011, to implement the requirements of ASME Code Case N-770-1, subject to the conditions specified in paragraphs $(\mathrm{g})(6)(\mathrm{ii})(\mathrm{F})(2)$ through $(\mathrm{g})(6)(\mathrm{ii})(\mathrm{F})(10)$ by the first refueling outage after August 22, 2011. This is the basic implementing requirement imposing Code Case N-770-1 with conditions.

Condition $\S 50.55 \mathrm{a}(\mathrm{g})(6)(\mathrm{ii})(\mathrm{F})(2)$ of the rule allows welds mitigated by mechanical stress improvement to be categorized as Inspection Items D or E, as appropriate, provided the criteria of Appendix I of the Code Case have been met. As noted previously, the Code Case provides performance criteria in Appendix I for ensuring that the basic objectives of Section XI for maintaining structural integrity are met. Prior to this Code Case, MSIPs were installed following industry-qualified procedures and guidance in NUREG-0313 (Hazelton and Koo 1988). MSIP had not been subject to NRC review. Accordingly, under Condition (F)(2) licensees are not required to obtain NRC approval to categorize MSIP welds as Inspection Items D or E, as appropriate, provided the criteria of Appendix I are satisfied and the evaluation documented in accordance with Code Case N-770-1, Note (12)(d).

Code Case N-770-1, paragraph -2500(c) states that, "For axial and circumferential flaws, examination shall be performed to the maximum extent practical using qualified personnel and procedures. If essentially $100 \%$ coverage for circumferential flaws (100\% of the susceptible material volume) can be achieved, the examination for axial flaws shall be completed to achieve the maximum coverage practical." The NRC disagreed with this provision. Axial flaws can lead to through-wall cracks and leakage of reactor coolant, which is a safety concern. Condition $\$ 50.55 \mathrm{a}(\mathrm{g})(6)(\mathrm{ii})(\mathrm{F})(4)$ requires that the axial (flaw) examination coverage requirements of -2500 (c) may not be considered to be satisfied unless essentially $100 \%$ coverage is achieved. The industry guidelines of MRP-139 (EPRI 2005b) allow less than essentially $100 \%$ coverage in some cases; therefore, a number of previously conducted baseline examinations may not satisfy the rule. This condition was added by the NRC to ensure that, through NRC review of an authorization of alternative inspection coverage, appropriate actions are being taken to address potential inspection limitations for axial flaws. This condition applies to pre- and post-MSIP examinations. 
Condition $\S 50.55 \mathrm{a}(\mathrm{g})(6)(\mathrm{ii})(\mathrm{F})(6)$ is an ISI reporting requirement for mitigated welds if growth of existing flaws is found that exceeds the previous IWB-3600 flaw evaluations or if new flaws are detected. In such cases, licensees are required to provide a report to the NRC, prior to entering Mode 4, that summarizes the licensee's flaw evaluation with inputs, methodologies, assumptions, and the cause of new flaws or flaw growth. If volumetric examination detects new flaws or growth of existing flaws in the required examination volume, the mitigation will not be performing as designed and the NRC will need to evaluate the licensee's actions to address the problem. Therefore, this condition was added to verify the acceptability of the weld prior to being placed back in service.

Condition $\S 50.55 \mathrm{a}(\mathrm{g})(6)(\mathrm{ii})(\mathrm{F})(9)$ pertains, in part, to deferral of examinations and is discussed in Appendix B.1.2 above in connection with Table 1, Note (11). 

Appendix C

\section{Dissimilar Metal Weld Inspection Limitations of a Typical Westinghouse Plant}





\section{Appendix C}

\section{Dissimilar Metal Weld Inspection Limitations of a Typical Westinghouse Plant}

\section{C.1 Introduction}

The information contained in this appendix was obtained during a workshop held with LMT, Inc., an inspection vendor for the commercial nuclear power industry. This vendor uses ultrasonic testing (UT) inspection methods qualified under ASME Code, Section XI, Appendix VIII, including phased-array (PA) techniques and conventional UT techniques in encoded and non-encoded delivery modes, as specified by the utility. This workshop was held to discuss the characteristics of UT data of indications attributed to stress corrosion cracking (SCC). This data was from encoded examinations of piping welds acquired from scans of the outside diameter (OD) surface. This workshop was also held to discuss limitations to achieving Code-required volume (CRV) coverage on Alloy 82/182 butt welds in a typical Westinghouse plant and a typical Combustion Engineering (CE) plant. This appendix provides information on limitations to obtaining the CRV coverage that may be encountered during examinations of Alloy 82/182 butt welds in the reactor coolant system in a Westinghouse plant.

Table C. 1 provides a listing of the Alloy 82/182 butt welds that are typically found in a Westinghouse plant. The location of these welds is depicted in Figure C.1. The CRV coverage for the Alloy 82/182 in butt welds in the piping systems in Table C.1 is dependent on site-specific configurations and allowable scan access thereof. Site-specific designs vary in regards to material and component configuration(s). Therefore, the coverage depicted is applicable only to the site-specific design used to prepare this document. Standard $45^{\circ}$ and $60^{\circ}$ angles were utilized for CRV coverage assessments unless specified otherwise in the illustrations. The Alloy 82/182 butt welds depicted in Sections A.2-A.4 in the sitespecific design used to prepare this document had been mitigated by weld overlays.

Table C.1. Alloy 82/182 Butt Welds and Dimensions in Typical Westinghouse

\begin{tabular}{lccc}
\hline \multicolumn{1}{c}{ Description } & Quantity & $\begin{array}{c}\text { Circumference } \\
\text { (Weld Centerline) }\end{array}$ & $\begin{array}{c}\text { Thickness } \\
\text { (Weld Centerline) }\end{array}$ \\
\hline PZR Surge Nozzle & 1 & $47.5^{\prime \prime}$ & $1.60^{\prime \prime}$ \\
PZR Spray Nozzle & 1 & $18.7^{\prime \prime}$ & $0.87^{\prime \prime}$ \\
PZR Safety and Relief Nozzle & 4 & $25^{\prime \prime}$ & $1.37^{\prime \prime}$ \\
RPV Hot Leg Nozzle & $3 / 4$ & $113^{\prime \prime}$ & $2.50^{\prime \prime}$ \\
SG Hot Leg Nozzle & $3 / 4$ & $132.3^{\prime \prime}$ & $4.90^{\prime \prime}$ \\
SG Cold Leg Nozzle & $3 / 4$ & $132.3^{\prime \prime}$ & $4.90^{\prime \prime}$ \\
RPV Cold Leg Nozzle & $3 / 4$ & $113^{\prime \prime}$ & $2.50^{\prime \prime}$ \\
\hline PZR - pressurizer; RPV - reactor pressure vessel; SG - steam generator; 3/4 - 3 or 4 loops \\
\hline
\end{tabular}




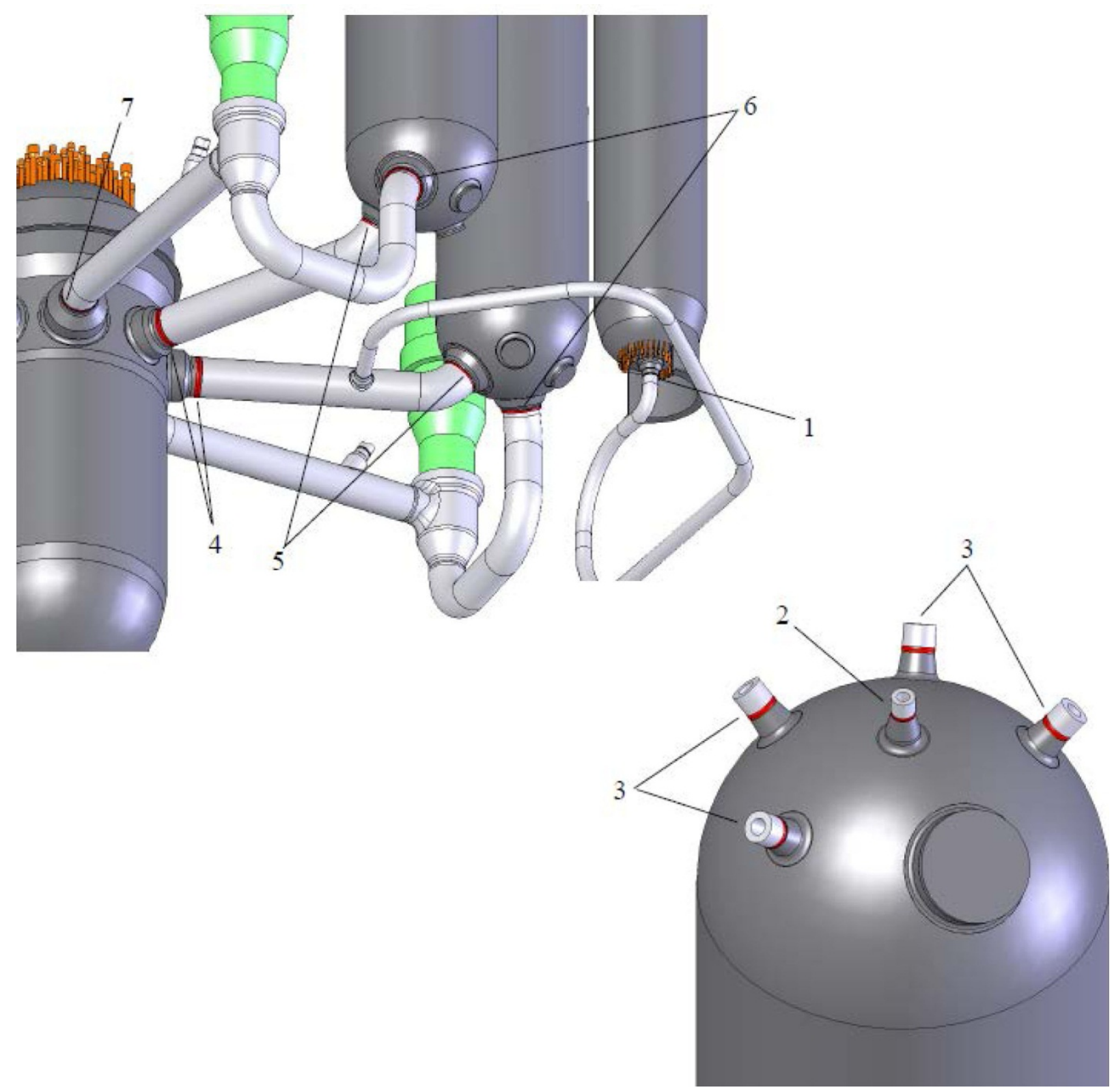

Figure C.1. Typical Locations of Alloy 82/182 Butt Welds in Westinghouse Design Plants 


\section{C.2 Pressurizer Surge Nozzle}



Figure C.2. Photograph of Pressurizer Surge Nozzle, Nozzle Weld, and Safe End

The examination limitations for the pressurizer surge nozzle Alloy 82/182 butt weld were minimal scanning surface and the OD examination surface contour and condition.

The cross-sectional examination coverage in the axial scan direction for circumferential flaws is depicted in Figure C.3. The axial scan direction CRV coverage achievable was $80 \%$. The cross-sectional examination coverage in the circumferential scan direction for axial flaws is depicted in Figure C.4. The circumferential scan direction CRV coverage achievable was $100 \%$. 


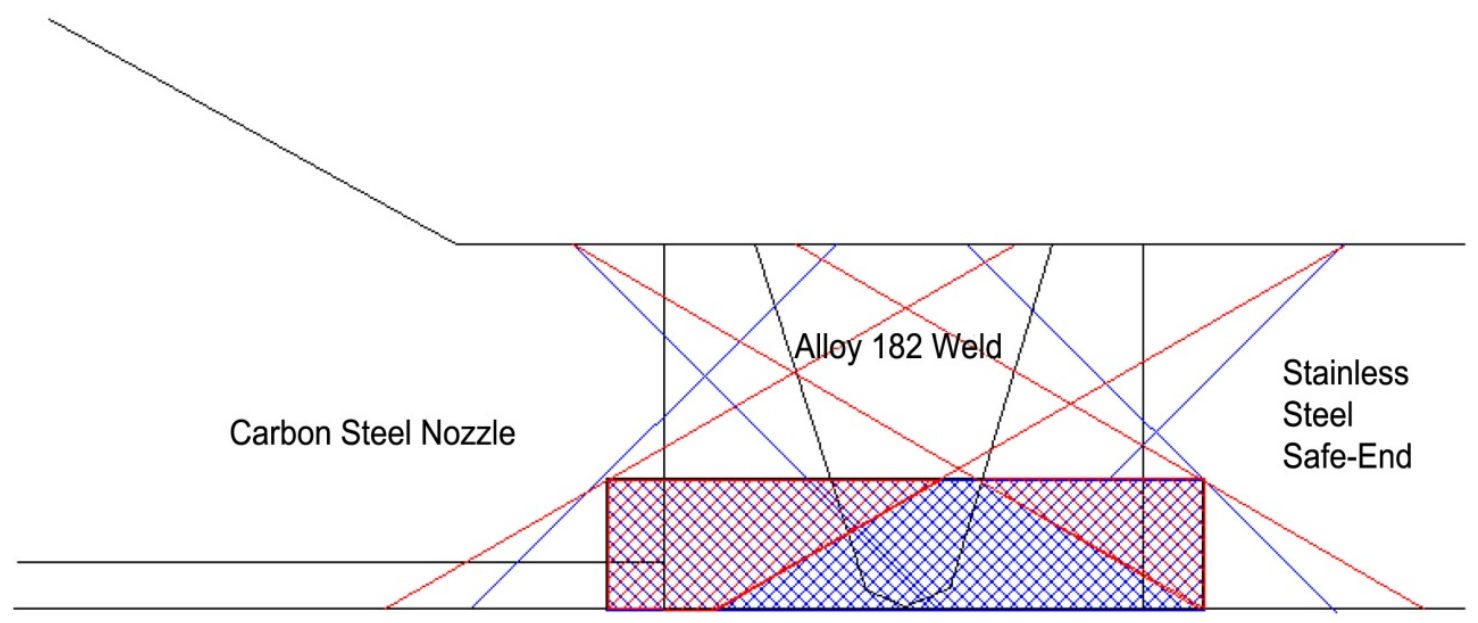

Figure C.3. Pressurizer Surge Nozzle Weld Axial Scan CRV Coverage Assessment



Figure C.4. Pressurizer Surge Nozzle Weld Circumferential Scan CRV Coverage Assessment 


\section{C.3 Pressurizer Spray Nozzle}

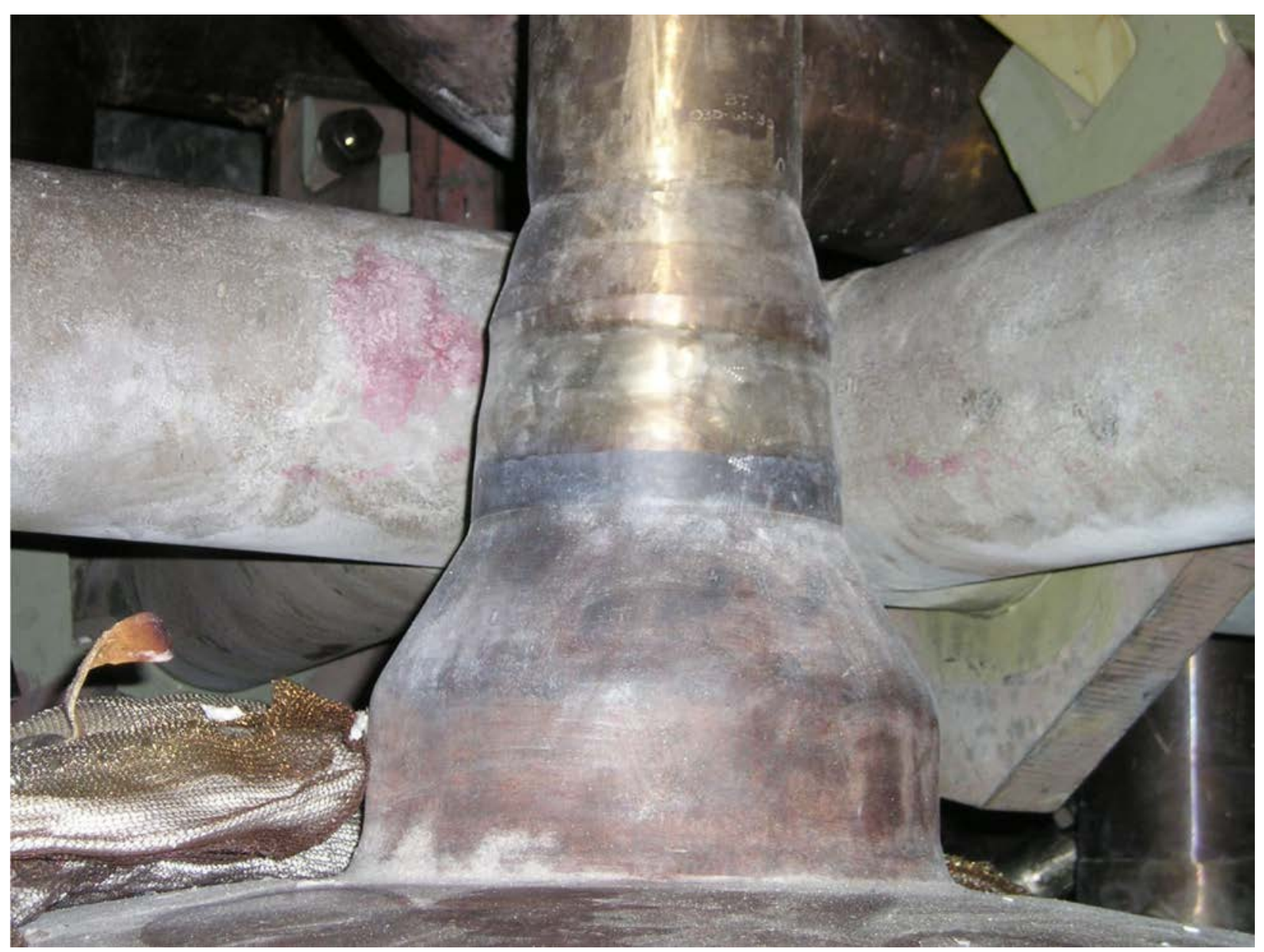

Figure C.5. Photograph of Pressurizer Spray Nozzle, Nozzle Weld, and Safe End

The examination limitations for the pressurizer spray nozzle Alloy 82/182 butt weld were minimal scanning surface and the OD examination surface contour and condition.

The cross-sectional examination coverage in the axial scan direction for circumferential flaws is depicted in Figure C.6. The axial scan direction CRV coverage achievable was $40 \%$. The cross-sectional examination coverage in the circumferential scan direction for axial flaws is depicted in Figure C.7. The circumferential scan direction CRV coverage achievable was $34 \%$. 


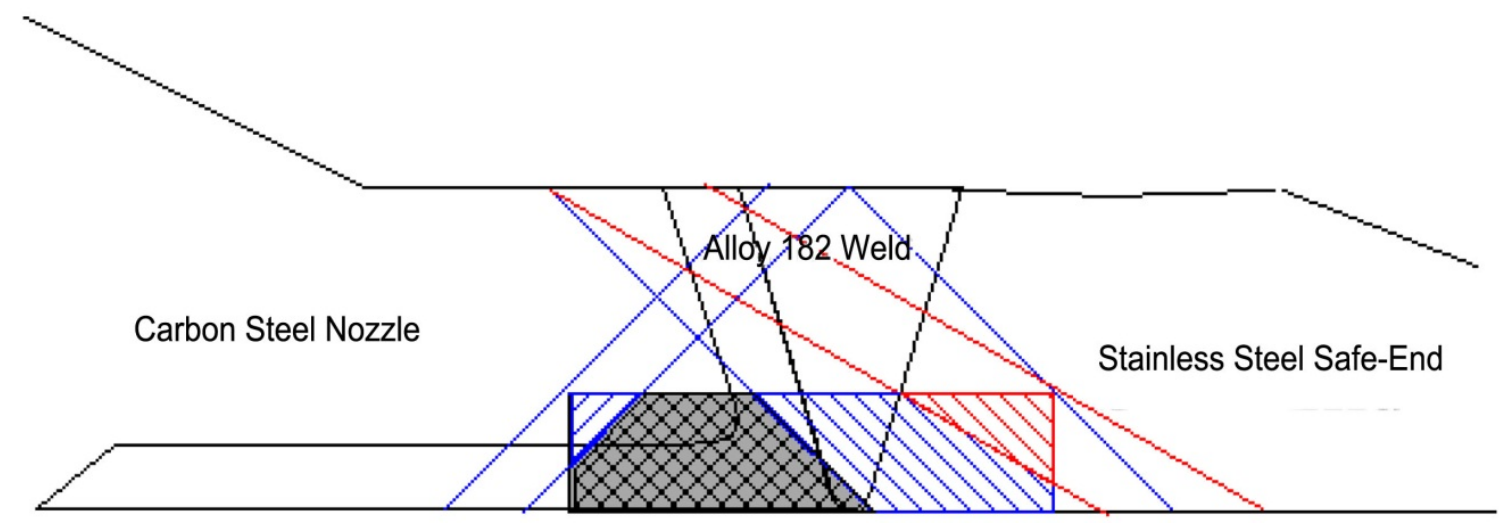

Figure C.6. Pressurizer Spray Nozzle Weld Axial Scan CRV Coverage Assessment

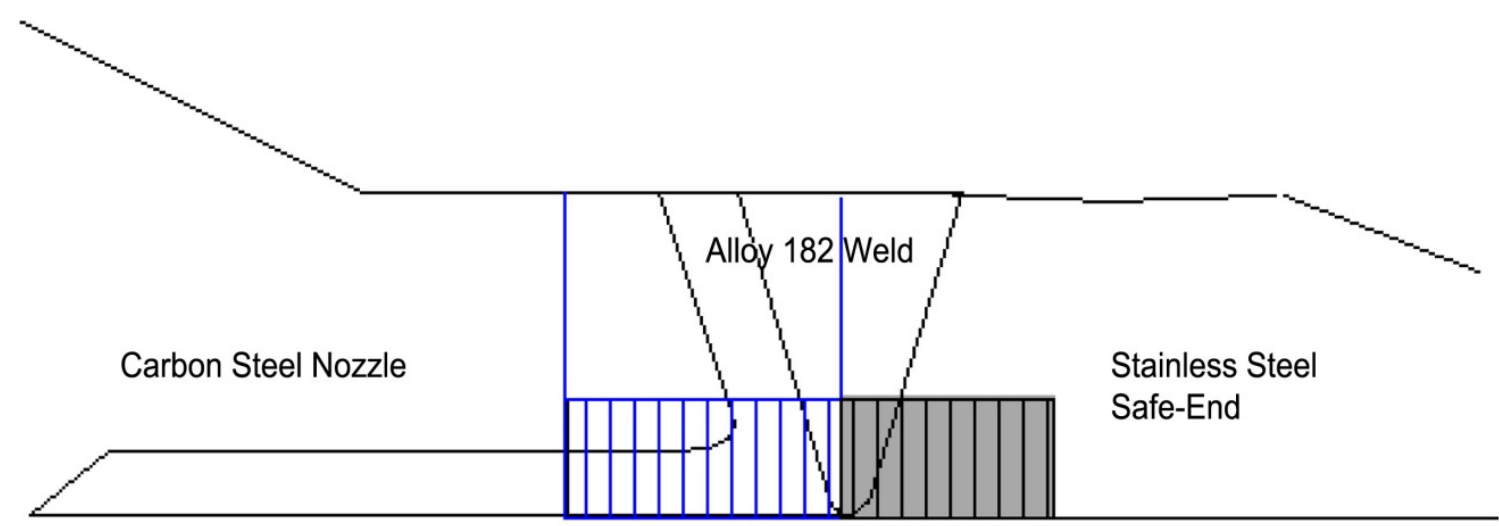

Figure C.7. Pressurizer Spray Nozzle Weld Circumferential Scan CRV Coverage Assessment 


\section{C.4 Pressurizer Safety and Relief Nozzle}

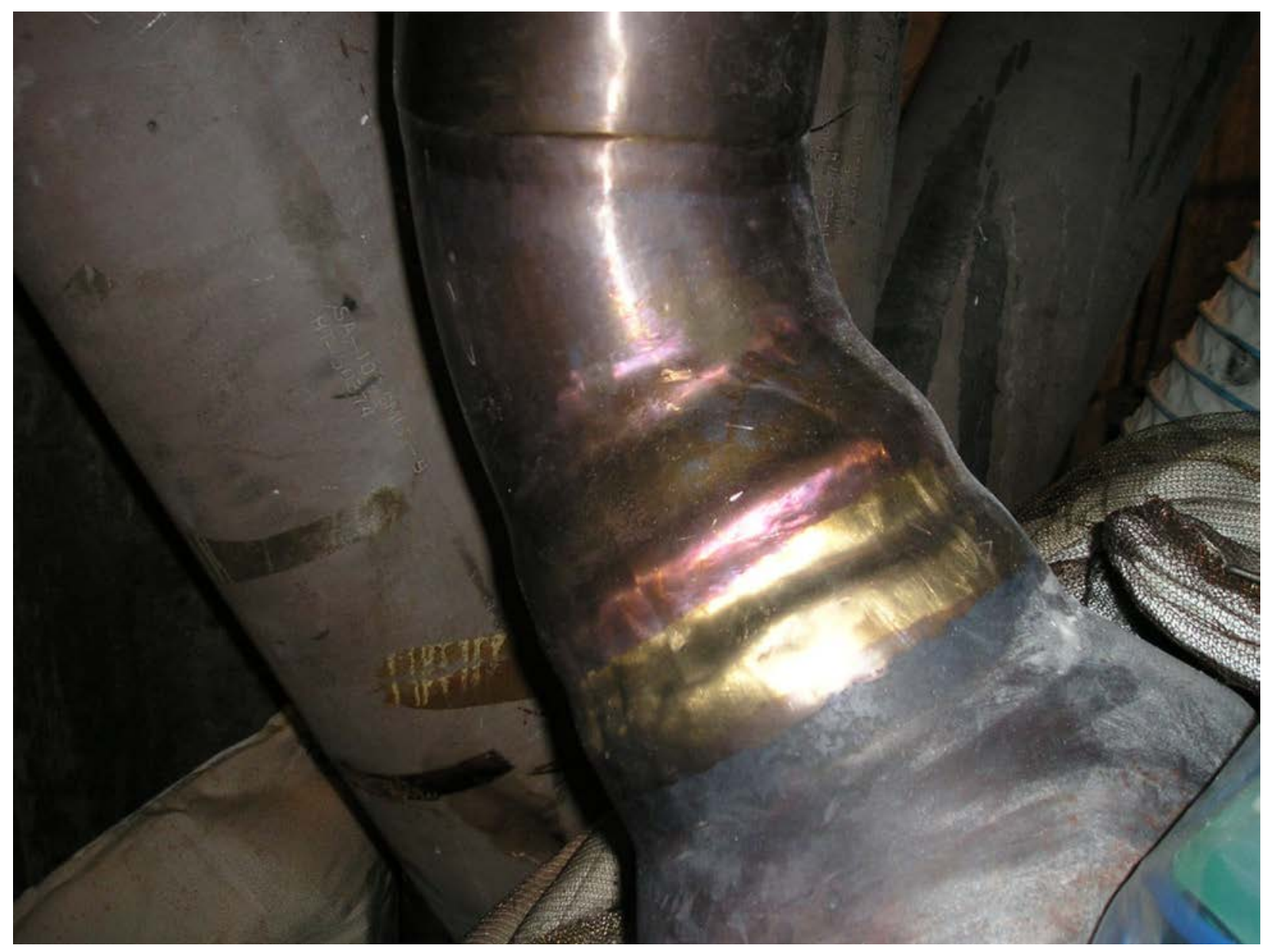

Figure C.8. Photograph of Pressurizer Safety and Relief Nozzle, Nozzle Weld, and Safe End

The examination limitations for the pressurizer safety and relief nozzle Alloy 82/182 butt weld were minimal scanning surface and the OD examination surface contour and condition.

The cross-sectional examination coverage in both the axial scan direction for circumferential flaws and in the circumferential direction for axial flaws was $0 \%$. This configuration does not allow a meaningful examination for either circumferential or axial flaws. The cross-sectional examination coverage for both scan directions is depicted in the assessment diagram in Figure C.9. 


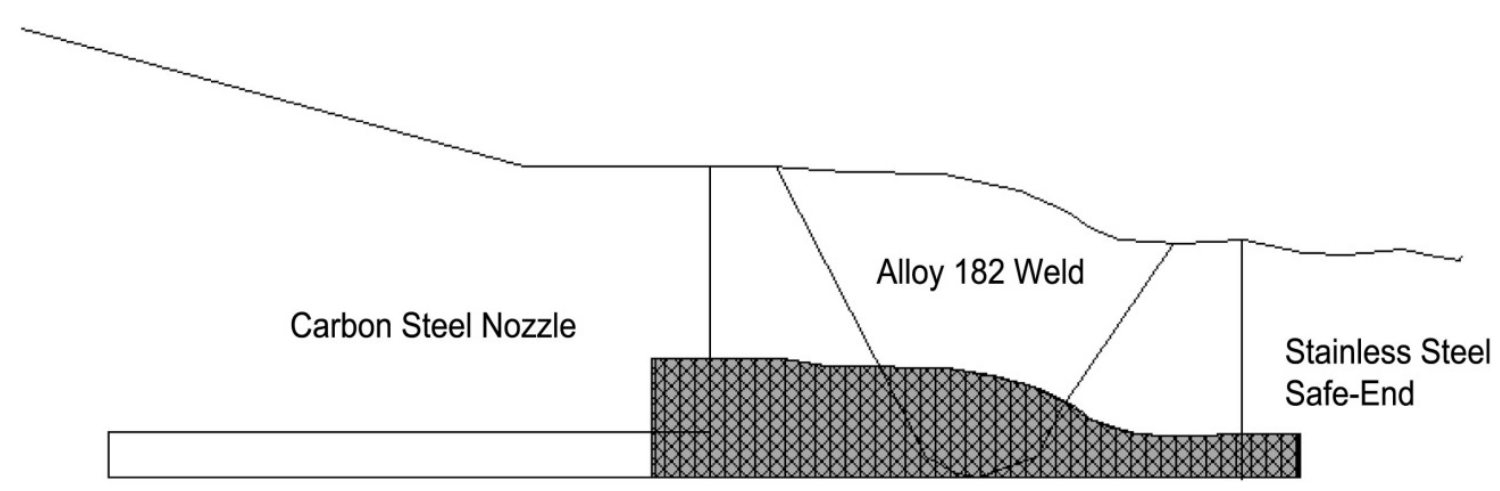

Figure C.9. Pressurizer Safety and Relief Nozzle Weld Axial Scan CRV Coverage Assessment

\section{C.5 Reactor Pressure Vessel Hot Leg Nozzle}

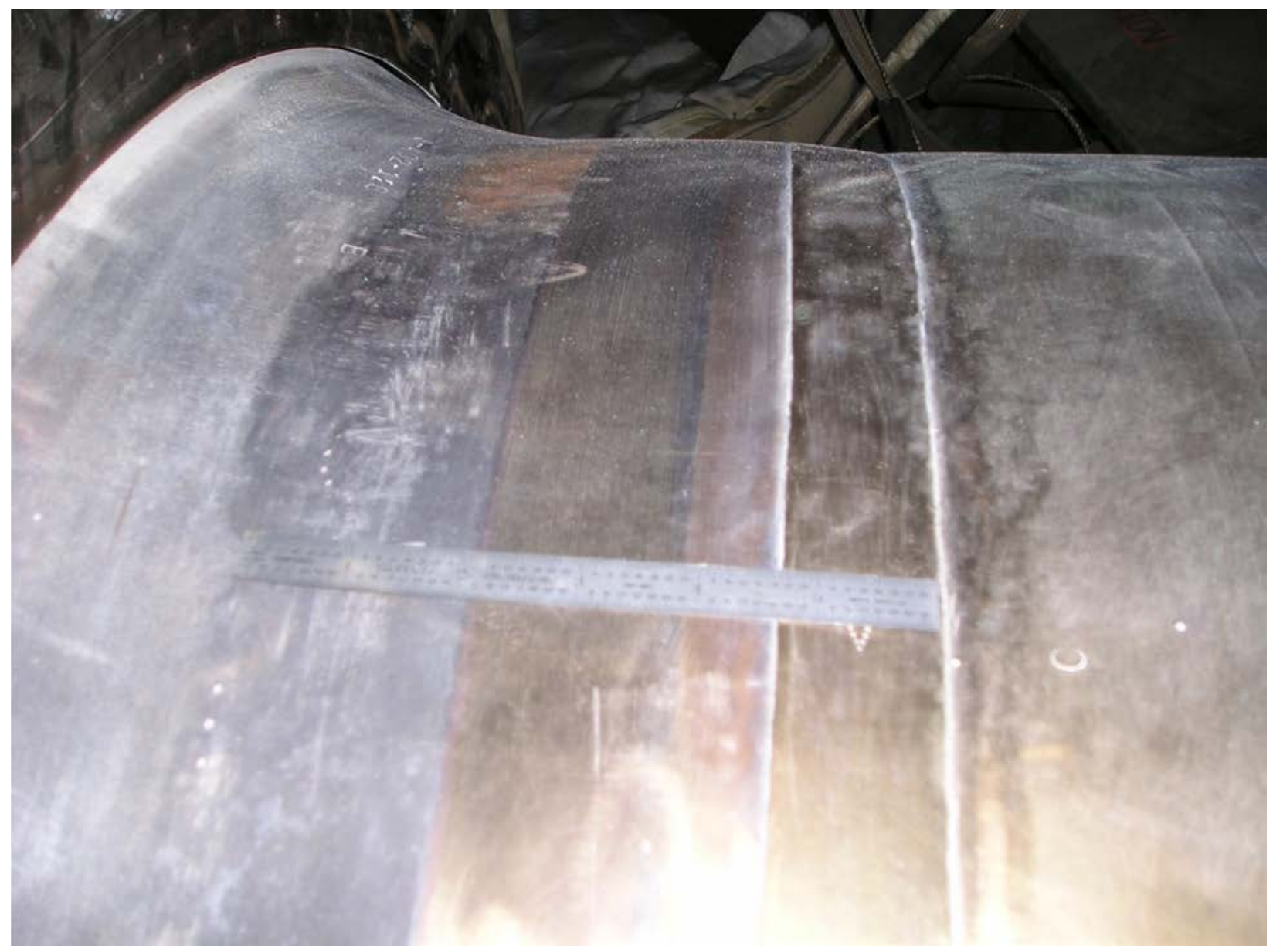

Figure C.10. RPV Hot Leg Nozzle, Nozzle Weld, and Safe End 
The examination limitations for the RPV hot leg nozzle Alloy 82/182 butt weld were minimal scanning surface and OD examination surface contour and condition.

The cross-sectional examination coverage in the axial scan direction for circumferential flaws is depicted in Figure C.11. The axial scan direction CRV coverage achievable was $28.8 \%$. The crosssectional examination coverage in the circumferential scan direction for axial flaws is depicted in Figure C.12. The circumferential scan direction CRV coverage achievable was $100 \%$.

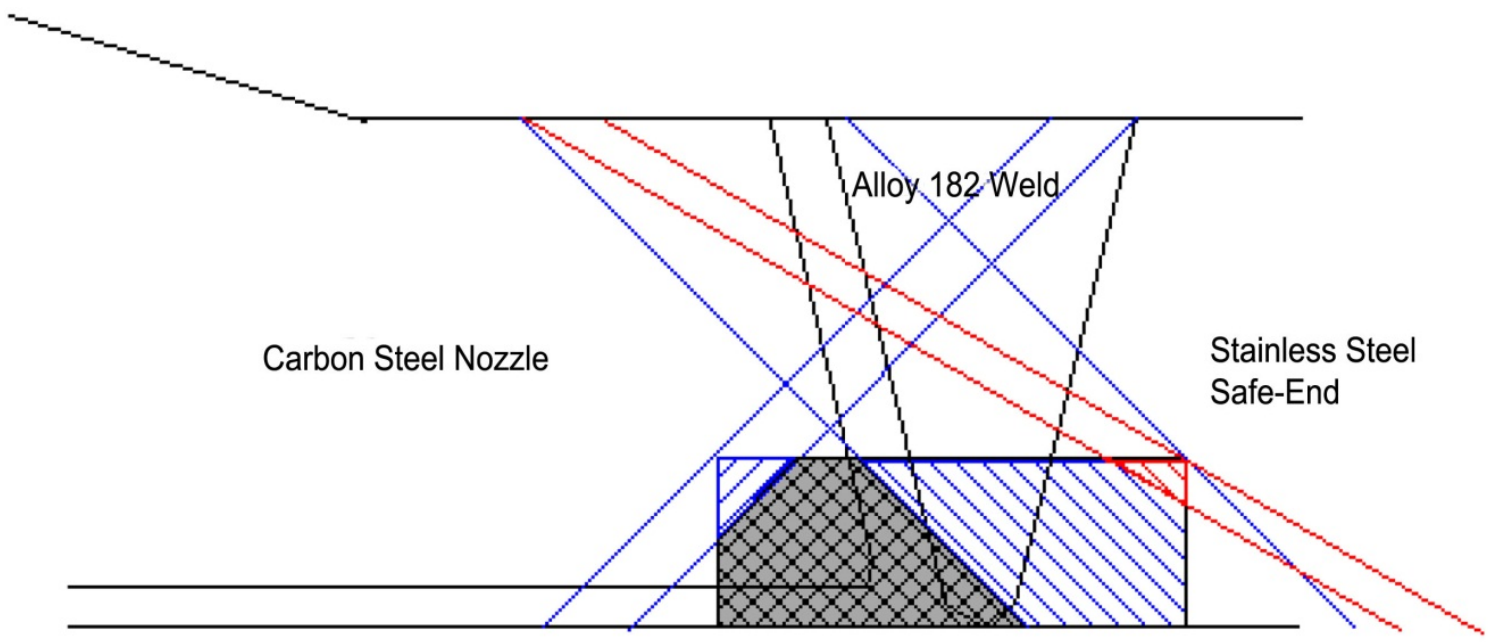

Figure C.11. RPV Hot Leg Nozzle Weld Axial Scan CRV Coverage Assessment



Figure C.12. RPV Hot Leg Nozzle Weld Circumferential Scan CRV Coverage Assessment 


\section{C.6 Steam Generator Hot Leg Nozzle}

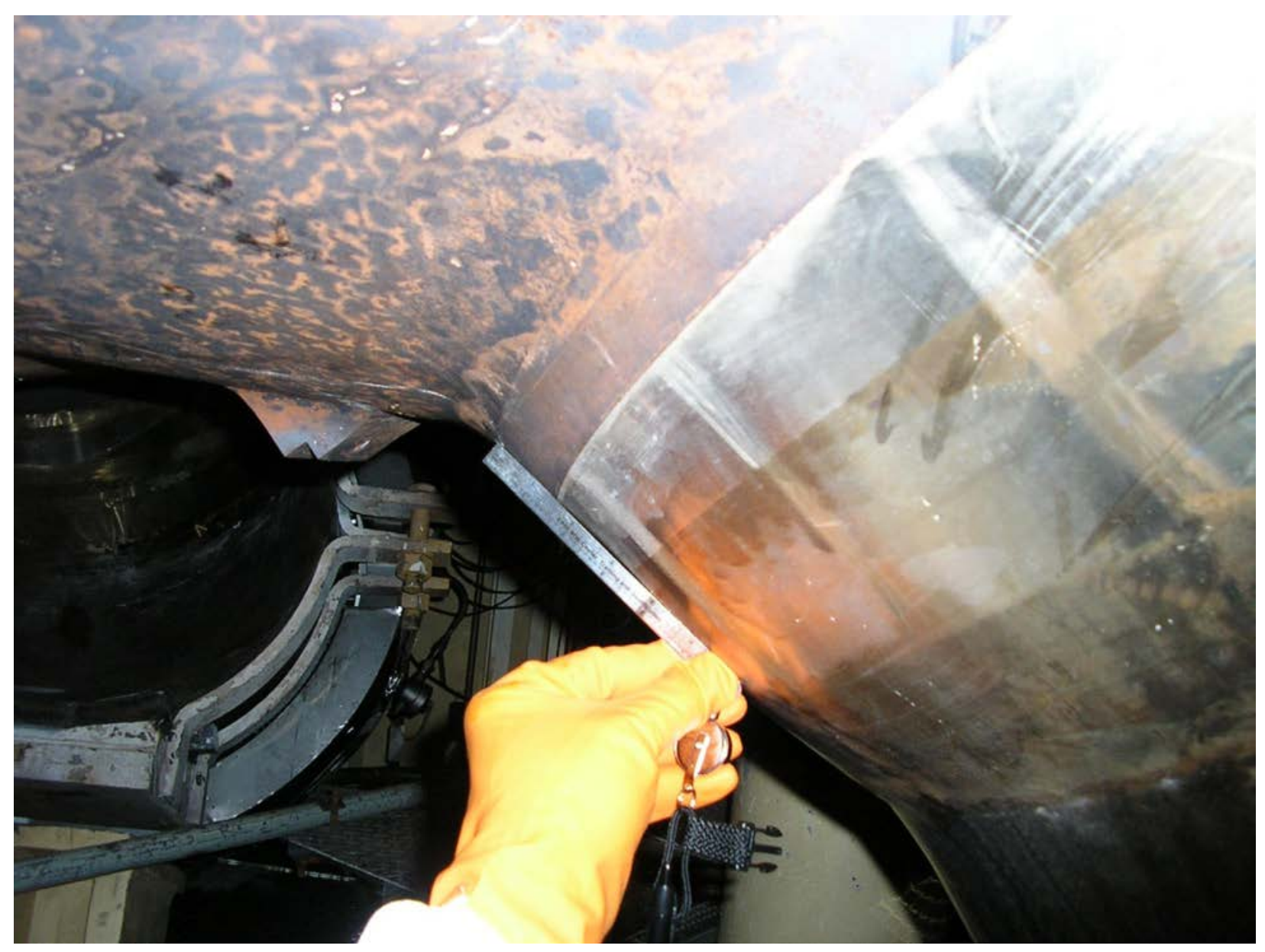

Figure C.13. Photograph of Steam Generator Hot Leg Nozzle, Nozzle Weld, and Safe End

The examination limitations for the steam generator hot leg nozzle Alloy 82/182 butt weld were minimal scanning surface and OD examination surface contour and condition.

The cross-sectional examination coverage in the axial scan direction for circumferential flaws is depicted in Figure C.14. The axial scan direction CRV coverage achievable was 95.4\%. This examination consisted, in part, of a PAUT technical justification of performance demonstration per sitespecific mock-up criteria. The cross-sectional examination coverage in the circumferential scan direction for axial flaws is depicted in Figure C.15. The axial scan direction CRV coverage achievable was 100\%. 


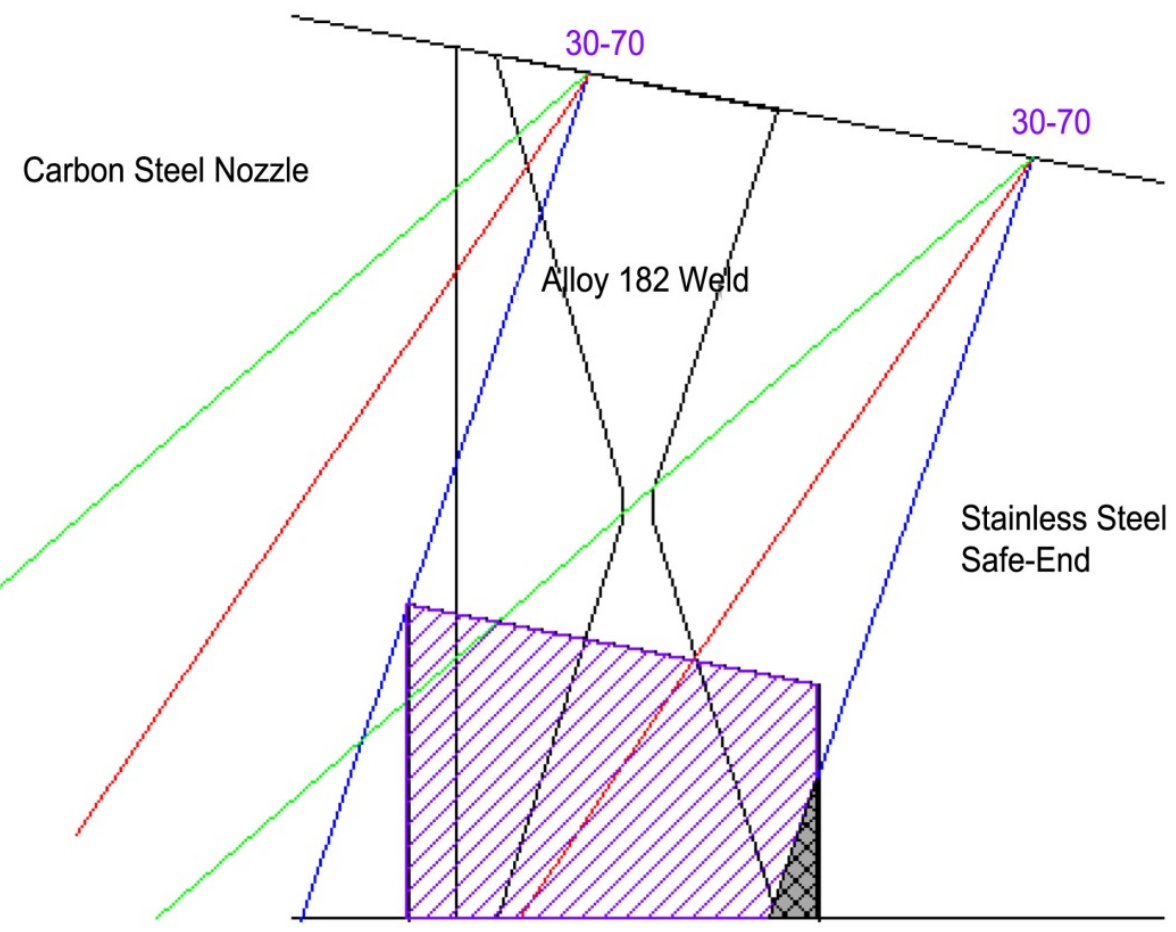

Figure C.14. Steam Generator Hot Leg Nozzle Weld Axial Scan CRV Coverage Assessment

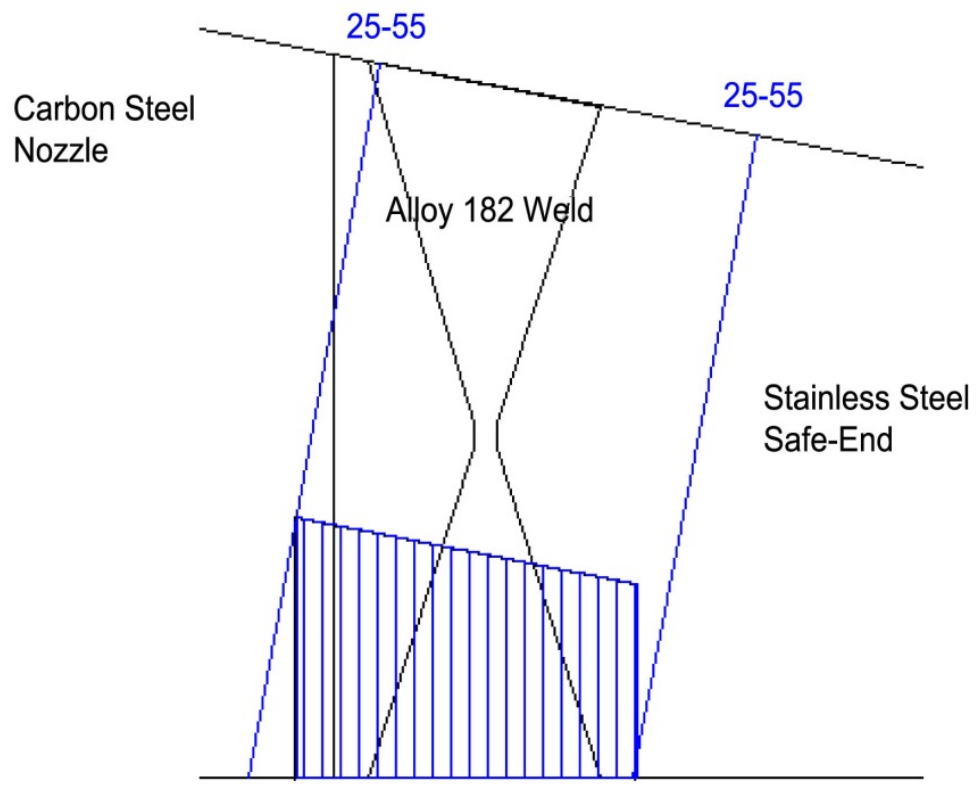

Figure C.15. Steam Generator Hot Leg Nozzle Weld Circumferential Scan CRV Coverage Assessment 


\section{C.7 Steam Generator Cold Leg Nozzle}

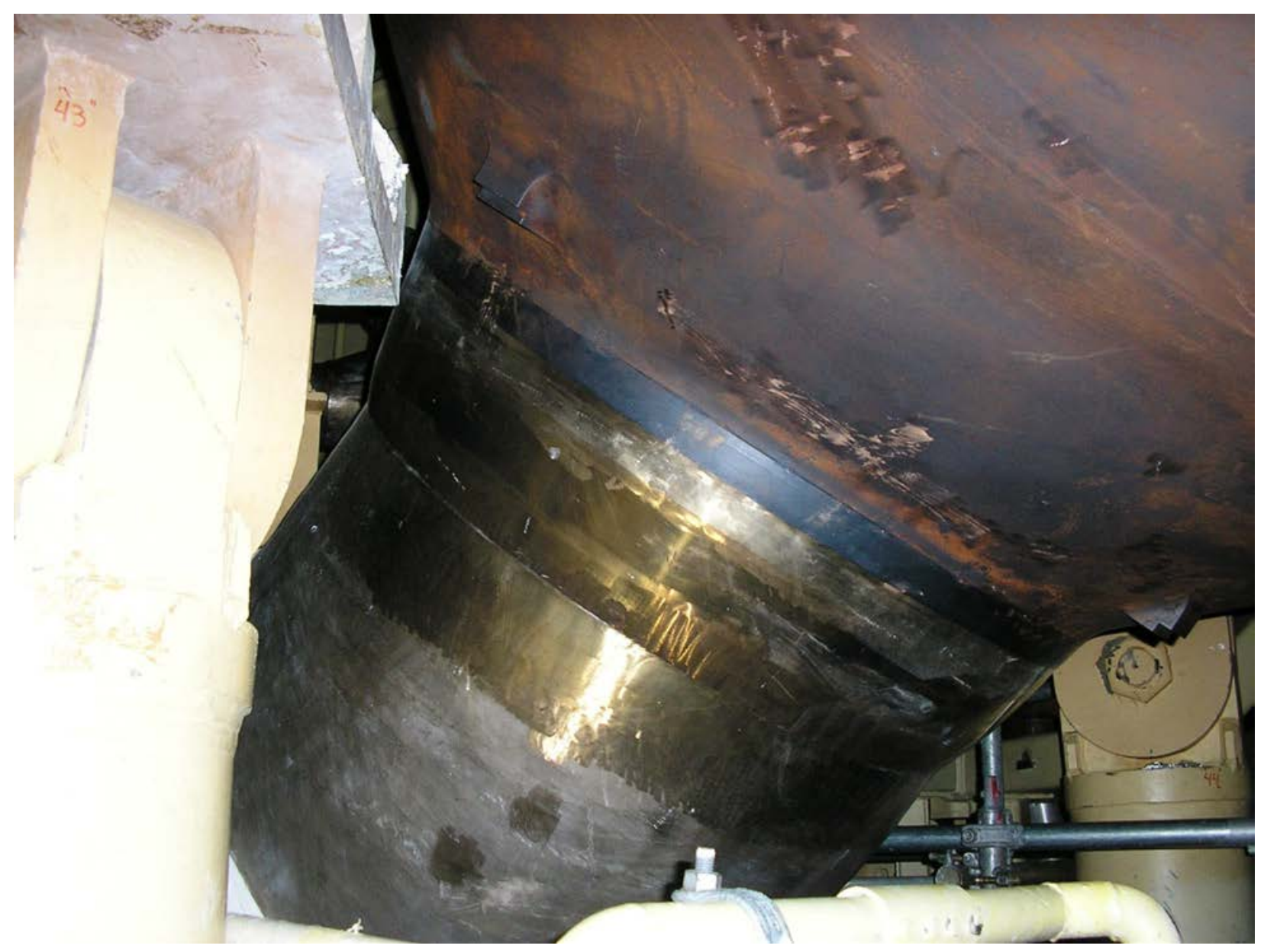

Figure C.16. Photograph of Steam Generator Cold Leg Nozzle, Nozzle Weld, and Safe End

The examination limitations for the steam generator cold leg nozzle Alloy 82/182 butt weld were minimal scanning surface and OD examination surface contour and condition.

The cross-sectional examination coverage in the axial scan direction for circumferential flaws is depicted in Figure C.17. The axial scan direction CRV coverage achievable was 95.4\%. This examination consisted, in part, of a PAUT technical justification of performance demonstration per sitespecific mock-up criteria. The cross-sectional examination coverage in the circumferential scan direction for axial flaws is depicted in Figure C.18. The axial scan direction CRV coverage achievable was 100\%. 


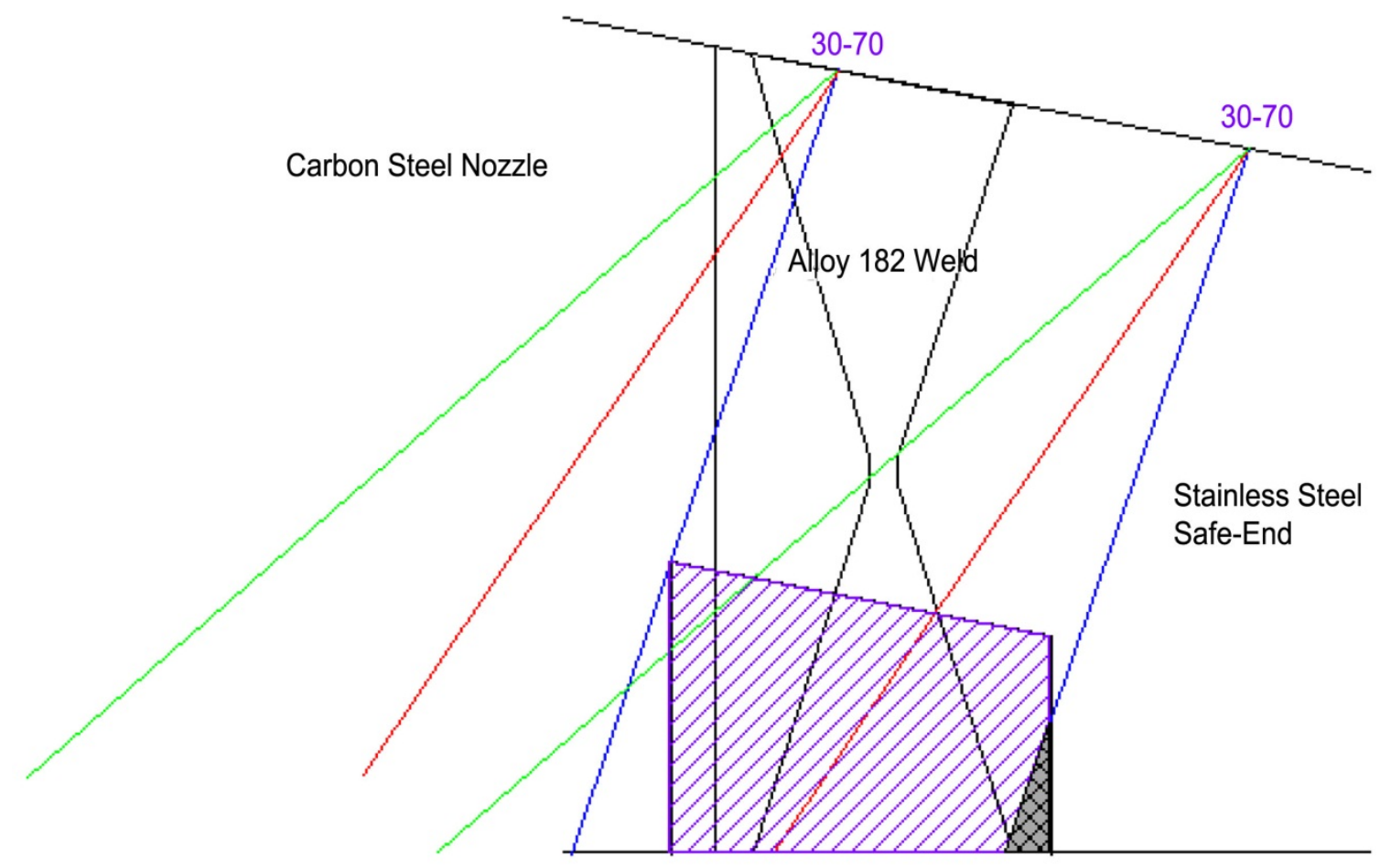

Figure C.17. Steam Generator Cold Leg Nozzle Weld Axial Scan CRV Coverage Assessment

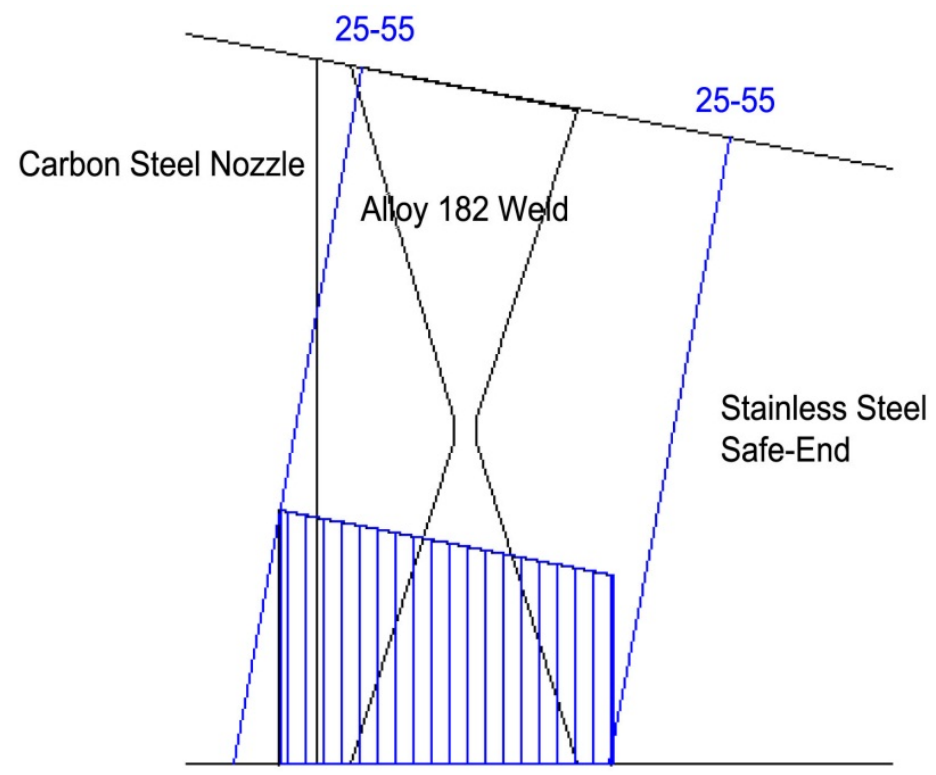

Figure C.18. Steam Generator Cold Leg Nozzle Weld Circumferential Scan CRV Coverage Assessment 


\section{C.8 RPV Cold Leg Nozzle}



Figure C.19. Photograph of RPV Cold Leg Nozzle

The examination limitations for the RPV cold leg nozzle Alloy 82/182 butt weld were minimal scanning surface and OD examination surface contour and condition.

The cross-sectional examination coverage in the axial scan direction for circumferential flaws is depicted in Figure C.20. The axial scan direction CRV coverage achievable was $100 \%$. This examination consisted, in part, of a PAUT technical justification of performance demonstration per sitespecific mock-up criteria. The cross-sectional examination coverage in the circumferential scan direction for axial flaws is depicted in Figure C.21. The axial scan direction CRV coverage achievable was 100\%. 


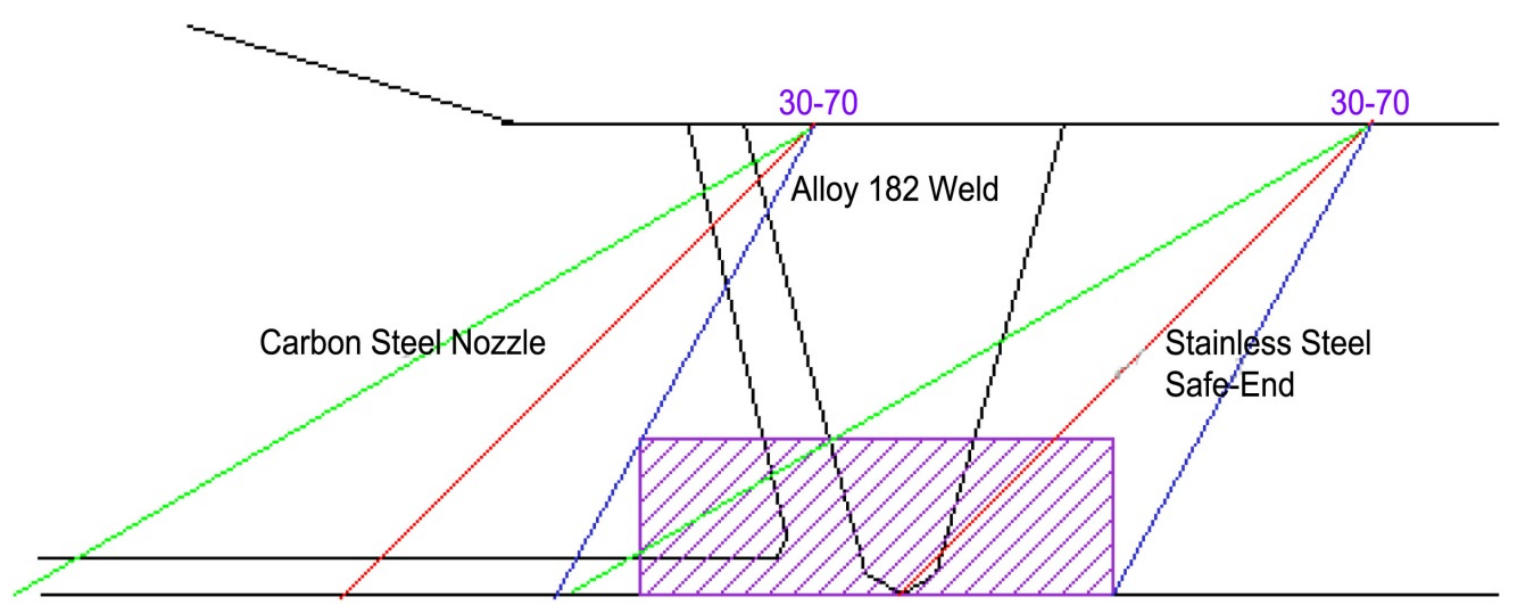

Figure C.20. RPV Cold Leg Nozzle Weld Axial Scan CRV Coverage



Figure C.21. RPV Cold Leg Nozzle Weld Circumferential Scan CRV Coverage 



\section{Appendix D}

\section{Dissimilar Metal Weld Inspection Limitations of a Typical Combustion Engineering (CE) Plant}





\section{Appendix D}

\section{Dissimilar Metal Weld Inspection Limitations of a Typical Combustion Engineering (CE) Plant}

\section{D.1 Introduction}

The information contained in this appendix was obtained during a workshop held with LMT, Inc., an inspection vendor for the commercial nuclear power industry. This vendor uses ultrasonic testing (UT) inspection methods qualified under ASME Code, Section XI, Appendix VIII, including phased-array (PA) techniques and conventional UT techniques in encoded and non-encoded delivery modes, as specified by the utility. This workshop was held to discuss the characteristics of UT data of indications attributed to stress corrosion cracking (SCC). This data was from encoded examinations of piping welds acquired from scans of the outside diameter (OD) surface. This workshop was also held to discuss limitations to achieving Code-required volume (CRV) coverage on Alloy 82/182 butt welds in a typical Westinghouse plant and a typical Combustion Engineering (CE) plant. This appendix provides information on limitations to obtaining the CRV coverage that may be encountered during examinations of Alloy 82/182 butt welds in the reactor coolant system in a CE plant.

Table D.1 provides a listing of the Alloy $82 / 182$ butt welds that are typically found in a CE plant. The location of these welds is depicted in Figure D.1. The CRV coverage for the Alloy 82/182 butt welds in the piping systems in in Table D.1 is dependent on site-specific configurations and allowable scan access thereof. Site-specific designs vary in regards to material and component configuration(s). Therefore, the coverage depicted is applicable only to the site-specific design used to prepare this document. Standard $45^{\circ}$ and $60^{\circ}$ angles were utilized for CRV coverage assessments unless specified otherwise in the illustrations. The Alloy 82/182 butt welds depicted in Sections D.2-D.13 in the sitespecific design used to prepare this document had been mitigated by weld overlays.

Table D.1. Alloy $82 / 182$ Butt Welds and Dimensions in Typical CE Plant

\begin{tabular}{lccc}
\hline \multicolumn{1}{c}{ Description } & Quantity & $\begin{array}{c}\text { Circumference } \\
\text { (Weld Centerline) }\end{array}$ & $\begin{array}{c}\text { Thickness } \\
\text { (Weld Centerline) }\end{array}$ \\
\hline RCP Suction to RC Pipe & 4 & $36.60^{\prime \prime}$ & $3.45^{\prime \prime}$ \\
RCP Discharge to RC Pipe & 4 & $36.60^{\prime \prime}$ & $3.35^{\prime \prime}$ \\
RC Loop Surge Nozzle & 1 & $42.00^{\prime \prime}$ & $1.57^{\prime \prime}$ \\
Letdown and Drain Nozzle & 4 & $3.90^{\prime \prime}$ & $0.90^{\prime \prime}$ \\
Hot Leg Drain Nozzle & 1 & $3.90^{\prime \prime}$ & $0.90^{\prime \prime}$ \\
Charging Inlet Nozzle & 2 & $18.00^{\prime \prime}$ & $1.20^{\prime \prime}$ \\
Safety Injection Nozzle & 4 & $42.00^{\prime \prime}$ & $1.55^{\prime \prime}$ \\
Shutdown Cooling Nozzle & 1 & $50.25^{\prime \prime}$ & $1.57^{\prime \prime}$ \\
Spray Nozzle & 2 & $16.00^{\prime \prime}$ & $0.93^{\prime \prime}$ \\
PZR Surge Nozzle & 1 & $41.00^{\prime \prime}$ & $1.59^{\prime \prime}$ \\
PZR Spray Nozzle & 1 & $5.20^{\prime \prime}$ & $0.83^{\prime \prime}$ \\
PZR Safety Nozzle & 3 & $7.95^{\prime \prime}$ & $1.40^{\prime \prime}$ \\
\hline RCP - reactor coolant pump; RC - reactor coolant; PZR - pressurizer & \\
\hline
\end{tabular}






Figure D.1. Typical Locations of Alloy 82/182 Butt Welds in CE Design Plants 


\section{D.2 Reactor Coolant Pump (RCP) Suction}

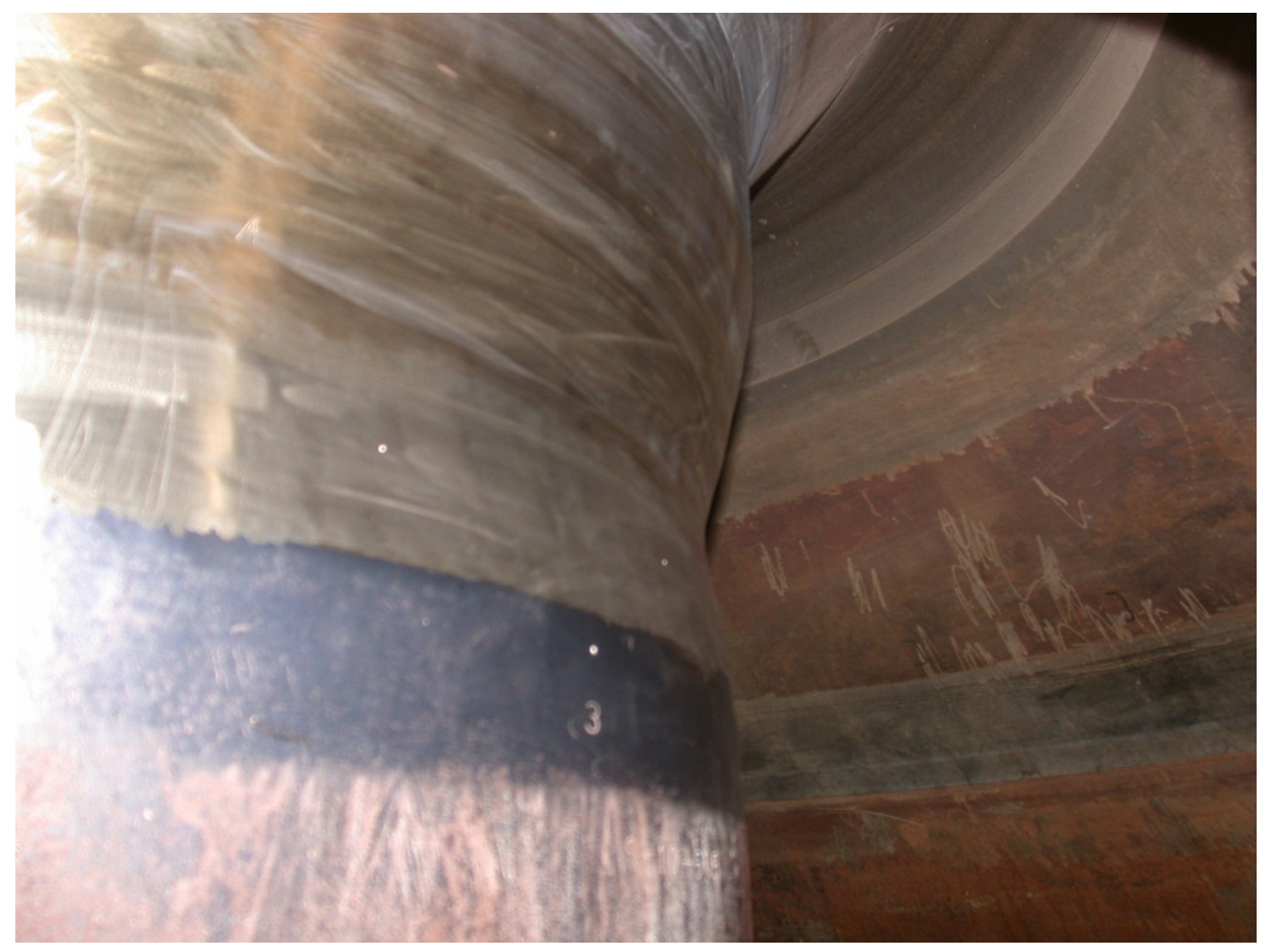

Figure D.2. Photograph of RCP Suction Nozzle, Nozzle Weld, and Safe End

The examination limitations for the RCP suction nozzle Alloy 82/182 butt weld were the CASS pump nozzle material on the downstream side of the Alloy 82/182 weld and the examination surface (OD) contour /condition.

The cross-sectional examination coverage in the axial scan direction for circumferential flaws is depicted in Figure D.3. The axial scan direction CRV coverage achievable was $100 \%$. The crosssectional examination coverage in the circumferential scan direction for axial flaws is depicted in Figure D.4. The circumferential scan direction CRV coverage achievable was $44.3 \%$. 




Figure D.3. RCP Suction Nozzle Weld Axial Scan Coverage Assessment

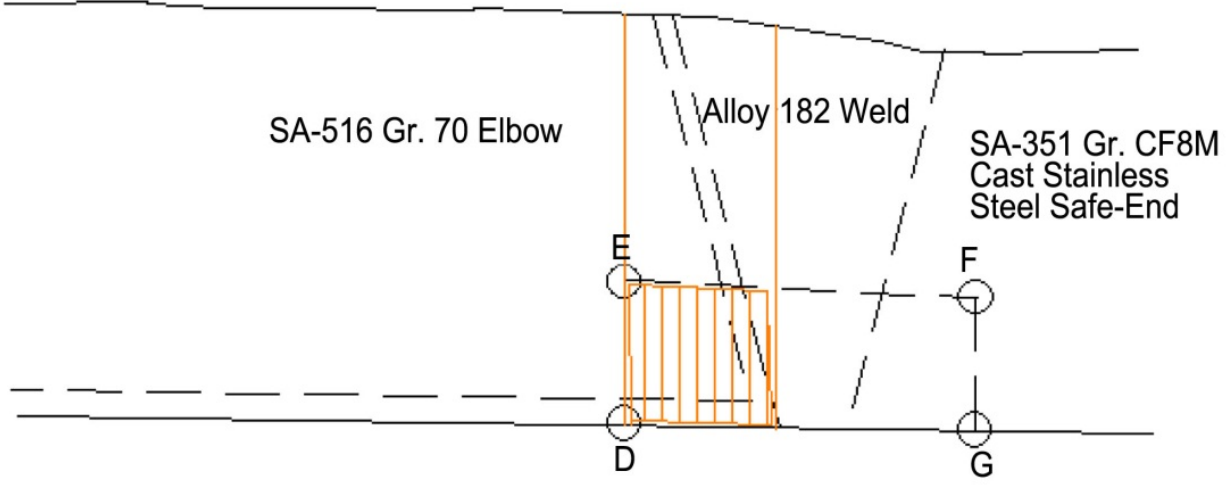

Figure D.4. RCP Suction Nozzle Weld Circumferential Scan Coverage Assessment 


\section{D.3 Reactor Coolant Pump Discharge}

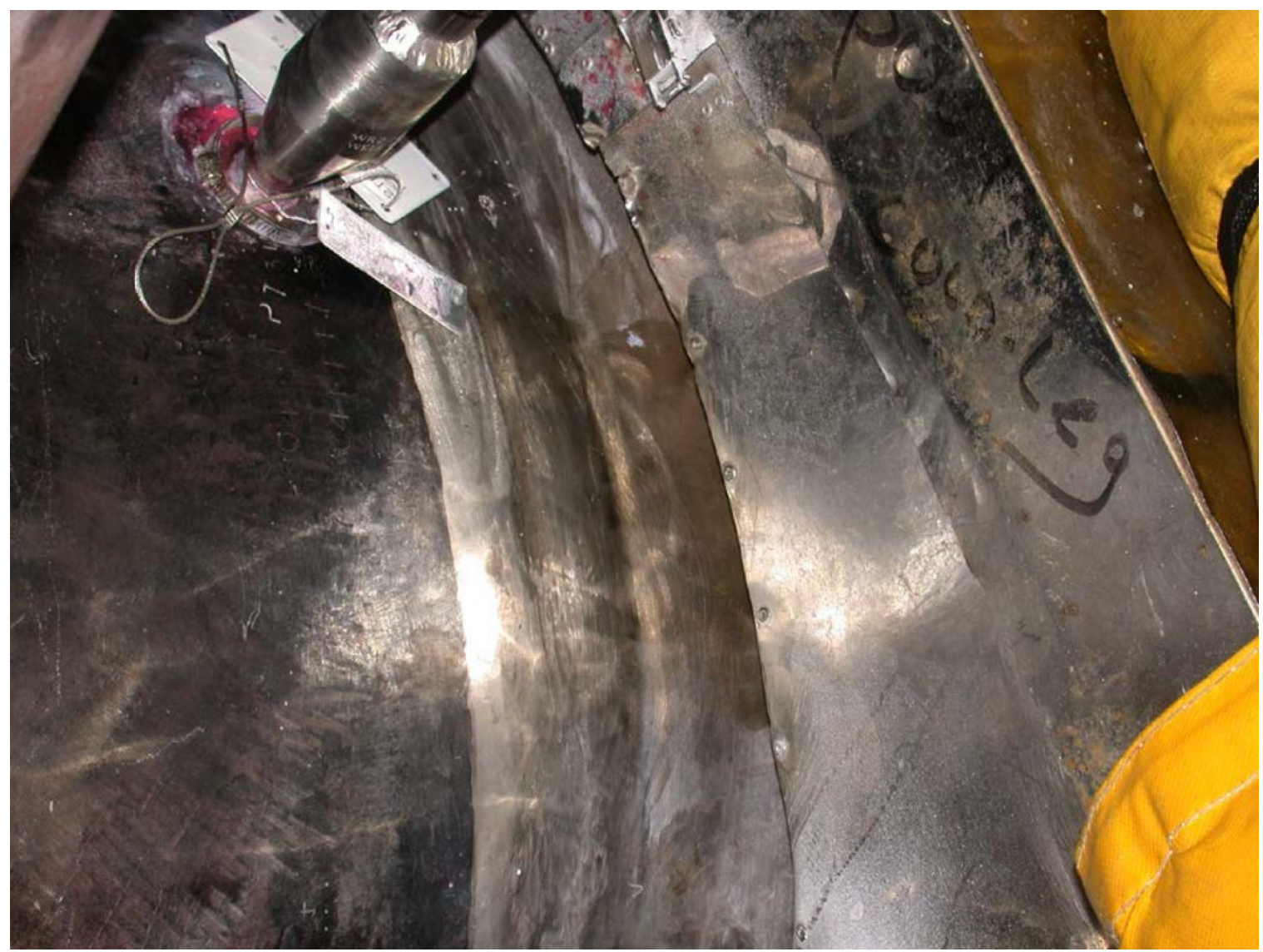

Figure D.5. Photograph of RCP Discharge Nozzle, Nozzle Weld, and Safe End

The examination limitations for the RCP discharge nozzle Alloy 82/182 butt weld were the CASS pump nozzle material on the upstream side of the Alloy 82/182 weld, the examination surface (OD) contour/condition, and instrumentation, safety injection, charging and spray nozzle connections. No coverage was obtainable in the locations where nozzle connections interfere with probe travel.

The cross-sectional examination coverage in the axial scan direction for circumferential flaws is depicted in Figure D.6. The axial scan direction CRV coverage achievable was $77 \%$. The cross-sectional examination coverage in the circumferential scan direction for axial flaws is depicted in Figure D.7. The circumferential scan direction CRV coverage achievable was $34 \%$. 


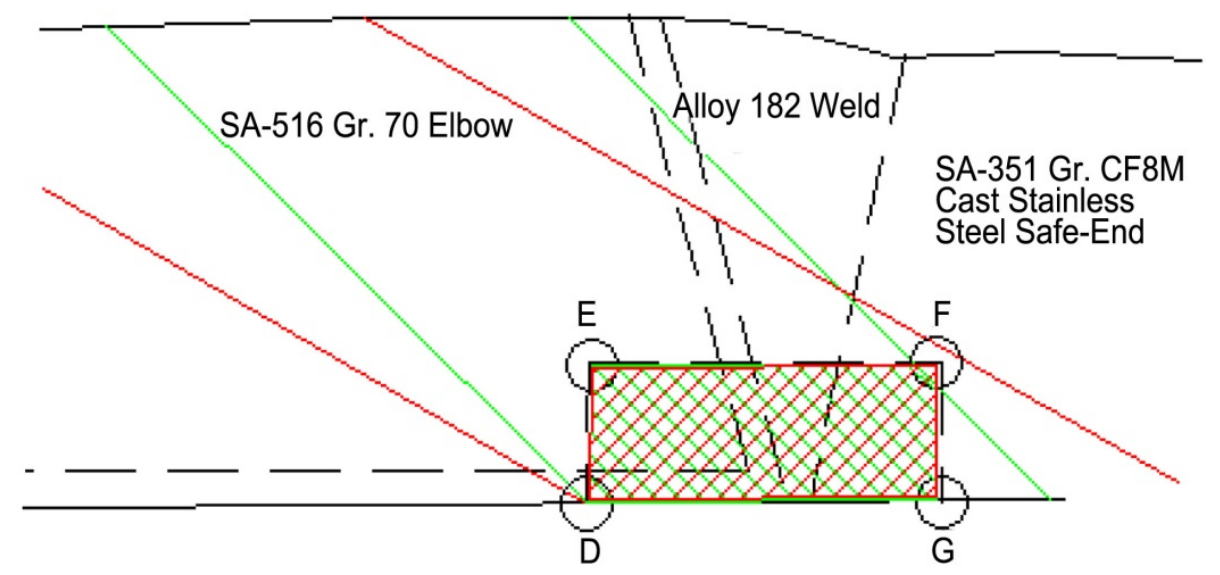

Figure D.6. RCP Discharge Nozzle Weld Axial Scan CRV Coverage Assessment

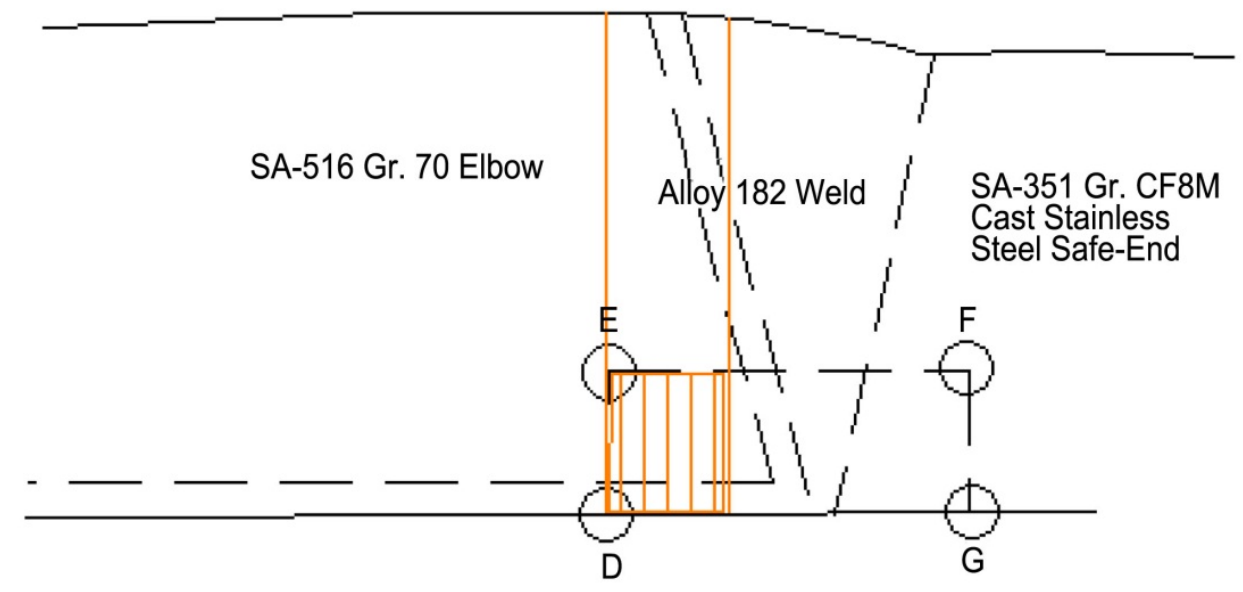

Figure D.7. RCP Discharge Nozzle Weld Circumferential Scan CRV Coverage Assessment 


\section{D.4 Reactor Coolant (RC) Loop Surge}

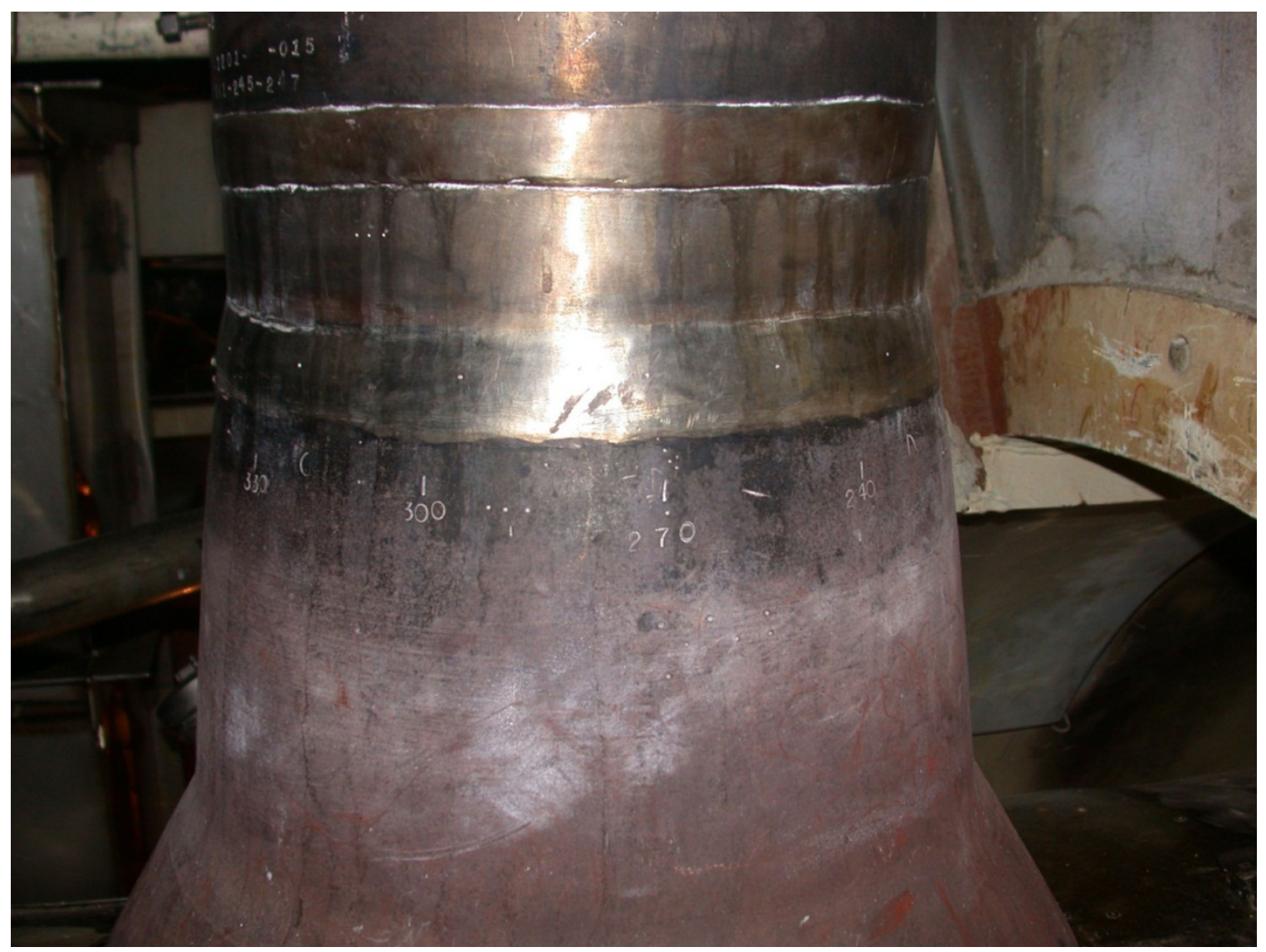

Figure D.8. Photograph of Surge Nozzle, Nozzle Weld, and Safe End

The examination limitations for the surge nozzle Alloy 82/182 butt weld were the CASS safe-end material on downstream side of the Alloy 82/182 weld and the examination surface (OD) contour/ condition.

The cross-sectional examination coverage in the axial scan direction for circumferential flaws is depicted in Figure D.9. The axial scan direction CRV coverage achievable was $82.4 \%$. The crosssectional examination coverage in the circumferential scan direction for axial flaws is depicted in Figure D.10. The circumferential scan direction CRV coverage achievable was $31.3 \%$. 


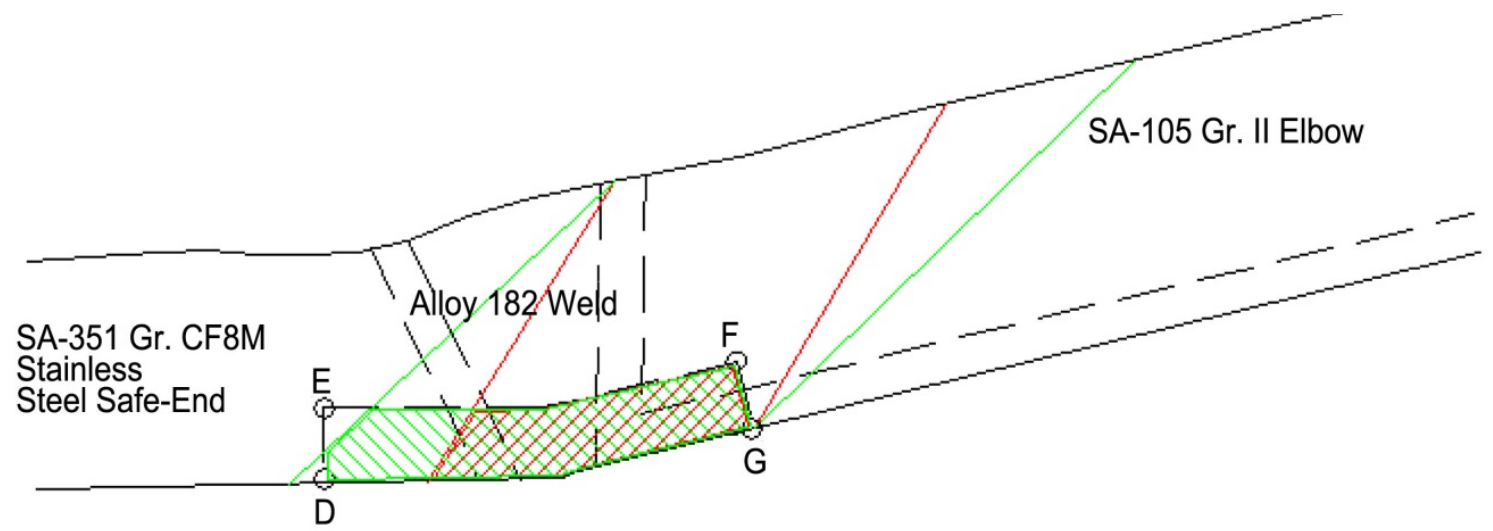

Figure D.9. Surge Nozzle Weld Axial Scan CRV Coverage Assessment

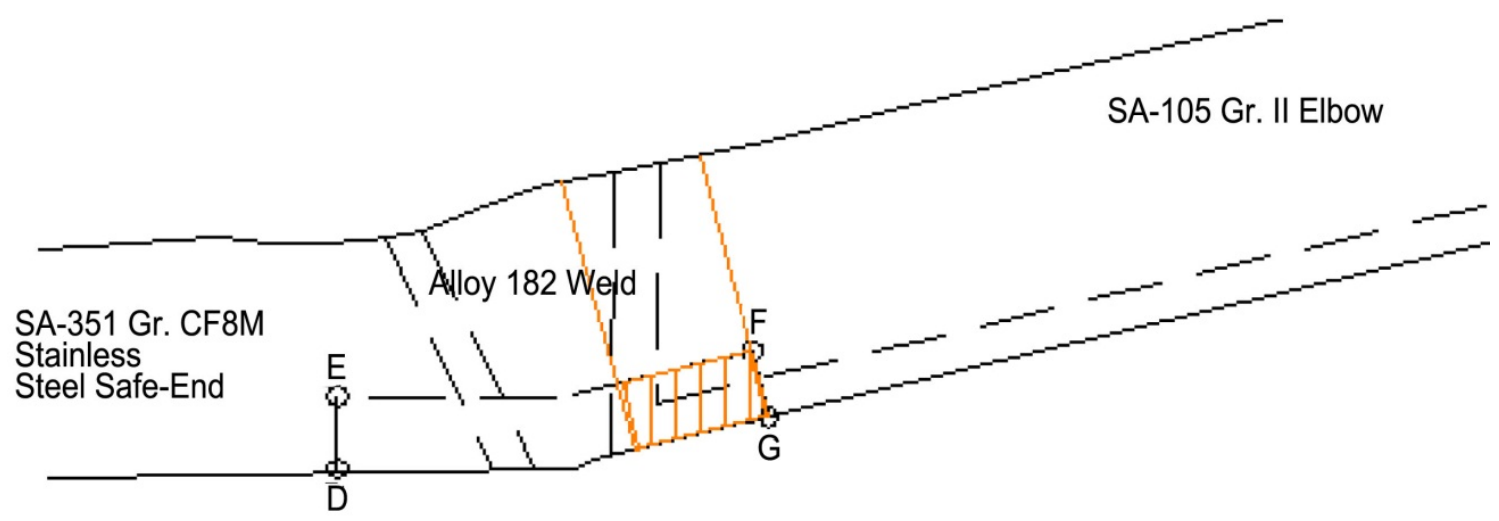

Figure D.10. Surge Nozzle Weld Circumferential Axial Scan CRV Coverage Assessment 


\section{D.5 Letdown and Drain}

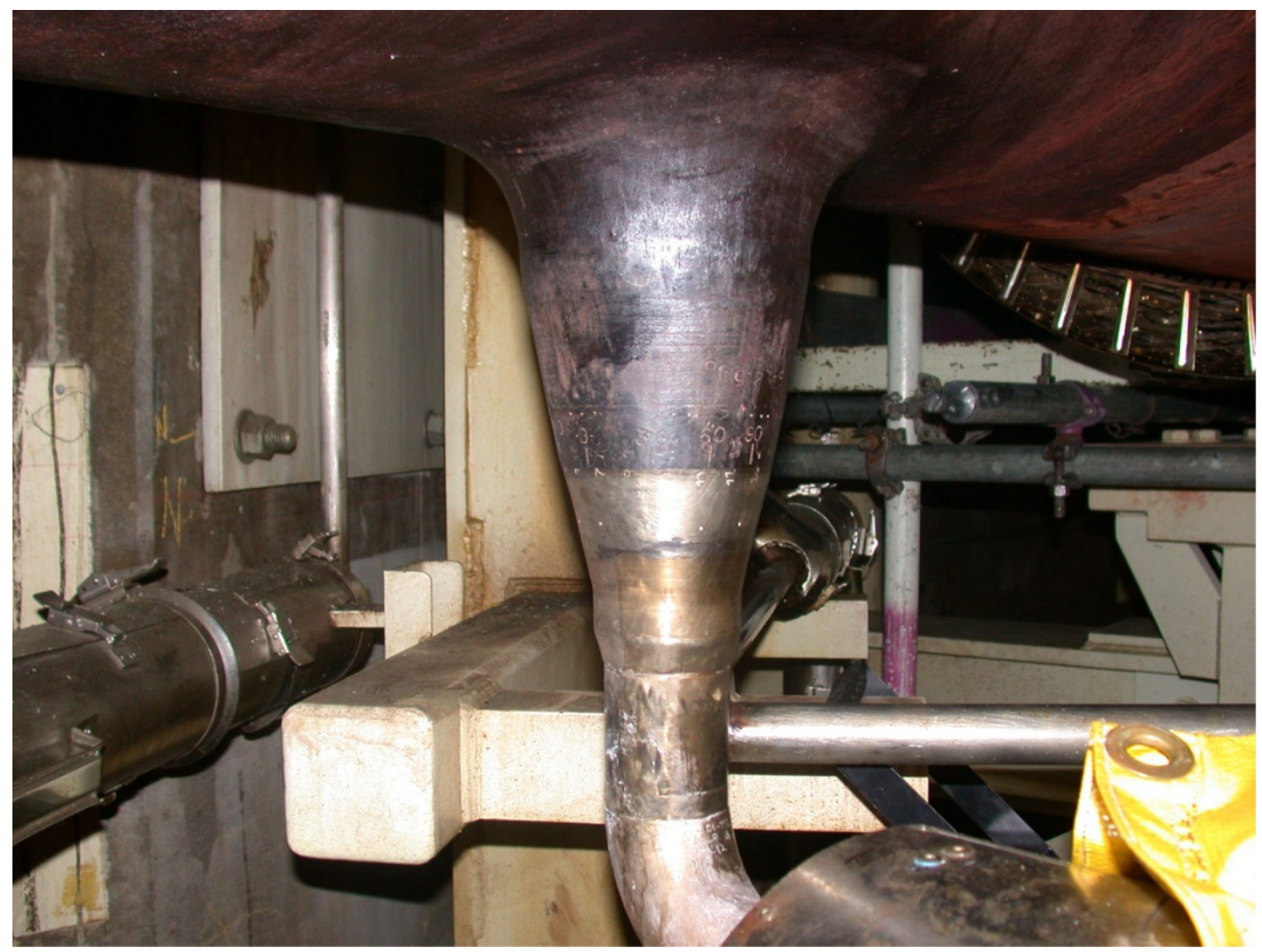

Figure D.11. Photograph of Letdown and Drain Nozzle, Nozzle Weld, and Safe End

There were no examination limitations for the letdown and drain nozzle Alloy 82/182 butt weld.

The cross-sectional examination coverage in the axial scan direction for circumferential flaws is depicted in Figure D.12. The axial scan direction CRV coverage achievable was 100\%. The crosssectional examination coverage in the circumferential scan direction for axial flaws is depicted in Figure D.13. The circumferential scan direction CRV coverage achievable was $100 \%$. 

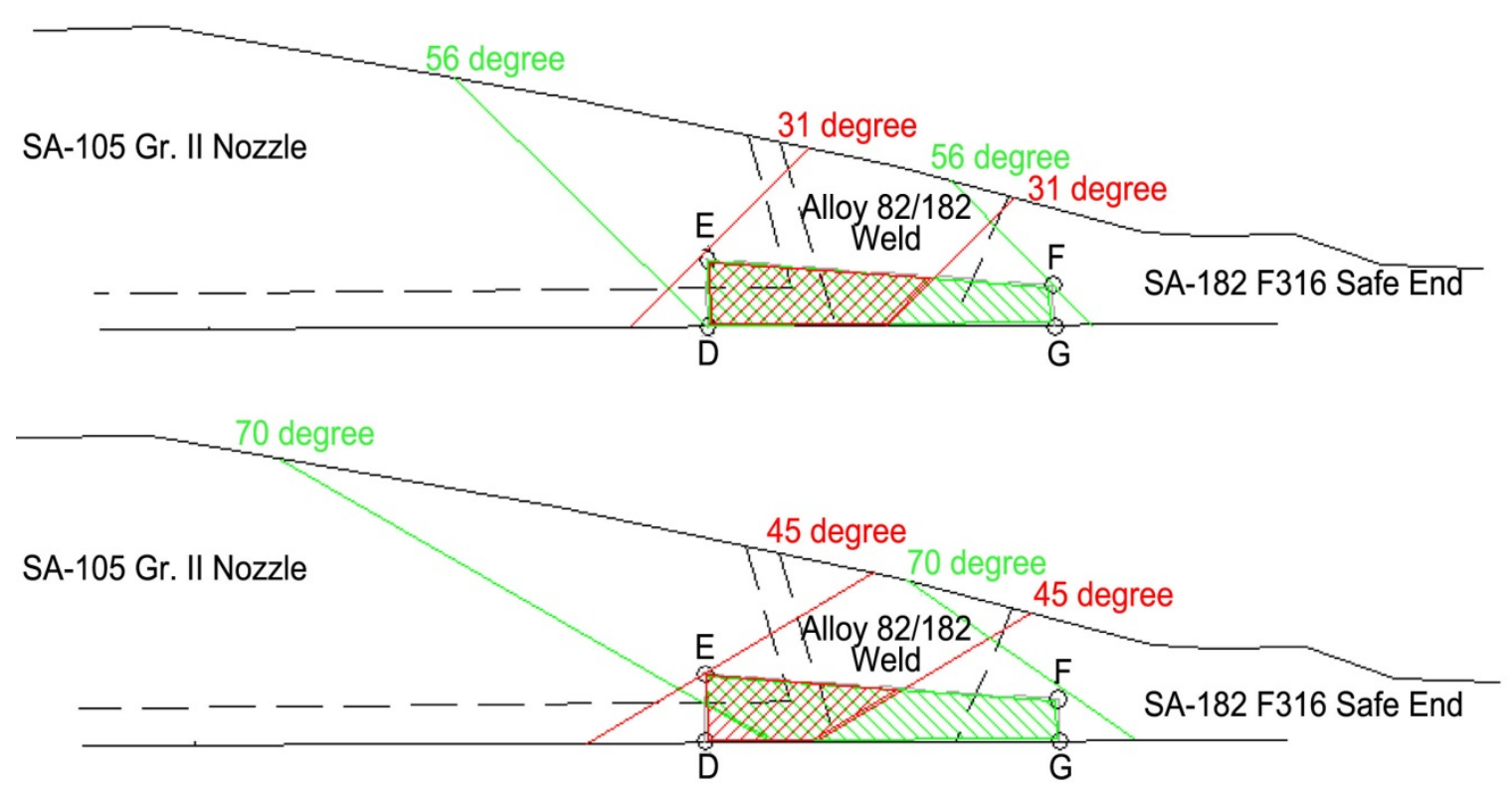

Figure D.12. Letdown and Drain Nozzle Weld Axial Scan CRV Coverage Assessment



Figure D.13. Letdown and Drain Nozzle Weld Circumferential Scan CRV Coverage Assessment 


\section{D.6 Hot Leg Drain}

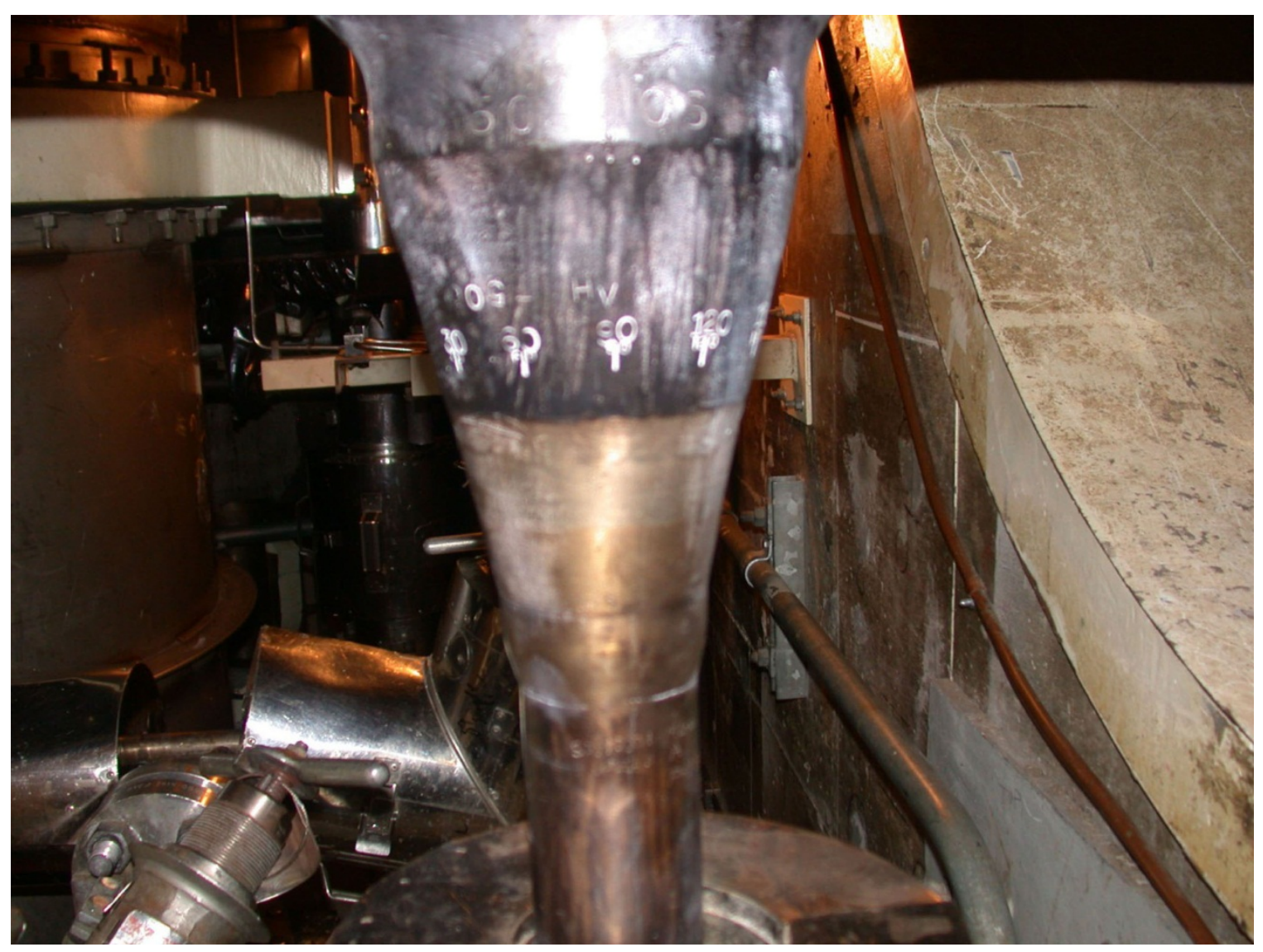

Figure D.14. Photograph of Hot Leg Drain Nozzle, Nozzle Weld, and Safe End

There were no examination limitations for the hot leg drain nozzle Alloy 82/182 butt weld.

The cross-sectional examination coverage in the axial scan direction for circumferential flaws is depicted in Figure D.15. The axial scan direction CRV coverage achievable was $100 \%$. The crosssectional examination coverage in the circumferential scan direction for axial flaws is depicted in Figure D.16. The circumferential scan direction CRV coverage achievable was $100 \%$. 



Figure D.15. Hot Leg Drain Nozzle Weld Axial Scan CRV Coverage Assessment



Figure D.16. Hot Leg Drain Nozzle Weld Circumferential Scan CRV Coverage Assessment 


\section{D.7 Charging Inlet}

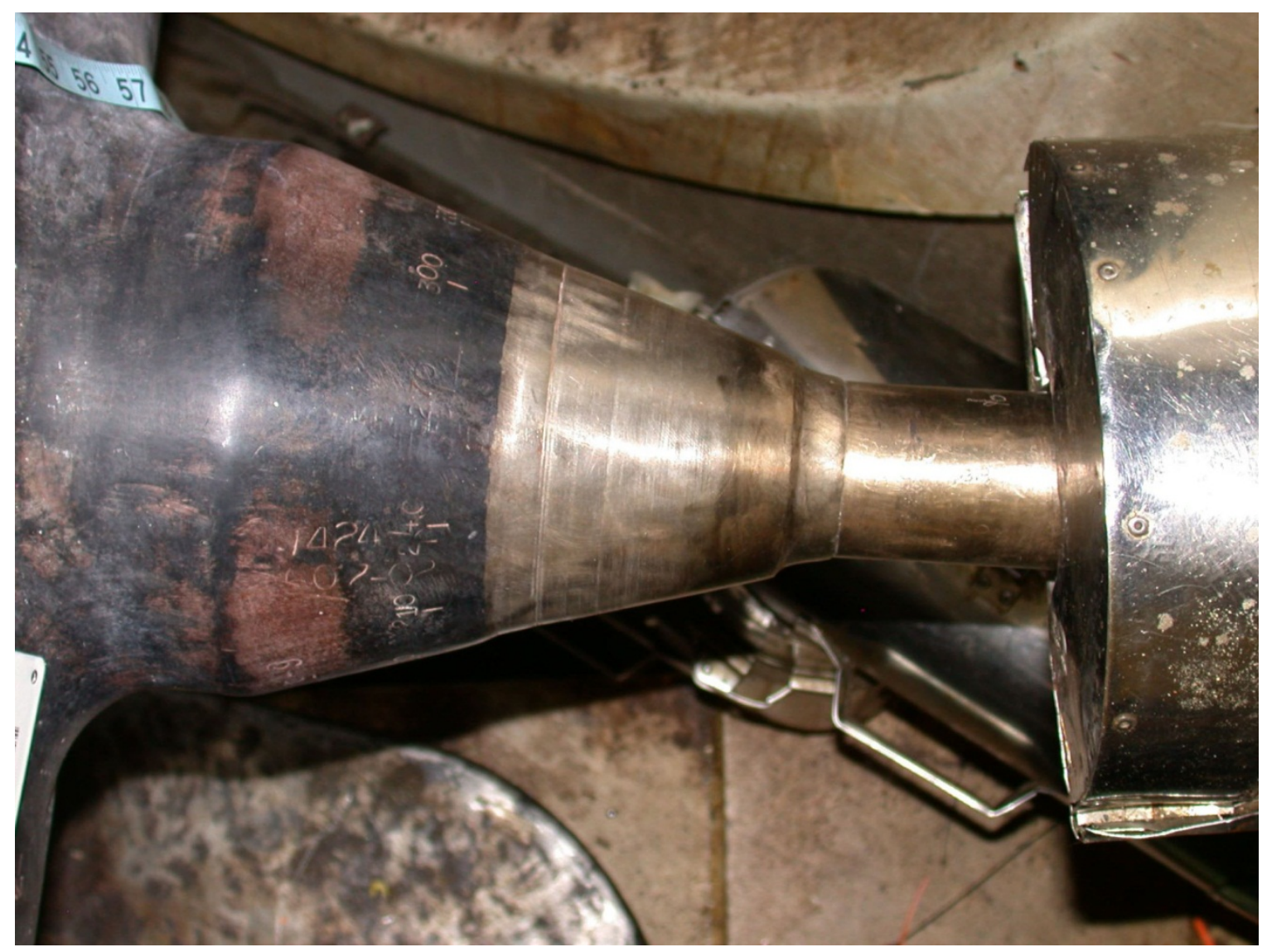

Figure D.17. Photograph of Charging Inlet Nozzle, Nozzle Weld, and Safe End

There were no examination limitations for the charging inlet nozzle Alloy 82/182 butt weld.

The cross-sectional examination coverage in the axial scan direction for circumferential flaws is depicted in Figure D.18. The axial scan direction CRV coverage achievable was $100 \%$. The crosssectional examination coverage in the circumferential scan direction for axial flaws is depicted in Figure D.19. The circumferential scan direction CRV coverage achievable was $100 \%$. 

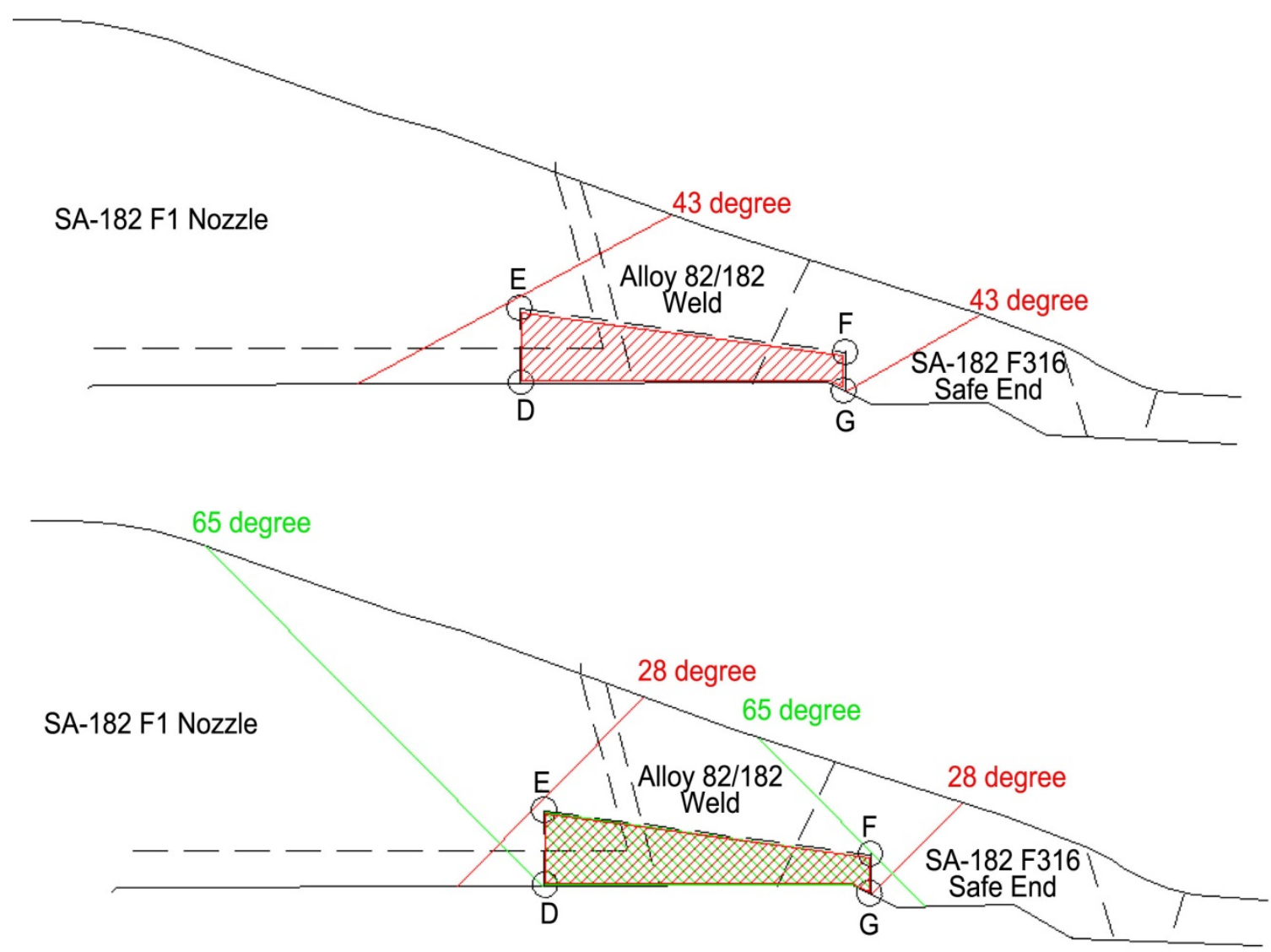

Figure D.18. Charging Inlet Nozzle Weld Axial Scan CRV Coverage Assessment

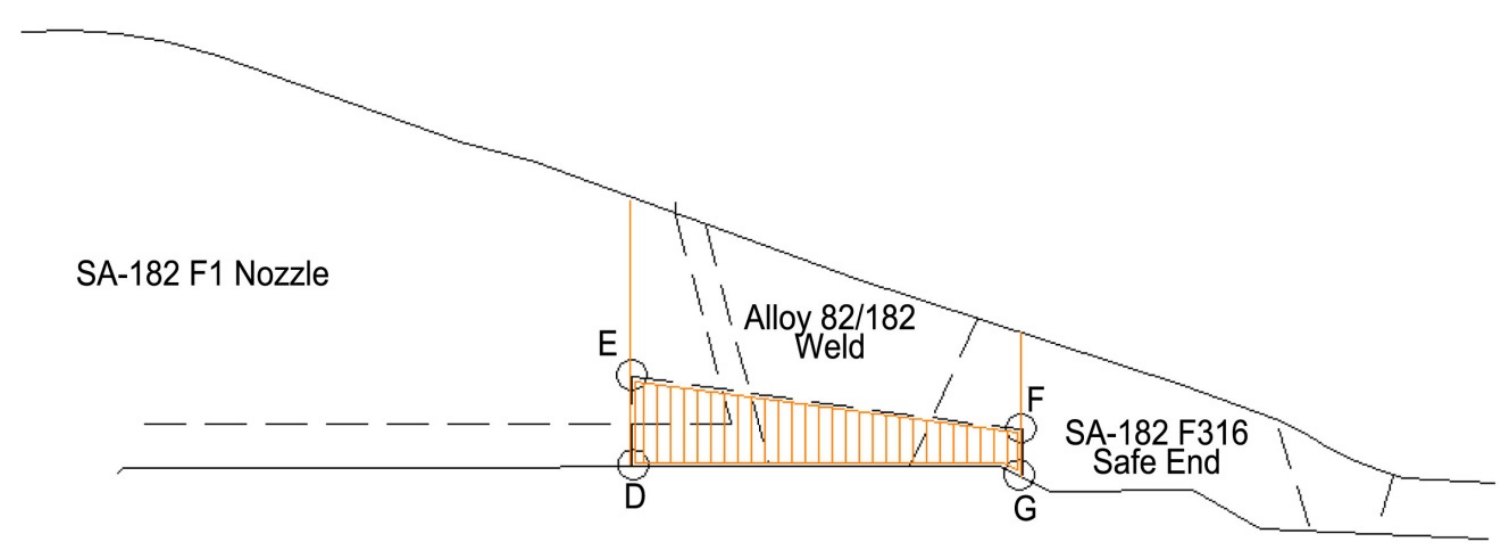

Figure D.19. Charging Inlet Nozzle Weld Circumferential Scan CRV Coverage Assessment 


\section{D.8 Safety Injection}

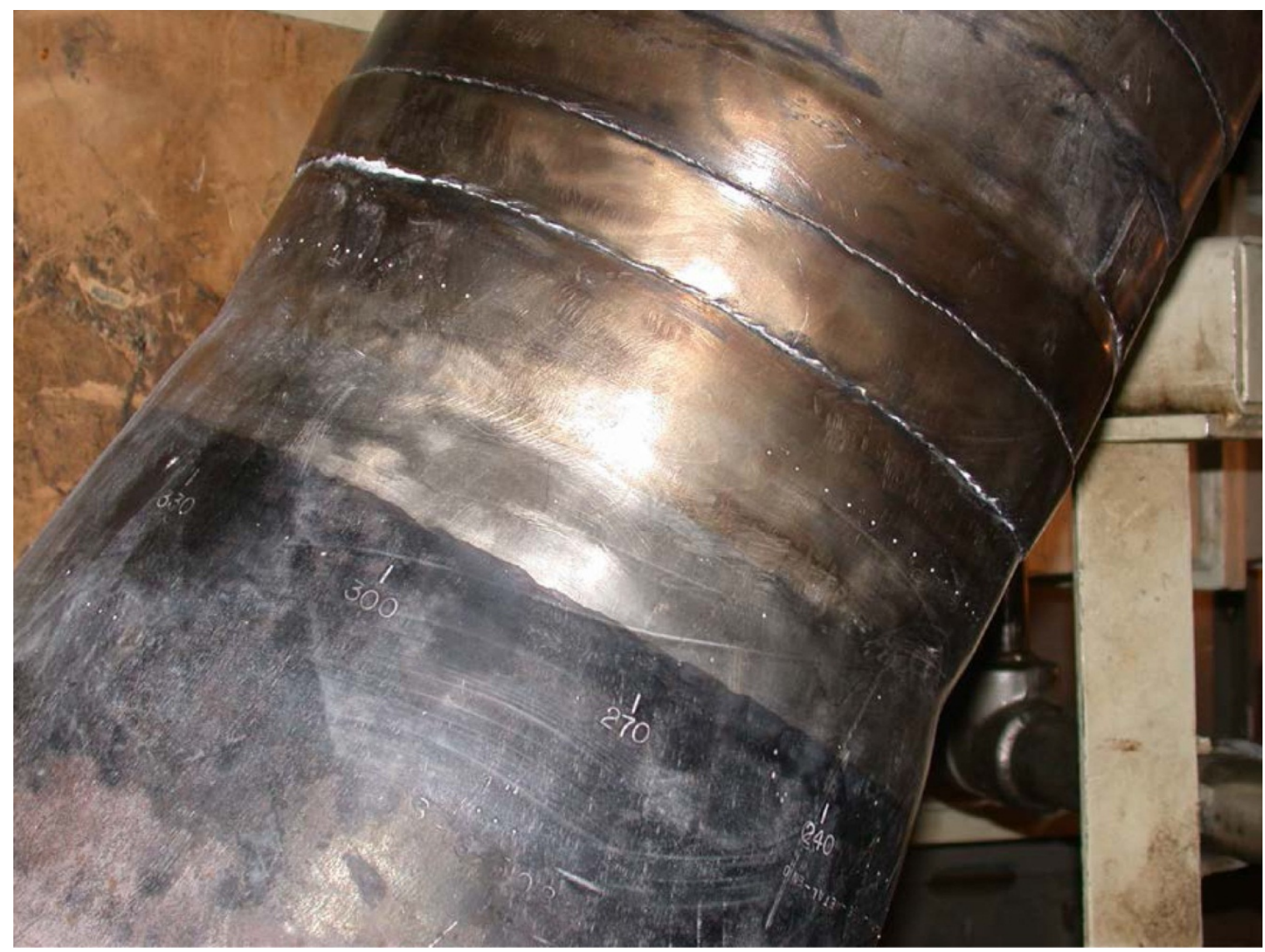

Figure D.20. Photograph of Safety Injection Nozzle, Nozzle Weld, and Safe End

The examination limitations for the safety injection nozzle Alloy 82/182 butt weld were the CASS safe-end material on upstream side of the Alloy 82/182 weld and the examination surface (OD) contour/ condition.

The cross-sectional examination coverage in the axial scan direction for circumferential flaws is depicted in Figure D.21. The axial scan direction CRV coverage achievable was $94.3 \%$. The crosssectional examination coverage in the circumferential scan direction for axial flaws is depicted in Figure D.22. The circumferential scan direction CRV coverage achievable was $26.6 \%$. 


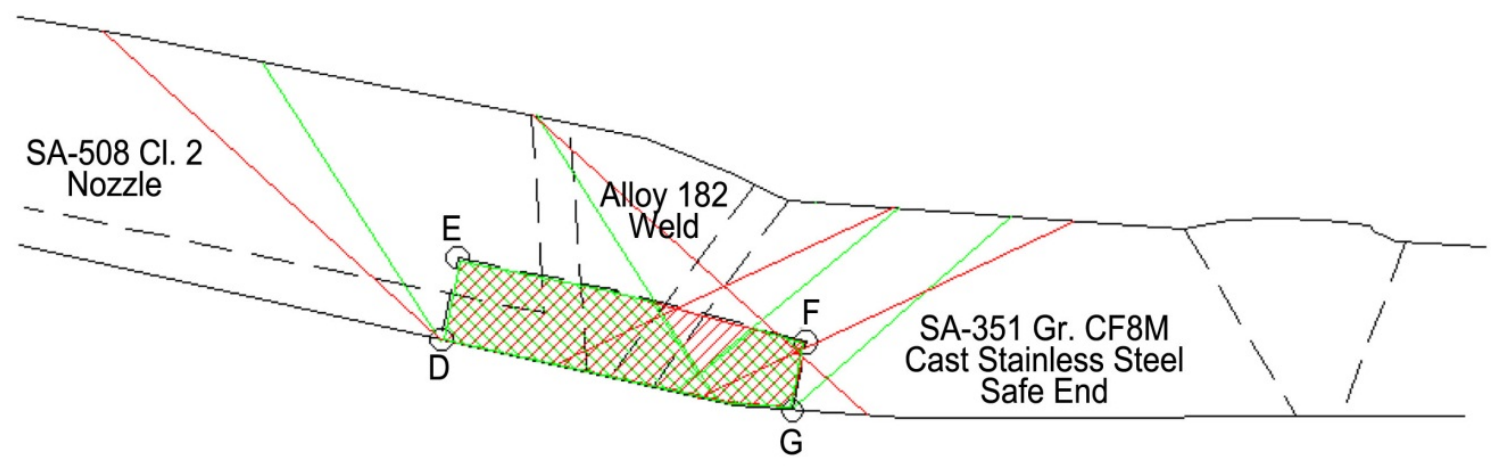

Figure D.21. Safety Injection Nozzle Weld Axial Scan CRV Coverage Assessment



Figure D.22. Safety Injection Nozzle Weld Circumferential Scan CRV Coverage Assessment 


\section{D.9 Shutdown Cooling}

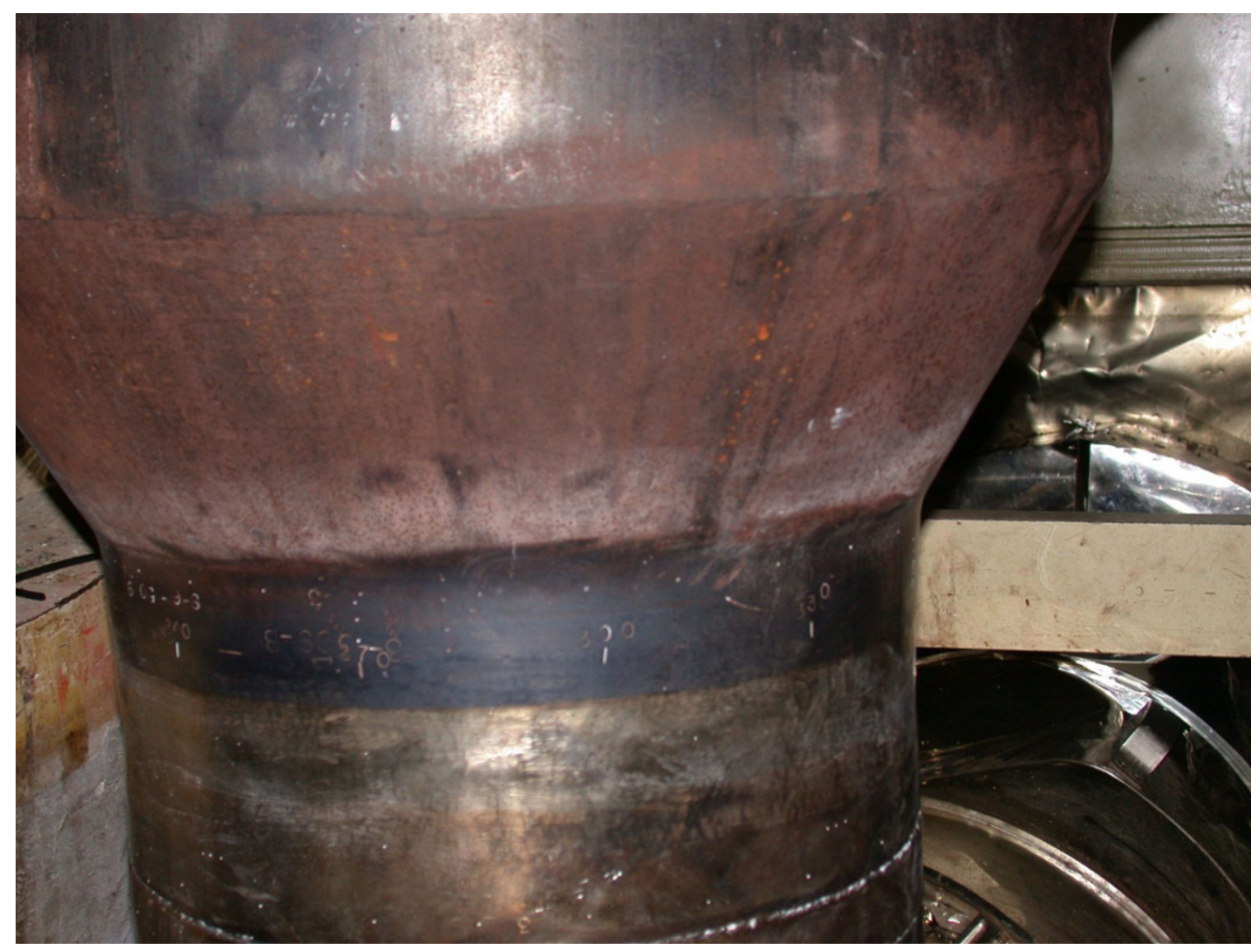

Figure D.23. Photograph of Shutdown Cooling Nozzle, Nozzle Weld, and Safe End

The examination limitations for the shutdown cooling nozzle Alloy 82/182 butt weld were the CASS safe-end material on the downstream side of the Alloy 82/182 weld and the examination surface (OD) contour/condition.

The cross-sectional examination coverage in the axial scan direction for circumferential flaws is depicted in Figure D.24. The axial scan direction CRV coverage achievable was 98\%. The crosssectional examination coverage in the circumferential scan direction for axial flaws is depicted in Figure D.25. The circumferential scan direction CRV coverage achievable was $100 \%$. 


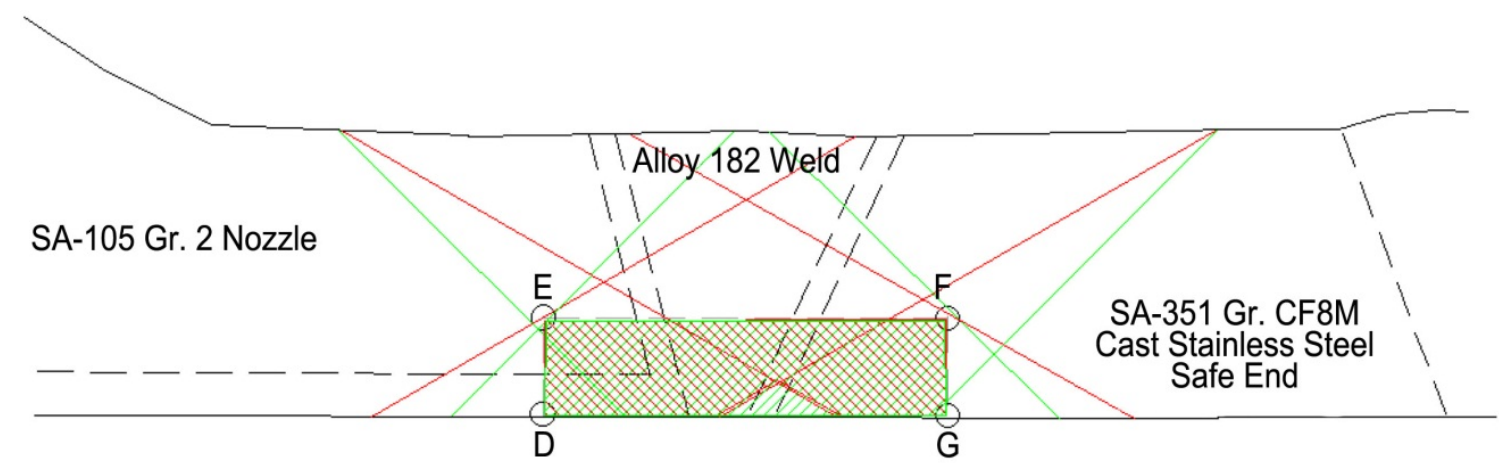

Figure D.24. Shutdown Cooling Nozzle Weld Axial Scan CRV Coverage Assessment

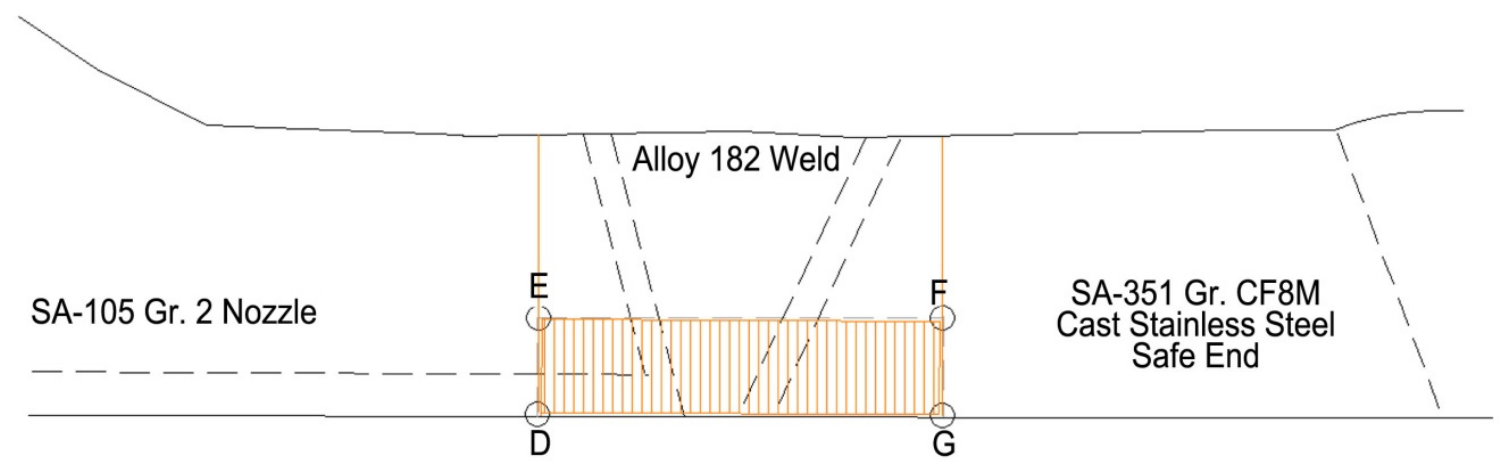

Figure D.25. Shutdown Cooling Nozzle Weld Circumferential Scan CRV Coverage Assessment 


\section{D.10 Spray}

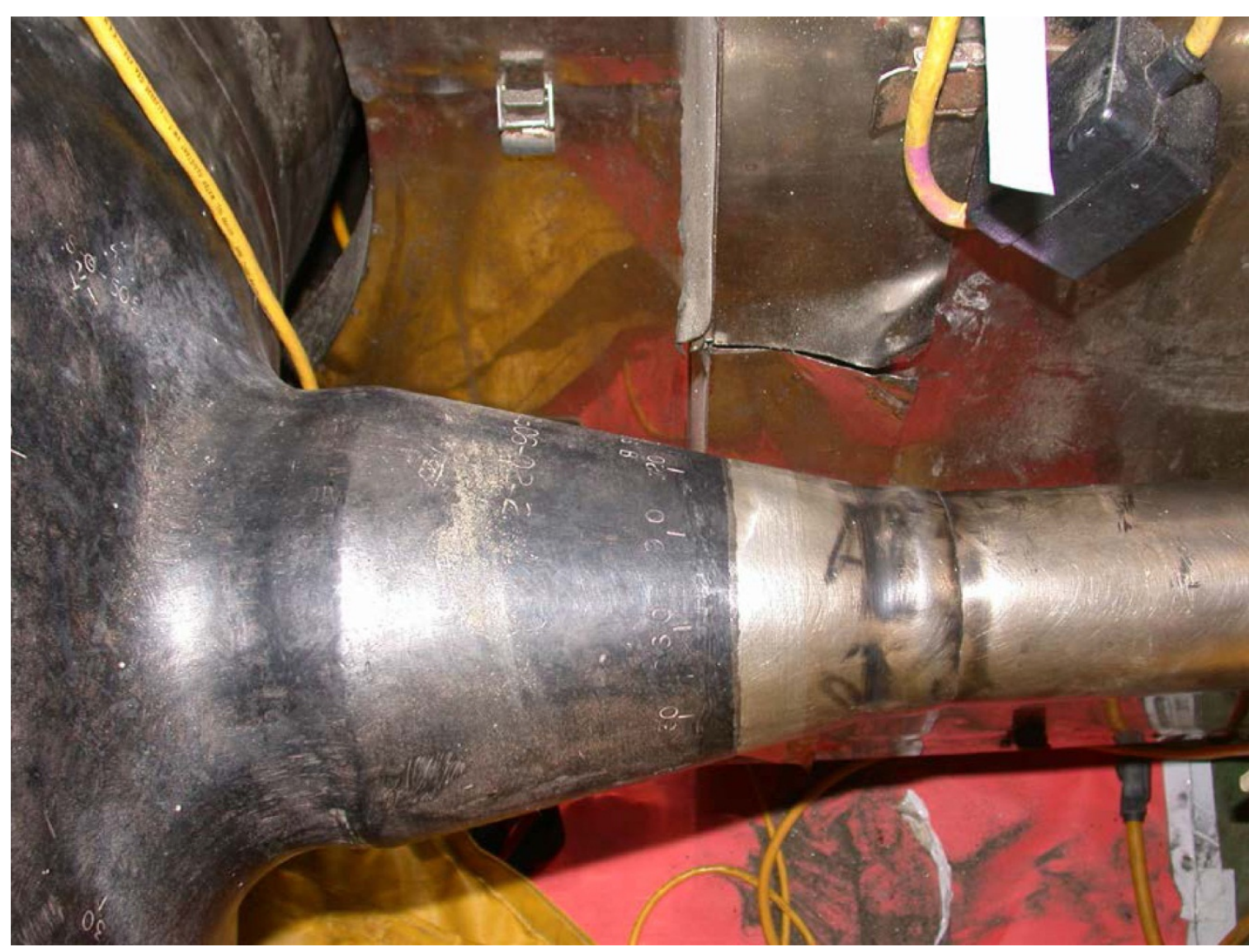

Figure D.26. Photograph of Spray Nozzle, Nozzle Weld, and Safe End

There were no examination limitations for the spray nozzle Alloy 82/182 butt.

The cross-sectional examination coverage in the axial scan direction for circumferential flaws is depicted in Figure D.27. The axial scan direction CRV coverage achievable was $100 \%$. The crosssectional examination coverage in the circumferential scan direction for axial flaws is depicted in Figure D.28. The circumferential scan direction CRV coverage achievable was 100\%. 


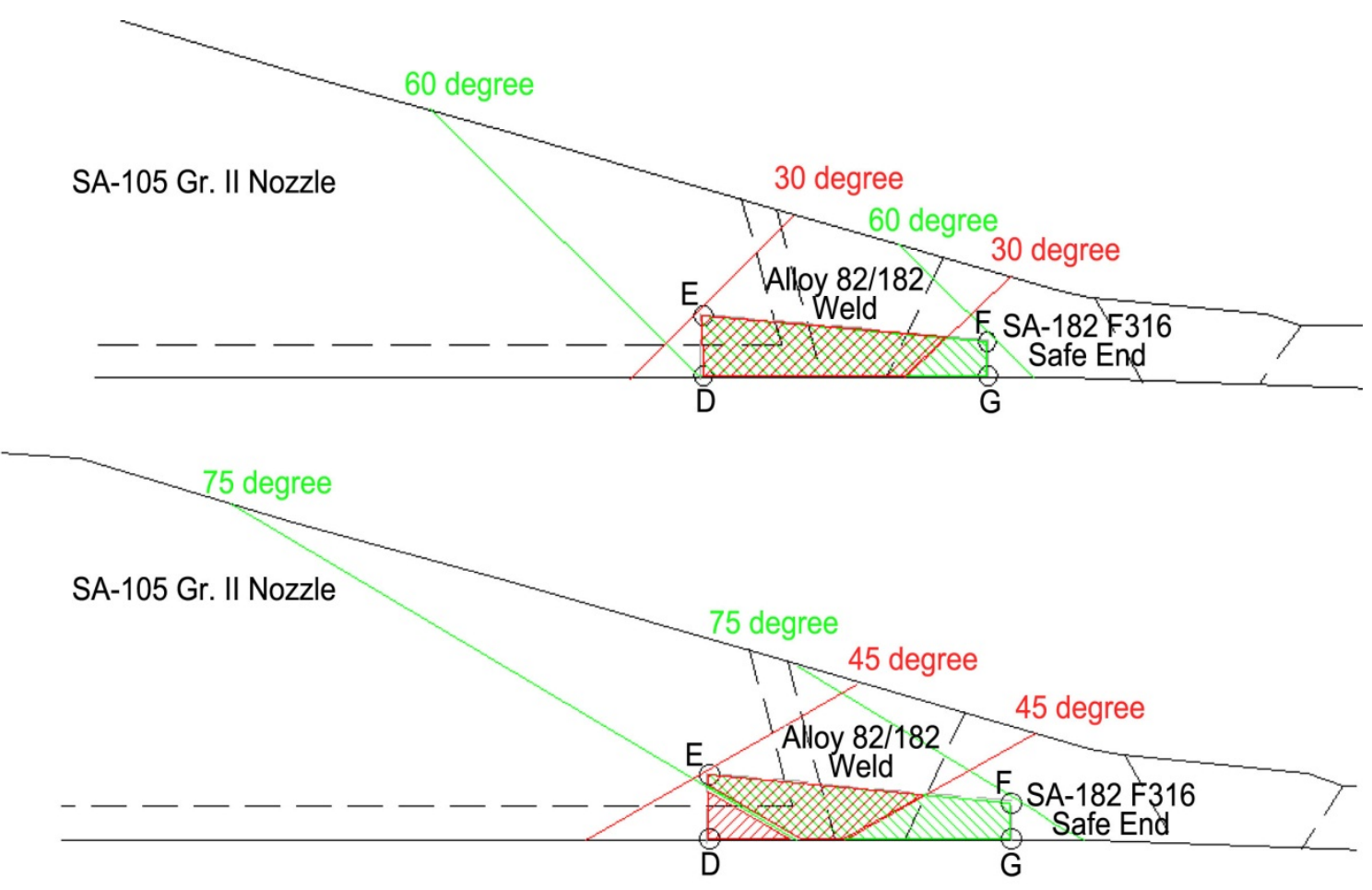

Figure D.27. Spray Nozzle Weld Axial Scan CRV Coverage Assessment

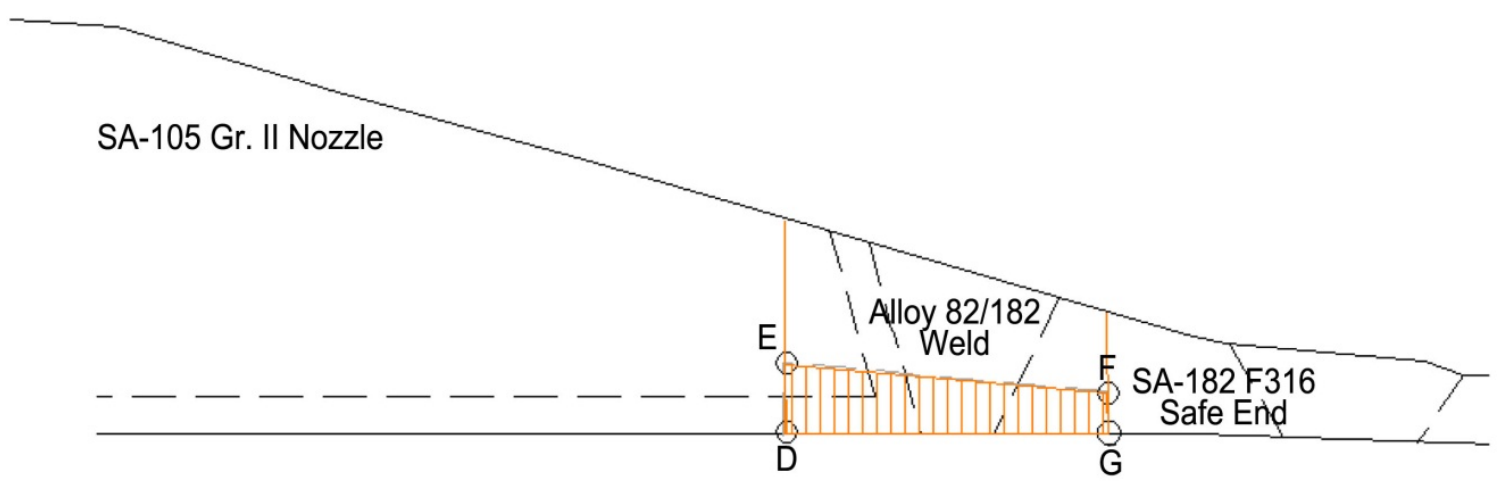

Figure D.28. Spray Nozzle Weld Circumferential Scan CRV Coverage Assessment 


\section{D.11 Pressurizer Surge}

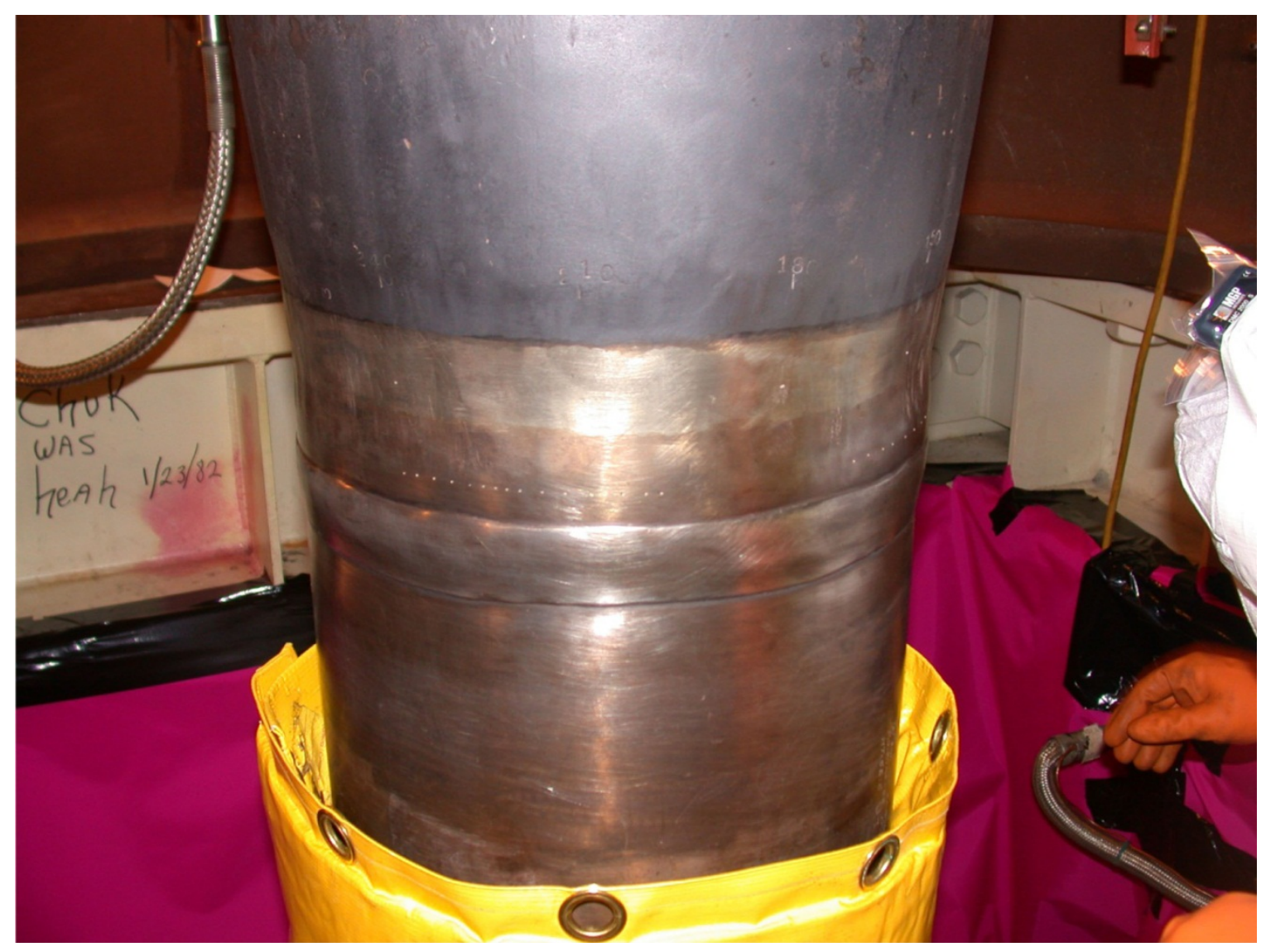

Figure D.29. Photograph of Pressurizer Surge Nozzle, Nozzle Weld, and Safe End

There were no examination limitations for the pressurizer surge nozzle Alloy 82/182 butt weld.

The cross-sectional examination coverage in the axial scan direction for circumferential flaws is depicted in Figure D.30. The axial scan direction CRV coverage achievable was $100 \%$. The crosssectional examination coverage in the circumferential scan direction for axial flaws is depicted in Figure D.31. The circumferential scan direction CRV coverage achievable was $100 \%$. 




Figure D.30. Pressurizer Surge Nozzle Weld Axial Scan CRV Coverage Assessment

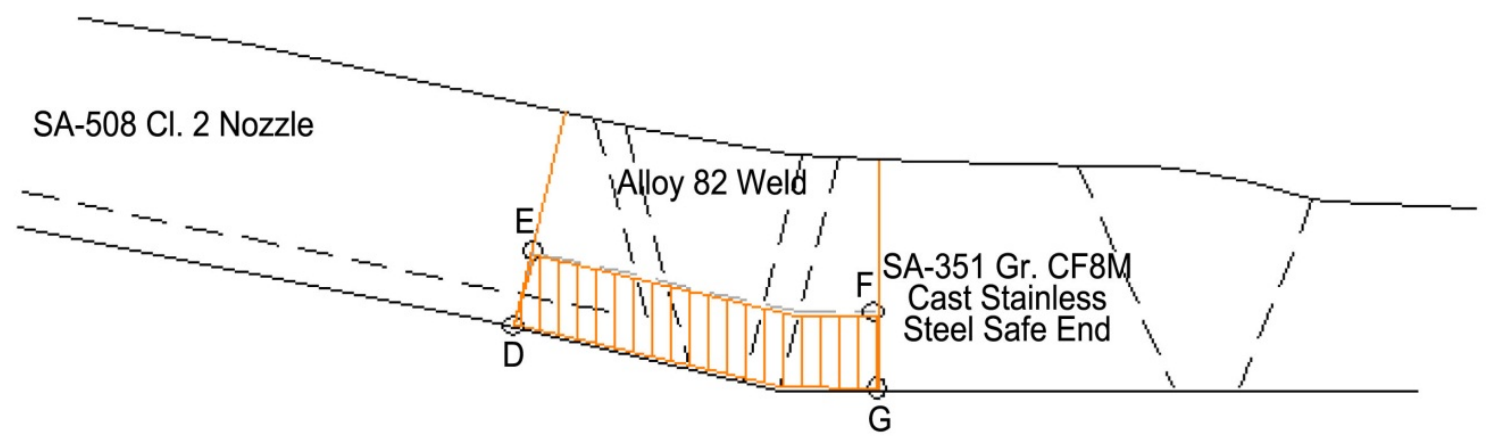

Figure D.31. Pressurizer Surge Nozzle Weld Circumferential Scan CRV Coverage Assessment 


\section{D.12 Pressurizer Spray}

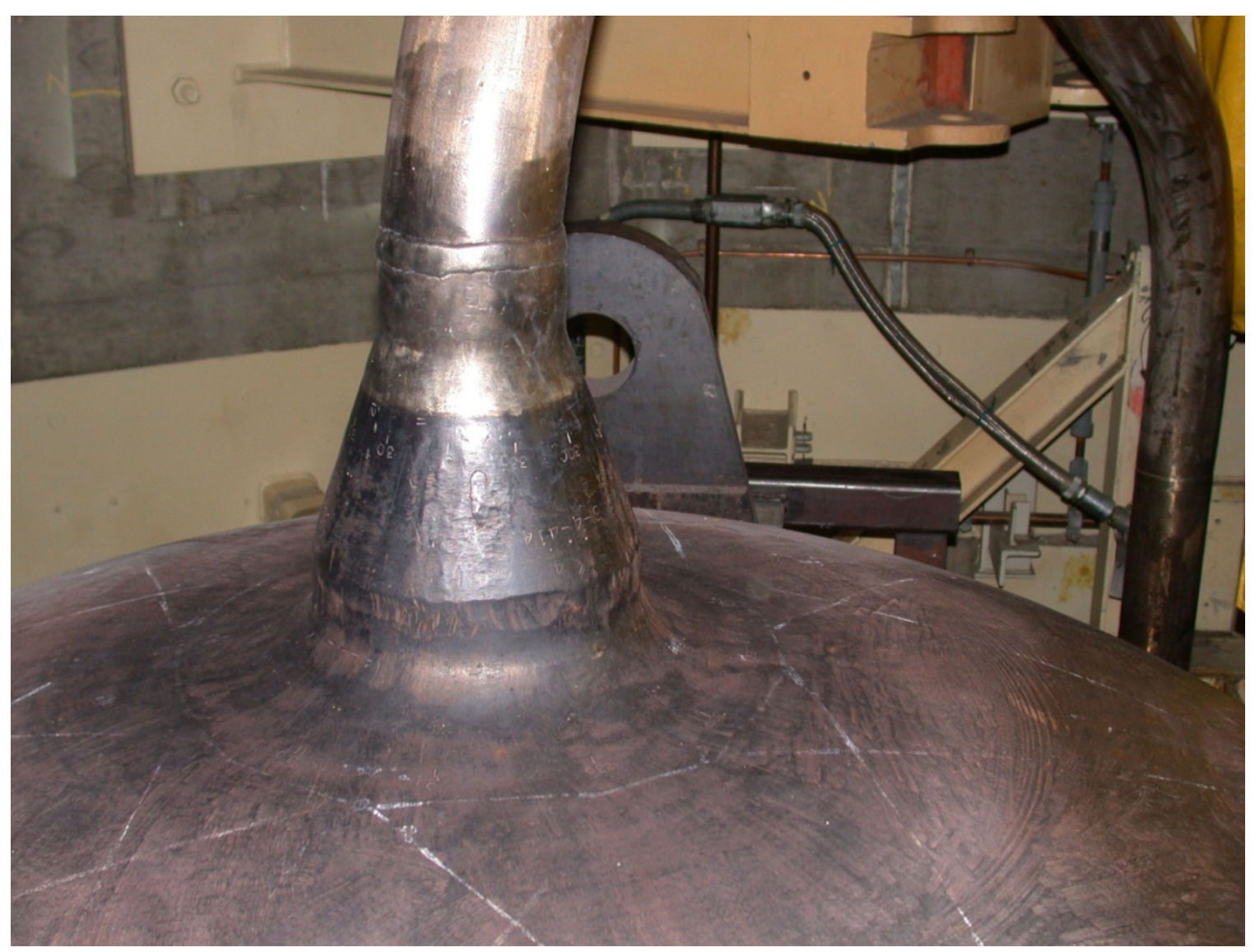

Figure D.32. Photograph of Pressurizer Spray Nozzle, Nozzle Weld, and Safe End

The examination limitation for the pressurizer spray nozzle Alloy 82/182 butt weld was the examination surface (OD) contour /condition.

The cross-sectional examination coverage in the axial scan direction for circumferential flaws is depicted in Figure D.33. The axial scan direction CRV coverage achievable was $100 \%$. The crosssectional examination coverage in the circumferential scan direction for axial flaws is depicted in Figure D.34. The circumferential scan direction CRV coverage achievable was $68.9 \%$. 


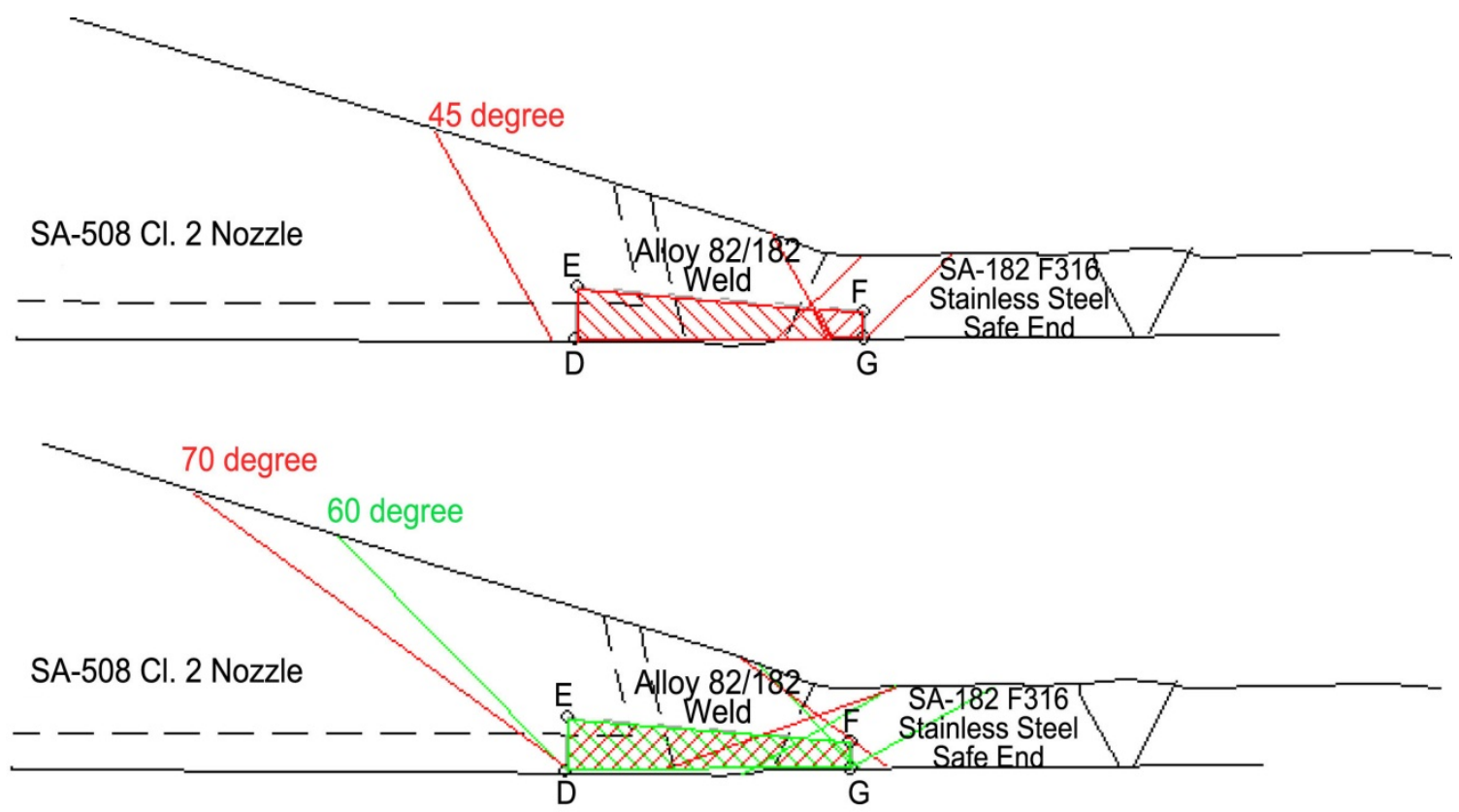

Figure D.33. Pressurizer Spray Nozzle Weld Axial Scan CRV Coverage Assessment

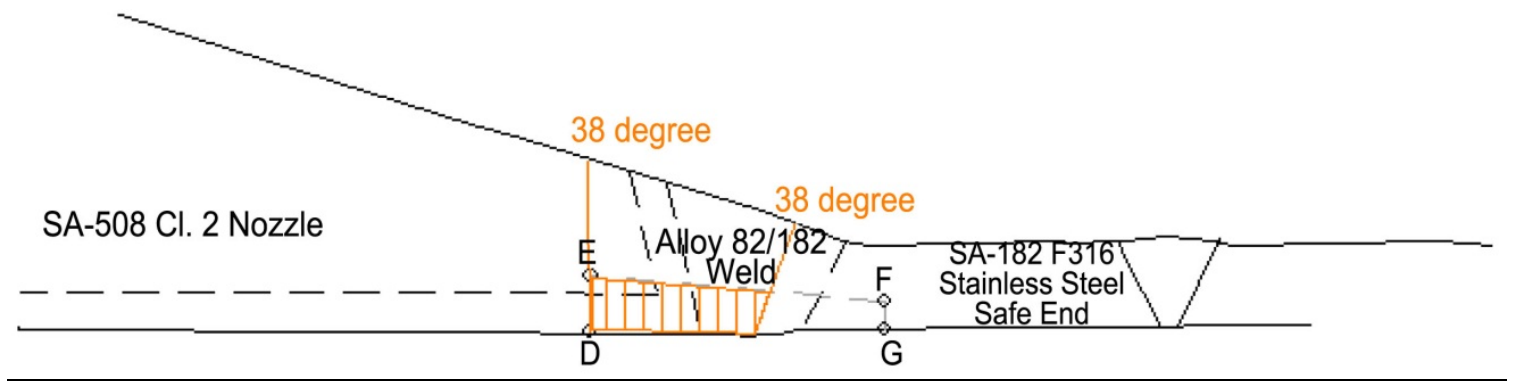

Figure D.34. Pressurizer Spray Nozzle Weld Circumferential Scan CRV Coverage Assessment 


\section{D.13 Pressurizer Safety \& Relief}

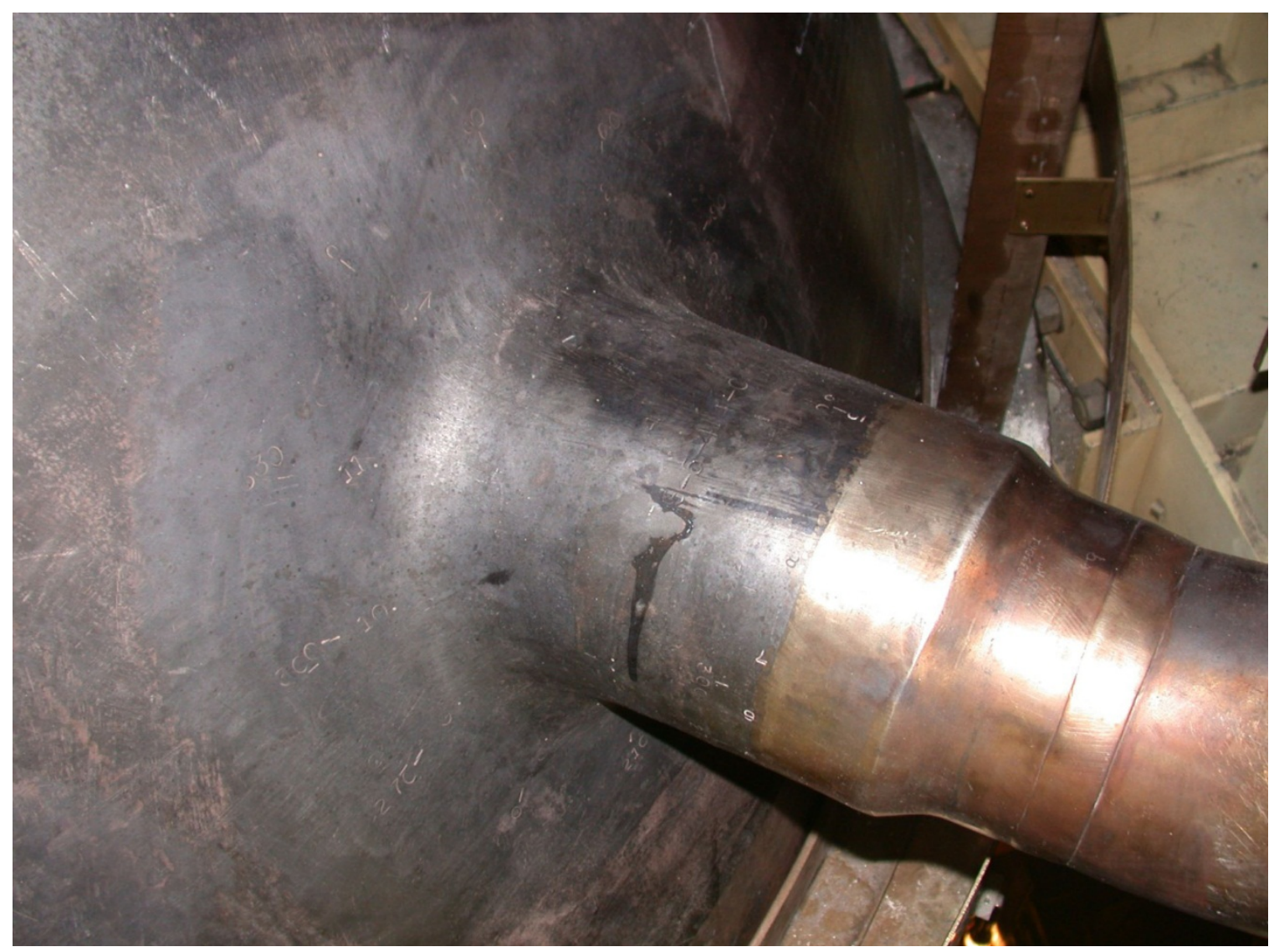

Figure D.35. Photograph of Pressurizer Safety \& Relief Nozzle, Nozzle Weld, and Safe End

There were no examination limitations for the pressurizer safety and relief nozzle Alloy 82/182 butt weld.

The cross-sectional examination coverage in the axial scan direction for circumferential flaws is depicted in Figure D.36. The axial scan direction CRV coverage achievable was $100 \%$. The crosssectional examination coverage in the circumferential scan direction for axial flaws is depicted in Figure D.37. The circumferential scan direction CRV coverage achievable was $100 \%$. 


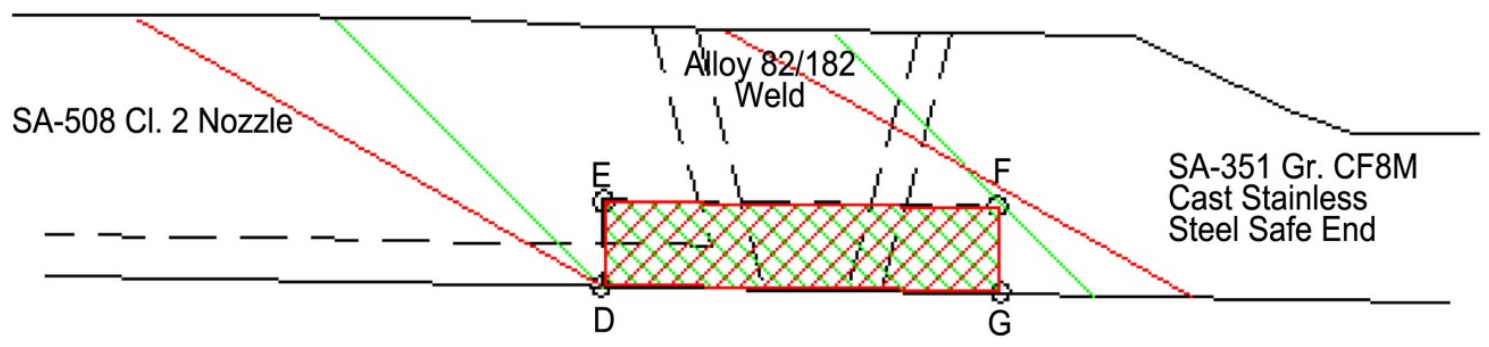

Figure D.36. Pressurizer Safety and Relief Nozzle Weld Axial Scan CRV Coverage Assessment

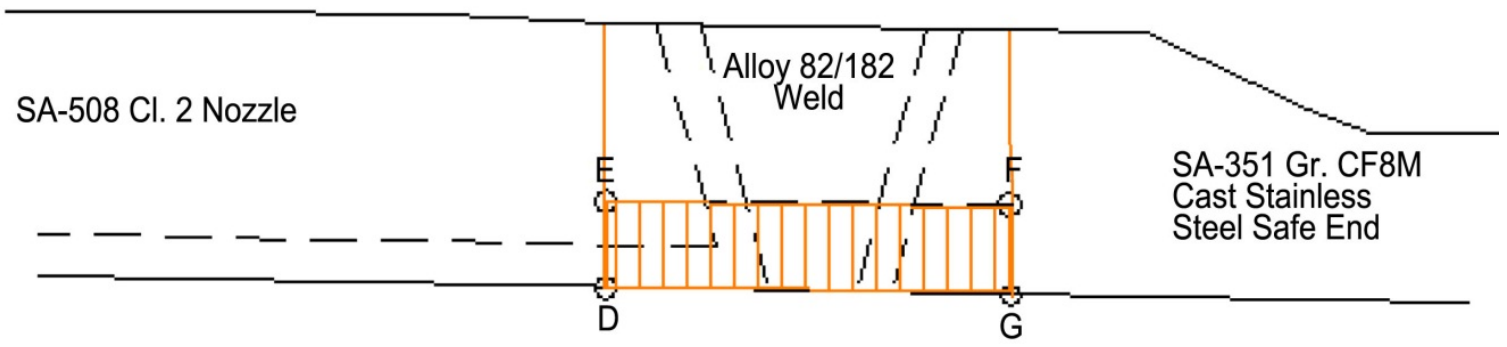

Figure D.37. Pressurizer Safety and Relief Nozzle Weld Circumferential Scan CRV Coverage Assessment 



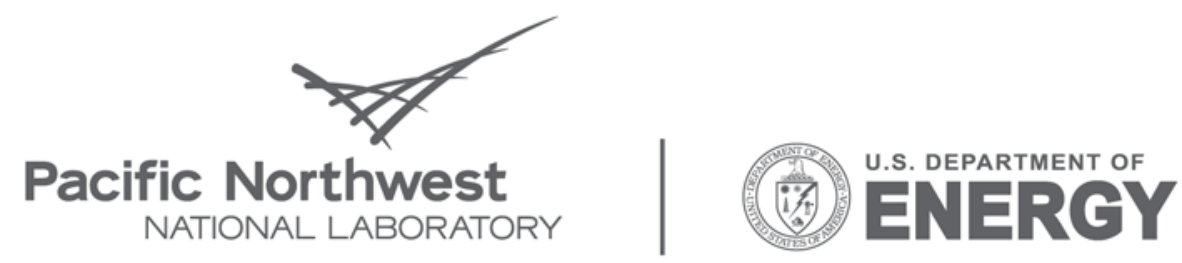

Proudly Operated by Battelle Since 1965

902 Battelle Boulevard

P.O. Box 999

Richland, WA 99352

1-888-375-PNNL (7665)

www.pnl.gov 